\title{
The pre-assessment learning effects of consequential assessment: modelling how the examination game is played
}

Citation for published version (APA):

Cilliers, F. J. (2012). The pre-assessment learning effects of consequential assessment: modelling how the examination game is played. [Doctoral Thesis, Maastricht University]. Datawyse / Universitaire Pers Maastricht. https://doi.org/10.26481/dis.20120905fc

Document status and date:

Published: 01/01/2012

DOI:

$10.26481 /$ dis.20120905fc

Document Version:

Publisher's PDF, also known as Version of record

Please check the document version of this publication:

- A submitted manuscript is the version of the article upon submission and before peer-review. There can be important differences between the submitted version and the official published version of record.

People interested in the research are advised to contact the author for the final version of the publication, or visit the DOI to the publisher's website.

- The final author version and the galley proof are versions of the publication after peer review.

- The final published version features the final layout of the paper including the volume, issue and page numbers.

Link to publication

\footnotetext{
General rights rights.

- You may freely distribute the URL identifying the publication in the public portal. please follow below link for the End User Agreement:

www.umlib.nl/taverne-license

Take down policy

If you believe that this document breaches copyright please contact us at:

repository@maastrichtuniversity.nl

providing details and we will investigate your claim.
}

Copyright and moral rights for the publications made accessible in the public portal are retained by the authors and/or other copyright owners and it is a condition of accessing publications that users recognise and abide by the legal requirements associated with these

- Users may download and print one copy of any publication from the public portal for the purpose of private study or research.

- You may not further distribute the material or use it for any profit-making activity or commercial gain

If the publication is distributed under the terms of Article $25 \mathrm{fa}$ of the Dutch Copyright Act, indicated by the "Taverne" license above, 


\section{The Pre-assessment Learning Effects of Consequential Assessment}

Modelling how the Examination Game is Played 
The research reported here was carried out at

Mastricht University in Leamuing!

SHE

in the School of Health Professions Education

(C) Copyright François J Cilliers, Maastricht 2012

Universitaire Pers Maastricht

ISBN 9789461591692 


\title{
The Pre-assessment Learning Effects of Consequential Assessment:
}

\section{Modelling how the Examination Game is Played}

\author{
DISSERTATION
}

to obtain the degree of Doctor at Maastricht University, on the authority of the Rector Magnificus Prof.dr. L.L.G. Soete, in accordance with the decision of the Board of Deans, to be defended in public on Wednesday $5^{\text {th }}$ September 2012, at 12:00 hours

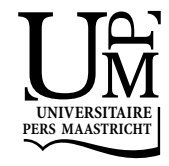




\section{Promotors}

Prof. dr. L.W.T. Schuwirth

Prof. dr. C.P.M. van der Vleuten

\section{Assessment Committee}

Prof. dr. D.H.J.M. Dolmans (chair)

Prof. dr. J. Cohen-Schotanus, UMC Groningen

Dr. M.J.B. Govaerts

Prof. dr. M.S.R. Segers

Dr. E.H. Tigelaar, ICLON, University Leiden 


\section{CONTENTS}

Chapter 1 Introduction: Assessment Drives Learning, You Say? Please

Explain How.

Chapter 2 The Mechanism of Impact of Summative Assessment on

Medical Students' Learning

Published as:

Cilliers, F. J., Schuwirth, L. W. T., Adendorff, H. J., Herman, N., \& van der Vleuten, C. P. M. (2010). The mechanism of impact of summative assessment on medical students' learning.

Advances in Health Sciences Education, 15(5), 695-715.

Chapter 3 A Model of the Pre-assessment Learning Effects of Summative Assessment in Medical Education

Published as:

Cilliers, F. J., Schuwirth, L. W. T., Herman, N., Adendorff, H., \& van der Vleuten, C. P. M. (2012). A model of the pre-

assessment learning effects of summative assessment in medical education.

Advances in Health Sciences Education, 17(1), 39-53.

Chapter 4 A Model of the Pre-assessment Learning Effects of Assessment is Operational in an Undergraduate Clinical Context

Published as:

Cilliers, F. J., Schuwirth, L. W. T., \& van der Vleuten, C. P. M. (2012). A model of the pre-assessment learning effects of assessment is operational in an undergraduate clinical context.

BMC Medical Education, 12: 9. 
Appendix Additional Illustrative Quotes: Some Quotes to Illustrate a Model of the Pre-assessment Learning Effects of Consequential Assessment

Published as:

An additional file available online with the paper reported in Chapter 4. Available at:

http://www.biomedcentral.com/imedia/7258051026868646/supp1.p df

Chapter 5 Modelling the Pre-assessment Learning Effects of Assessment: Evidence in the Validity Chain

Published as:

Cilliers, F. J., Schuwirth, L. W. T., \& van der Vleuten, C. P. M. (In press). Modelling the pre-assessment learning effects of assessment: Evidence in the validity chain. Medical Education. doi: 10.1111/j.1365-2923.2012.04334.x

Chapter 6 Generalizability Findings for a Model of the Pre-assessment Learning Effects of Assessment in New Contexts

Under editorial review

Chapter 7 General Discussion: Updating the Players' Guide to the Examination Game

Summary

Samenvatting: Summary in Dutch

Opsomming: Summary in Afrikaans

Acknowledgements 


\section{CHAPTER 1}

\section{Introduction: \\ Assessment Drives Learning, You Say? \\ Please Explain How.}




\section{Introduction}

Assessment drives learning. If any statement relating to the messy and wonderful reality that is educational practice can be considered for designation as a law, this must surely be it. This contention is to be found in literally hundreds of articles and books. There can be few lecturers in higher education whose experience with students would lead them to argue against this statement. Yet sadly, this statement refers all too often to the deleterious effects of assessment on learning and this has long been the case. Ramsden (1984) cites 19th century texts expressing concern with the negative impact of assessment on learning in higher education generally. Osler (1913) voiced similar concerns in the context of medical education. What, then, of the potential of assessment to exert beneficial influences on learning or, to take it further, the possibilities that assessment must surely offer as a component of a purposively designed and powerful (de Corte, Verschaffel, Entwistle, \& van Merriënboer, 2003) learning environment?

The impact of assessment on learning has long enjoyed scientific attention. There is a heritage of literature stretching back about a century exploring various aspects of this relationship (e.g., Douglass \& Tallmadge, 1934; Jones, 1923; Meyer, 1935). The idea of using assessment to influence learning is not new either (e.g., Jersild, 1929; Kellogg \& Payne, 1938; Vallance, 1947). Much of this work was experimental and much was undertaken in school contexts, however. It could be argued that it is of limited ecological validity in higher education, given the challenges of generalising from controlled to classroom settings (Lundeberg \& Fox, 1991) and from school to higher education contexts.

The 1960's saw new light being brought to bear on the topic in higher education contexts. An array of qualitative studies based in the lived experiences of students from various disciplines on both sides of the Atlantic illuminated the impact of assessment on learning in complex, authentic field settings (Becker, Geer, \& Hughes, 1968; Becker, Geer, Hughes, \& Strauss, 1961; Miller \& Parlett, 1974; Snyder, 1971). Snyder's work popularised the concept of the "hidden curriculum", a concept coined earlier by sociologist Philip W. Jackson (Jackson, 1968). Subsequent work exploring factors influencing student learning in higher education illustrated the role that assessment played as one of many factors having an impact in this regard (Biggs, 1978; Laurillard, 1978, 1979; Marton \& Säljö, 1976; Ramsden, 1979, 1981; Thomas \& Bain, 1984). An early model of factors influencing learning that included assessment was that of Biggs (1978).

Since then, assessment has been a feature in models of factors influencing learning (Biggs, 1987, 1994; Ramsden, 1984; Ross, Salisbury-Glennon, Guarino, Reed, \& Marshall, 2003; Vermunt, 1996). Many reports exploring various aspects of the relation- 
ship between assessment and learning in higher education have subsequently been published. Our understanding of the impact of assessment on learning has progressed to the point where a distinction can now be drawn between pre-, post- and pure assessment effects (Dochy, Segers, Gijbels, \& Struyven, 2007). Nonetheless, progress towards the goal of successfully utilising assessment to positively influence learning remains frustratingly slow.

This is not to say there are not thoughtful and well-conceived efforts to influence learning with assessment. There have been increasing numbers of reports in the literature about interventions designed in part or entirely with the goal of enhancing desirable learning using assessment. However, reports still abound of cases where assessment did not have the desired effects (Case \& Gunstone, 2003; Gijbels, Coertjens, Vanthournout, Struyf, \& Van Petegem, 2009; Heijne-Penninga, Kuks, Hofman, \& Cohen-Schotanus, 2008; Nijhuis, Segers, \& Gijselaers, 2005). On the face of it, this seems puzzling given that we have a century of research to inform our assessment design decisions.

However, stepping back from and critically interrogating the literature that has been published about the relationship between assessment and learning in higher education yields a potentially crucial clue in this regard. Under the hegemony of variance theory informed research, a plethora of research has been conducted seeking and reporting statistically significant relationships between various components of assessment and various dimensions of learning or as Maxwell (2004) put it "whether $\mathrm{x}$ caused $y$ " (emphasis in original). A bird's eye view reveals a gap in the woods, however, one that is invisible when navigating this forest at ground level. What is missing from this body of work is research aimed at explaining how assessment brings about the effects that it does i.e., "how [x caused y]" (Maxwell, 2004, emphasis in original), rather than just what that effect is.

A review of the literature in various fields including health sciences education, higher education, educational psychology, cognitive psychology, assessment and language testing reveals that very little is known about the mechanism(s) at play at the interface between assessment and learning. Various authors have proposed, with a greater or lesser degree of empirical support, models to describe or mechanisms to explain the learning effects of assessment (Alderson \& Wall, 1993; Bailey, 1996; Becker et al., 1968; Broekkamp \& van Hout-Wolters, 2007; Ross, Green, SalisburyGlennon, \& Tollefson, 2006; Ross et al., 2003; van Etten, Freebern, \& Pressley, 1997). None of these has gained traction as a basis for further investigation. Essentially, any effort to utilise assessment to impact learning remains a shot in the dark. Simply put, while we know something about what their reaction might be, we do not understand why the key actors in any assessment-learning scenario, the students, act as they do in response to assessment. 


\section{Aim and goals}

The topic of this dissertation, then, is the learning effects of assessment, specifically the pre-assessment learning effects of summative assessment. The overall aim of this work is to construct a theoretically sound model explaining the pre-assessment learning effects of summative assessment. The rationale for doing this work is ultimately to enhance the ability of lecturers to purposively utilise the powerful impact that summative assessment has to bring about desirable and calculated rather than haphazard and unplanned effects on learning. Central to the dissertation is the thesis that before we can more effectively and predictably utilise assessment to influence learning, we must first understand how assessment influences learning.

The goals of this work were fourfold.

1. We were interested in discerning what components of assessment influenced what dimensions of learning in an authentic, complex system of summative assessment.

2. We also wanted to explore what mechanism was at play at the interface between assessment and learning in this assessment system.

3. Achieving these goals would allow the construction of a theoretically grounded model.

4. Finally, we wanted to take steps to start validating this model.

\section{Delimitations}

Within the universe of assessment practices, we were particularly interested in the pre-assessment learning effects of internal-to-programme summative assessment in higher education. Internal-to-programme summative assessment is pervasive in undergraduate education and probably exerts a substantial influence on what, when and how students learn. As Boud (1995) highlighted, such assessment is inescapable. Summative assessment is also probably more typically constructed by its users in health sciences education as "assessment of learning" rather than "assessment for learning". This is particularly the case given the certification function that exit summative assessment plays in this arena. The result is that psychometric rather than learning considerations likely take precedence in assessment design. Irrespective of whether an assessment system includes well designed formative assessment, it is quite likely that the impact of summative assessment could trump any beneficial effects. 
Given our interest in summative assessment, we were also more interested in the pre-assessment learning effects of assessment than the post- or the pure assessment effects. This dissertation will therefore not explore topics relating to postassessment learning effects like feedback, the testing effect or the relationship between assessment and student achievement. With most internal-to-programmesummative assessment, there is typically no meaningful opportunity for the subsequent reflection and remediation upon which systems of feedback and formative assessment are predicated. Yet given the inevitability of summative assessment, the influence on learning must be considerable. If not constructively utilised, an inescapable and powerful influence on learning is shaping learning in unplanned and potentially undesirable ways.

\section{Outline of the thesis}

Chapter Two relates a study that explored the mechanism of impact of summative assessment on the process of learning of theory in higher education. Such literature as there is on the mechanism of impact of assessment on learning is reviewed. Using a grounded theory approach, in-depth interviews were conducted with individual medical students and analysed qualitatively.

Chapter Three deals with the nature of the effects of summative assessment on student learning. The chapter first provides an extensive review of relevant literature. It goes on to describe a study that explored the pre-assessment learning effects of summative assessment by exploring the variables at play in a multifaceted assessment system and the relationships between them. A study that entailed individual, in-depth interviews with medical students that were analysed qualitatively is then reported.

The purpose of the study reported in Chapter Four was to determine whether the model proposed in Chapter Three was valid for the same set of respondents as provided the data from which the model was derived, but in a different i.e., clinical context. Our approach was informed by process theory. Data from in-depth interviews with eighteen medical students were subject to content analysis utilising a previously-developed code book.

Chapter Five addresses the process of validating the model in the context in which it was originally described. The aim of this study was to validate the components and relationships in the model in the same context as the original work, but with a larger population. We opted to focus on those interactions that appeared to be weakest in the baseline qualitative work, this choice being informed by Popper's falsifiability 
maxim (Prochaska, Wright, \& Velicer, 2008). This approach offered the "softest" target for an attempt to falsify the associations under study.

Chapter Six takes the process of validation one step further by exploring the validity of the model in populations of students beyond the university where the model derived. The aim of this study was to validate the components and relationships in the model in a different context to the original work. Students were recruited from two other universities in the same country as the original institution.

In Chapter Seven, the results are reviewed and the implications of this work for educational practice and staff development are explored. 


\section{References}

Alderson, J. C., \& Wall, D. (1993). Does Washback Exist? Applied Linguistics, 14(2), 115-129.

Bailey, K. M. (1996). Working for washback: a review of the washback concept in language testing. Language Testing, 13(3), 257-279.

Becker, H. S., Geer, B., \& Hughes, E. C. (1968). Making the grade: The academic side of college life. New York: John Wiley \& Sons, Inc.

Becker, H. S., Geer, B., Hughes, E. C., \& Strauss, A. (1961). Boys in White. Student Culture in Medical School. Chicago: University of Chicago Press.

Biggs, J. B. (1978). Individual and group differences in study processes. British Journal of Educational Psychology, 48(3), 266-279.

Biggs, J. B. (1987). Student Approaches to Learning and Studying. Hawthorn, Australia: Australian Council for Educational Research Ltd.

Biggs, J. B. (1994). Student learning research and theory: Where do we currently stand? In G. Gibbs (Ed.), Improving Student Learning - Theory and Practice. Oxford: Oxford Centre for Staff Development, Oxford Brookes University.

Boud, D. (1995). Assessment and learning: contradictory or complementary? In P. Knight (Ed.), Assessment for Learning in Higher Education (pp. 35-48). London: Kogan Page.

Broekkamp, H., \& van Hout-Wolters, B. H. A. M. (2007). Students' Adaptation of Study Strategies When Preparing for Classroom Tests. Educational Psychology Review, 19(4), 401-428.

Case, J., \& Gunstone, R. (2003). Going Deeper than Deep and Surface Approaches: a study of students perceptions of time. Teaching in Higher Education, 8(1), 55-69.

de Corte, E., Verschaffel, L., Entwistle, N. J., \& van Merriënboer, J. J. G. (2003). Powerful Learning Environments: Unravelling Basic Components and Dimensions (1st ed.). Oxford: Pergamon.

Dochy, F., Segers, M., Gijbels, D., \& Struyven, K. (2007). Assessment Engineering: Breaking down barriers between teaching and learning, and assessment. In D. Boud \& N. Falchikov (Eds.), Rethinking assessment in higher education: learning for the longer term (pp. 87-100). Oxford: Routledge.

Douglass, H. R., \& Tallmadge, M. (1934). How University Students Prepare for New Types of Examination. School and Society, 39, 318-320.

Gijbels, D., Coertjens, L., Vanthournout, G., Struyf, E., \& Van Petegem, P. (2009). Changing students' approaches to learning: a two-year study within a university teacher training course. Educational Studies, 35(5), 503-513.

Heijne-Penninga, M., Kuks, J. B. M., Hofman, W. H. A., \& Cohen-Schotanus, J. (2008). Influence of openand closed-book tests on medical students' learning approaches. Medical Education, 42(10), $967-$ 974.

Jackson, P. W. (1968). The Daily Grind. Part V Life in Classrooms (pp. 33-37). New York: Holt, Rinehart and Winston, Inc.

Jersild, A. T. (1929). Examinations as an aid to learning. Journal of Educational Psychology, 20(8), 602-609.

Jones, H. E. (1923). Experimental studies of college teaching: The effect of examination on the permanence of learning. Archives of Psychology, 10, 1-70.

Kellogg, W. N., \& Payne, B. (1938). The true-false question as an aid in studying. Journal of Educational Psychology, 29, 581-589.

Laurillard, D. M. (1978). A study of the relationship between some of the cognitive and contextual factors in student learning. (PhD), University of Surrey.

Laurillard, D. M. (1979). The processes of student learning. Higher Education, 8(4), 395-409.

Lundeberg, M. A., \& Fox, P. W. (1991). Do Laboratory Findings on Test Expectancy Generalize to Classroom Outcomes? Review of Educational Research, 61(1), 94-106.

Marton, F., \& Säljö, R. (1976). Symposium: Learning processes and strategies - II. On qualitative differences in learning - II. Outcome as a function of the learner's conception of the task. British Journal of Educational Psychology, 46(2), 115-127. 
Maxwell, J. A. (2004). Causal explanation, qualitative research, and scientific inquiry in education. Educational Researcher, 33(2), 3-11.

Meyer, G. (1935). An experimental study of the old and new types of examination: II. Methods of study. Journal of Educational Psychology, 26(1), 30-40.

Miller, C. M. L., \& Parlett, M. (1974). Up to the mark: A study of the examination game. London: Society for Research into Higher Education.

Nijhuis, J. F. H., Segers, M. S. R., \& Gijselaers, W. H. (2005). Influence of Redesigning a Learning Environment on Student Perceptions and Learning Strategies. Learning Environments Research, 8(1), 67-93.

Osler, W., Sir. (1913). Examinations, Examiners and Examinees. The Lancet, 1047-1059.

Prochaska, J. O., Wright, J. A., \& Velicer, W. F. (2008). Evaluating Theories of Health Behavior Change: A Hierarchy of Criteria Applied to the Transtheoretical Model. Applied Psychology, 57(4), 561-588.

Ramsden, P. (1979). Student learning and perceptions of the academic environment. Higher Education, 8(4), 411-427.

Ramsden, P. (1981). A study of the relationship between student learning and its academic context. Ph.D. thesis, University of Lancaster.

Ramsden, P. (1984). The context of learning. In F. Marton, D. Hounsell \& N. J. Entwistle (Eds.), The Experience of Learning (pp. 144-164). Edinburgh: Scottish Academic Press.

Ross, M. E., Green, S., Salisbury-Glennon, J. D., \& Tollefson, N. (2006). College students' study strategies as a function of testing: an investigation into metacognitive self-regulation. Innovative Higher Education, 30(5), 361-375.

Ross, M. E., Salisbury-Glennon, J. D., Guarino, A., Reed, C. J., \& Marshall, M. (2003). Situated SelfRegulation: Modeling the Interrelationships Among Instruction, Assessment, Learning Strategies and Academic Performance. Educational Research and Evaluation, 9(2), 189-209.

Snyder, B. R. (1971). The Hidden Curriculum. New York: Alfred A. Knopf.

Thomas, P. R., \& Bain, J. D. (1984). Contextual dependence of learning approaches: the effects of assessments. Human Learning, 3, 227-240.

Vallance, T. R. (1947). A comparison of essay and objective examinations as learning experiences. Journal of Educational Research, 41(4), 279-288.

van Etten, S., Freebern, G., \& Pressley, M. (1997). College Students' Beliefs about Exam Preparation. Contemporary Educational Psychology, 22(2), 192-212.

Vermunt, J. D. (1996). Metacognitive, cognitive and affective aspects of learning styles and strategies: A phenomenographic analysis. Higher Education, 31(1), 25-50. 



\title{
CHAPTER 2
}

\author{
The Mechanism of Impact \\ of Summative Assessment \\ on Medical Students' Learning
}




\begin{abstract}
It has become axiomatic that assessment impacts powerfully on student learning, but there is a surprising dearth of research on how. This study explored the mechanism of impact of summative assessment on the process of learning of theory in higher education. Individual, in-depth interviews were conducted with medical students and analysed qualitatively. The impact of assessment on learning was mediated through various determinants of action. Respondents' learning behaviour was influenced by: appraising the impact of assessment; appraising their learning response; their perceptions of agency; and contextual factors. This study adds to scant extant evidence and proposes a mechanism to explain this impact. It should help enhance the use of assessment as a tool to augment learning.
\end{abstract}

Published as:

Cilliers, F. J., Schuwirth, L. W. T., Adendorff, H. J., Herman, N., \& van der Vleuten, C. P. M. (2010). The mechanism of impact of summative assessment on medical students' learning. Advances in Health Sciences Education, 15(5), 695-715. 


\section{Introduction}

I think, as a result of assessment, I know much less than I otherwise would have. (6(V)F65)

It has become axiomatic to refer to the powerful impact of assessment on student learning. Terms like the "backwash effect" (Biggs, 1996; L. Elton, 1987) and the "washback effect" (Alderson \& Wall, 1993; Bailey, 1996) of assessment, "consequential validity" (Boud, 1995), "test-enhanced learning", the "testing effect" or the "testing phenomenon" (Glover, 1989; Roediger \& Karpicke, 2006) and "test expectancy" (Lundeberg \& Fox, 1991) have been used in this regard. A heritage of literature stretching back almost a century (e.g., Jones, 1923; Meyer, 1936) is widely cited in support of this phenomenon.

The impact of assessment on student learning is generally held to be profound. Elton \& Laurillard (1979) went so far as to state that " the quickest way to change student learning is to change the assessment system". Boud et al (1999, p. 413) state that "[a]ssessment is the single most powerful influence on learning in formal courses". If this is the case, then assessment may well be one of the most powerful tools we have at our disposal to influence student learning. However, even after almost a century of research, efforts to positively influence learning through assessment do not always yield encouraging results (Gijbels, Coertjens, Vanthournout, Struyf, \& Van Petegem, 2009). In fact, how little we actually know about the complex relationship between assessment and student learning has been pointed out from various quarters (Alderson \& Banerjee, 2001; Lundeberg \& Fox, 1991; Ramsden, 2005; Segers \& Dochy, 2006).

Different authors write about different things when they write about the impact of assessment on student learning. As far as "assessment" goes, authors variously focus on approaches like formative assessment, continuous assessment or coursework, internal-to-programme summative assessment and external-to-programme standardised testing, or on specific methods. Internal-to-programme summative assessment may well exert both a stronger and a more pervasive influence on learning than other assessment practices in higher education (HE), however. As Boud (1995) highlighted, students cannot escape the impact of summative assessment. Given the stakes, the design of such assessment is more typically informed by psychometric than learning considerations and so even if other aspects of assessment in a course have been designed to promote meaningful learning, the impact of summative assessment could trump beneficial effects achieved by other means. Furthermore, more students in HE probably encounter internal-to-programme summative assessment than external-to-programme standardised testing. 
As for "learning", it is often not the only phenomenon that authors highlight when writing about the impact of assessment. Models of language testing washback (Alderson \& Banerjee, 2001; Bailey, 1996) and measurement driven instruction (Airasian, 1988; Madaus, 1988) both address the multifactorial impact of standardised testing on learning, teaching, materials, curricula and even research, though focussed largely on school-based settings. In $\mathrm{HE}$, the impact of assessment on not just learning but also on non-learning student behaviours intended to enhance marks e.g., ingratiating themselves with lecturers, on student stress and on students' choice of courses has been highlighted by various authors (Becker, Geer, \& Hughes, 1968, pp. 82-83; Miller \& Parlett, 1974; Snyder, 1971). From the opposite perspective, assessment is typically identified as one of the contextual factors that impact on learning in models of learning (Biggs, 1987; Ramsden, 1984; Ross, Salisbury-Glennon, Guarino, Reed, \& Marshall, 2003; Vermunt, 1996). Even when writing specifically about the impact of assessment on learning, authors variously write about the relationship between assessment and the product or outcome of student learning i.e., student performance and about the impact on the process of student learning.

Demonstrating a positive impact of assessment on desired student performance i.e., the outcome of student learning, may well be the ultimate goal of utilising assessment to enhance learning. However, efforts to effectively use assessment to achieve this would be enriched by an understanding of the intervening process(es) by which assessment impacts on the process of student learning. There is some descriptive literature focussing on the "what" of the impact of internal-toprogramme summative assessment on the process of student learning in HE i.e., the sources and consequences of the impact of such assessment or, as Maxwell (2004a: 4) puts it, "whether $x$ caused $y$ " (emphasis in original). In contrast, very little has been written explaining "how it did so" (Maxwell, 2004a: 4, emphasis in original). As Bunge (2004: 199) noted, "any mechanism-free account must be taken to be shallow and therefore a challenge to uncover unknown mechanism(s)". At issue in the present study is how summative assessment brings about its influence on the process of student learning. From a process theory perspective, this paper deals with "events and the processes that connect them" (Maxwell, 2004b: 248) specifically in one distinctive, internal-to-programme, high-stakes assessment system; thus, the local mechanisms at play in a "complex network of events and processes in a situation” (Miles \& Huberman, 1994b: 146; 147).

So what is known about the mechanism(s), the "how", of impact? Such literature as there is has, for the most part, accumulated piecemeal, often coincidentally during work addressing broader issues. (Given the difficulties generalising findings from 
controlled settings to the classroom (Lundeberg \& Fox, 1991), research conducted in controlled settings will not be reviewed here).

Extrinsic motivation. Assessment provides extrinsic motivation and impacts on the amount and distribution of students' learning efforts. The mere fact of assessment motivates students to learn and therefore influences the quantum of effort expended on learning (Miller \& Parlett, 1974; Snyder, 1971; van Etten, Freebern, \& Pressley, 1997). The impact of assessment on effort is not necessarily always positive, however. If students perceive they are unable to successfully negotiate assessment, for example because their marks are so bad they cannot hope to achieve a pass or they are so far behind they believe they cannot catch up, this can result in them stopping learning (Becker et al., 1968, pp. 102-103). Nor is the response to assessment as extrinsic motivation uniform. Sambell and McDowell (1998) described two case studies illustrating how differences in student motivation and student conceptions of learning elicit differing responses in different individual students to the same assessment task.

Consequences. The potential consequences of assessment also impact student learning. Students adapt both what and how they learn so as to meet the lecturers' requirements as manifested in assessment rather than understand the material being learned (Becker et al., 1968; Ramsden, 1984, 1992; Snyder, 1971). This is at least in part because the risks of not doing so are great, the rewards for conforming, substantial, both in terms of self-esteem and in terms of short and longer term material benefits (Parlett, 1969; Snyder, 1971, pp. 12-13; 15; 18; 51). The likelihood of subject matter featuring in assessment impacts on what content students select to learn (Becker et al., 1968; 98; Becker, Geer, Hughes, \& Strauss, 1961; Miller \& Parlett, 1974; Snyder, 1971; Vermunt, 1996, pp. 36-37) or not - what Snyder (1971, p. 59) referred to as "selective negligence". It also influences the thoroughness with which students engage with learning material (Laurillard, 1979; van Etten et al., 1997). This also holds for assignments students choose to do or not (Snyder, 1971, pp. $12-13 ; 15 ; 87$ ) and the amount of effort students devote to tasks (Becker et al., 1968; Janssens, Boes, \& Wante, 2002, cited by Struyven, Dochy \& Janssens, 2005). The thoroughness with which students engage with learning material is impacted by the contribution that performance on any given assignment will make towards the calculation of a final grade (Ramsden, 1992; Snyder, 1971). Personal consequences like the risk of appearing ignorant in an oral assessment also impacted how thoroughly students prepare (Joughin, 2007).

Achieving a desired outcome. The likelihood of any given learning behaviour bringing about a desired assessment outcome influences students' actions. The amount of time students spend studying increases, up to a point, as the volume of material and, independent of that, the degree of difficulty of the material, to be studied, 
increases (van Etten et al., 1997). Students select resources and activities to prepare for assessment that best prepare them for the demands of the assessment task (Frederiksen, 1984; Newble \& Jaeger, 1983). Students also match the nature of their learning to the demands of the assessment task to achieve a desired outcome (Becker et al., 1968; Sambell \& McDowell, 1998). Scouller (1998) also offered some tantalizing evidence that perceptions of the cognitive demands of an assessment task are correlated with the approach to learning adopted, but could not comment on causality. Students preparing for an MCQ assessment task were both more likely to adopt a surface approach and perceive the assessment to be pitched at a lower cognitive level than when they were preparing for an essay assignment.

Students seek cues from lecturers, other students and past papers to guide their selection of content to learn, in the interests of achieving their desired outcome with assessment (Becker et al., 1968, pp. 96-97; Becker et al., 1961), and may even cheat to achieve this end (Becker et al., 1968, pp. 100-102). High volumes of work drive students to be more selective about what content to engage with and to adopt low level cognitive processing tactics in the interests of achieving a desired outcome (Ramsden, 1984; Snyder, 1971, pp. 62-63; van Etten et al., 1997). Effort is allocated across courses based on where generating benefit or reward is deemed most useful at any given time (Becker et al., 1968, pp. 83-84; 87; 89; 96).

Goals. Students' goals influence their response to assessment. Students gauge the magnitude of their efforts by what grade they aim to achieve (Becker et al., 1968; 94; Miller \& Parlett, 1974; van Etten et al., 1997). Various factors influence the priority students accord reading assignments, including whether they need to improve in the subject, whether the material is interesting, whether the material is manageable (e.g., not impossible to understand) and whether the assignment is in their major area of study (van Etten et al., 1997). Interestingly, the type of learning students adopt to meet the perceived demands of assessment may be discordant with their long-term goals. Entwistle and Entwistle (1992, p. 15) referred to "the way in which the examination distorted the efforts of the students to achieve personal understanding" - students' learning was guided by the type of questions in past papers and thus the perceived requirements of old examination questions. Various authors describe how students experience a tension between learning what and how they would like to and learning what and how they need to, to succeed in examinations (Becker et al., 1968; Becker et al., 1961; N. J. Entwistle \& Entwistle, 2005; Ramsden, 1992; Snyder, 1971; Tang, 1994).

Norms. Individual responses to assessment can be modulated by a socially constructed and shared frame of reference within a peer group (Becker et al., 1968, pp. 92-93). The norms within a peer group can modulate when a student starts learning, 
resulting in them starting later than they would otherwise have chosen to (Thomson \& Falchikov, 1998).

Agency. Beliefs about agency appear to mediate students' response to assessment. Students' beliefs as to whether studying would influence their performance on assessments affects their motivation to learn (van Etten et al., 1997). When students start learning is influenced by their perception of their ability to cope with a task of given magnitude and complexity, given the prevailing workload (Snyder, 1971). Lowlevel processing may also be a response to work deemed too complex to understand, when the effort to understand outweighs the potential reward of doing so rather than just memorising (Becker et al., 1968).

Emotion. Lastly, emotion also mediates students' responses to assessment. In addition to interest, Fransson (1977) also reported students' approach to learning is impacted by the degree of threat and anxiety they experience, both factors associated with assessment. Worry about assessment has also been reported to influence allocation of effort to learning (Miller \& Parlett, 1974).

Two things about this literature are striking. The first is that, for the most part, these studies were not designed to systematically investigate the impact of assessment on learning. The findings reported above mostly represent fragments from the data reported in these studies; thus, at best, examples of how assessment can influence learning, rather than a systematic record of how this comes about. There are various studies that are often cited as providing evidence of the impact of assessment on learning. However, many of these were experimental work conducted in controlled settings with limited ecological validity (Lundeberg \& Fox, 1991). Furthermore, many of these studies were conducted in school settings, including elementary schools, further limiting their usefulness in HE settings.

The second thing that is striking about this literature is that only limited attempts have been made to explain the impact of assessment within a theoretical framework. In the washback literature, various hypotheses (Alderson \& Wall, 1993) and a theoretical model (Bailey, 1996) of washback have been proposed, but the impact of assessment on learning within this model enjoys only limited empirical support. Alderson and Wall (1993) did posit that the impact of assessment may result from an impact on motivation and therefore behaviour. Both van Etten (1997) and Ross (2006; 2003) and their co-workers invoke models of self-regulation. van Etten et al (1997) subsequently propose a framework based on empirical data comprising a number of propositions divided into four categories about students' beliefs about preparing for examinations. Ross et al's $(2006$; 2003) subsequent exploration of the relationships between instruction, assessment, learning strategies and academic performance, while grounded in theory, did not address the role of motivation. 
Furthermore, such evidence as they offer is generated in an experimental setting. Becker et al (1968, pp. 33-34) proposed the "grade point average perspective" which "describes the situation in which students see themselves working, the rewards they should expect from their academic work, the appropriate actions to take in various circumstances, the criteria by which people should be judged". Although they offer extensive evidence to support the existence of this perspective which, like the concept of washback, extends beyond the impact of assessment on learning, it is not tied to any underlying theoretical framework. Broekkamp and van Hout-Wolters (2007) propose and provide theoretical support for a model describing students' strategy adaptation when preparing for tests. Much of the literature they draw on in support of their model is school-based.

If assessment is to be used as a tool to enhance the power of the learning environment (de Corte, Verschaffel, Entwistle, \& van Merriënboer, 2003) and contribute to, rather than mitigate, the cultivation of productive learning (de Corte, 2007) in HE, we need to understand not only what impact assessment has but how that impact is brought about. The purpose of this study was, therefore, to investigate the impact of summative assessment on student learning and to specifically explore the mechanisms by which assessment impacts on learning. The key research question here was: How do various dimensions of summative assessment of theory bring about such influence as they exert on various dimensions of learning in a HE setting? This research was qualitative and exploratory in nature, aiming to inductively develop a model to start explaining the impact of assessment on student learning.

\section{Methods}

\section{Context}

This study was conducted at the Faculty of Health Sciences of Stellenbosch University in South Africa. Medical students there follow a six year, modular program. During the third of four phases of the program i.e., semesters four to nine, transdisciplinary, system-based theory modules (e.g., Cardiovascular System or Respiratory System, typically offered in lecture halls) alternate with discipline-based clinical modules (where students acquire clinical skills in various disciplines e.g., Surgery or Paediatrics, typically in clinical settings). Alternating four week periods of study are allocated to theory and clinical modules. Most modules are four weeks long, though some are shorter or longer. The final three semesters of the program, the fourth phase, comprise solely clinical modules. Students receive study guides for each module detailing module level and often also session level outcomes and detailed information on assessment procedures and requirements. 
During Phase 3, summative assessment takes place for each module and assessment stakes are high. In theory modules - the focus of this study - marks generated by assessment during the module are combined with marks generated by an end of module assessment to generate what is called the class mark. If students fail to achieve a class mark of at least $40 \%$, they do not qualify for access to the end of year examination in that module and therefore fail the year. In the year-end examination, students who score $<45 \%$ fail the module outright and therefore fail the year. Students who score between 45 and $50 \%$ qualify for a resit. All students who fail to achieve $\geq 50 \%$ in the resit, also fail the module and the year. If students fail any module, they have to repeat that year of study. Students may only repeat a year of study once during the program, although they may repeat more than one module in that year. Generally, attrition is about $25 \%$ during the course of the program and highest during the first two years.

\section{Subjects and ethics}

Ethical approval was obtained for the study from an institutional research ethics board. Based on the fact that they had had several semesters' experience being assessed on both theory and clinical skills, all students in the fourth and fifth years of the program were invited to participate. Each class was addressed once about the study and one email reminder was sent to each student. No incentive was offered for participation in the study.

Thirty-two students volunteered for interviews. Interviews were scheduled at the convenience of students and took place during students' seventh (for fourth year students) or ninth (for fifth year students) semester of study. Eighteen respondents were interviewed. The remainder were thanked but not interviewed, given that data saturation had been achieved (see below). During interviews, informed consent for study participation and later access to students' academic records was elicited using an information sheet and informed consent document.

Some characteristics of respondents are summarized in Table 1. Given that approximately one fifth of the two classes from which they were drawn achieved an average mark $\geq 70 \%$ (data not shown), it is evident that this group includes a higher proportion of more successful students than the classes from which they are drawn. However, the number of students who failed one or more modules (see footnote to Table 1) indicates these students' learning was not uniformly effective. Two-thirds of respondents were women, a slightly higher proportion than the $55 \%$ of the two classes concerned that were women. 
Table 1. Distribution of respondents based on year of study, gender and academic performance.

\begin{tabular}{|c|c|c|c|c|}
\hline \multirow[b]{2}{*}{ YEAR OF STUDY } & \multirow[b]{2}{*}{ GENDER } & \multicolumn{3}{|c|}{ AVERAGE MARK } \\
\hline & & $<70 \%$ & $70-79 \%$ & $\geq 80 \%$ \\
\hline \multirow{2}{*}{4} & $\mathbf{F}$ & 13(IV)F69 & & \\
\hline & M & & $\begin{array}{c}\text { 7(IV)M72 } \\
16(\mathrm{IV}) \mathrm{M} 79\end{array}$ & \\
\hline \multirow{6}{*}{5} & & $6(\mathrm{~V}) \mathrm{F} 65$ & $2(\mathrm{~V}) \mathrm{F} 77$ & $4(\mathrm{~V}) \mathrm{F} 81$ \\
\hline & $\mathbf{F}$ & 12(V)F61(1) & $11(\mathrm{~V}) \mathrm{F} 71(1)$ & $8(V) F 81$ \\
\hline & $\mathrm{r}$ & $15(\mathrm{~V}) \mathrm{F} 63(3)$ & & $9(\mathrm{~V}) \mathrm{F} 83$ \\
\hline & & 17(V)F65 & & $18(\mathrm{~V}) \mathrm{F} 86$ \\
\hline & $M$ & $3(\mathrm{~V}) \mathrm{M} 67$ & $5(\mathrm{~V}) \mathrm{M} 73$ & 1(V)M80 \\
\hline & $\mathrm{IVI}$ & & 14(V)M78 & 10(V)M82 \\
\hline
\end{tabular}

The following notation will be used to identify respondents: 12(V)F61(1), where the first figure indicates respondent number; the Roman numeral in parentheses their year of study; the letter their gender; the next figure their average mark across all six years of study (obtained some time after the interviews); and the last parentheses indicate the number of modules (if any) that the respondent failed across all years of study.

\section{Data collection and analysis}

In-depth, unstructured interviews (Charmaz, 2006; DiCicco-Bloom \& Crabtree, 2006; Kvale, 1996) were conducted with individual students, each lasting approximately 90 minutes. In keeping with the inductive nature of the study, no formal interview schedule was used. Interviews were loosely constructed around exploring three issues: how respondents learned, what assessment they had experienced and how assessment had impacted on their learning. Open-ended questions were used and statements respondents made were probed to clarify meaning, obtain additional detail and ascertain what assumptions underlie them. For example, vague statements like "I learn differently for long questions and multiple choice questions" were probed for detail about what respondents did differently in the two situations and why they did so.

Although the interviews were conducted at one point in time, students' experience of different assessment methods and how they learned in varying contexts across all of their years of study were explored, compared and contrasted during interviews, though typically not chronologically. This revealed qualitative and quantitative differences and changes in respondents' learning across varying assessment contexts and time. Each interview was allowed to develop its own direction within the broad three-topic framework, so as to allow in-depth exploration of each respondent's 
experiences and conceptions of the relationships being studied. Given that data collection proceeded in tandem with, and was later informed by, data analysis, as analysis proceeded, emerging constructs were also discussed with respondents to confirm interpretation and explored in greater depth in subsequent interviews.

All interviews were conducted by the same investigator, an educational adviser involved in curriculum development in the faculty with little direct student interaction, but much interaction with lecturers. All interviews were conducted in a setting suggested by respondents. Interviews were conducted in either English or Afrikaans, according to respondents' preference. Care was taken to alert respondents to the fact that their personal accounts were of interest, so that they recounted their own experiences and views rather than what they may have perceived the interviewer to want to hear. Several respondents had to be encouraged to relate their personal experiences and approaches "warts and all", rather than their sanitized impressions of how they thought they should be learning or of how they perceived the nebulous "they" (i.e., other students) to approach learning and assessment. Despite being given an undertaking regarding the confidentiality of data at the start of each interview, several respondents also had to be reassured during their interview about the confidentiality of their comments, before they proceeded to share information they perceived could elicit unfavourable responses from the lecturers concerned. That said, almost all interviews "caught fire" and had to be carefully kept on track as respondents enthusiastically discussed the topic at hand.

All interviews were audio recorded and transcribed verbatim, to ultimately generate almost 1000 pages of transcripts. Data analysis commenced even as data collection proceeded. Before progressing to more detailed analysis, field notes were reviewed and each transcript was read to obtain a global impression of how assessment impacts on student learning. Initial open coding was then undertaken by one of us (FC). As data collection and analysis progressed, codes were developed, refined and revised in an iterative process (Charmaz, 2006; Dey, 1993; Miles \& Huberman, 1994a). On-going data collection, comparisons of codes within and between interviews and discussions between team members served to confirm and clarify codes. Clustering and partitioning of codes led to the emergence of categories as data analysis progressed, which categories were also iteratively refined, revised, discussed and ultimately related to one another.

As analysis progressed and relationships between constructs became more established, it became evident that various dimensions of motivation and emotion featured prominently when exploring the link between assessment and learning. Focussed coding of the existing dataset at that point was undertaken. However, while confirming a role for motivation and emotion, this proved to be an inadequate explanatory framework. In many instances, it was simply not possible to label a mech- 
anism by which assessment exerted an influence on learning using this framework. Despite extensive efforts re-appraising existing data and exploring constructs in subsequent interviews, no further useful constructs could be discerned. In fact, nothing new emerged during data collection subsequent to interview fourteen, despite the individualized nature of each interview and adaptations that were made on the basis of preliminary data analysis. Analysis stalled at this point, it being apparent that a framework was needed that transcended motivation and emotion.

Recourse was had to the literature. This was informed by memo's generated during data analysis up to that point, that suggested a prominent role for two constructs i.e., imminence of assessment and the consequences of assessment. It became apparent that the variables at play were discernible as determinants of action (Bartholomew, Parcel, Kok, \& Gottlieb, 2001; Dörnyei, 2000; Gebhardt \& Maes, 2001). At this point, focussed coding of the entire dataset was undertaken again, this time using the various relevant constructs from this literature. This entailed some refinement of existing codes and the introduction of some new ones. However, not only were constructs relating to motivation and emotion successfully embraced by this new framework, but data that had previously proved recalcitrant to analysis also yielded to it. During this recoding process, no new constructs or relationships emerged from analysis of interviews 13-18.

\section{Results}

Where interviews were conducted in Afrikaans, quotations have been translated. Respondents will be identified as indicated in Table 1.

The impact of assessment on learning was mediated through various determinants of action. Respondents' learning behaviour was influenced by appraising the impact of assessment, appraising their learning response, by their perceptions of agency and by contextual factors.

\section{Appraisal of impact}

Respondents considered two factors relating to the impact of assessment: how likely consequences were to accrue and what the magnitude of consequences was likely to be. 


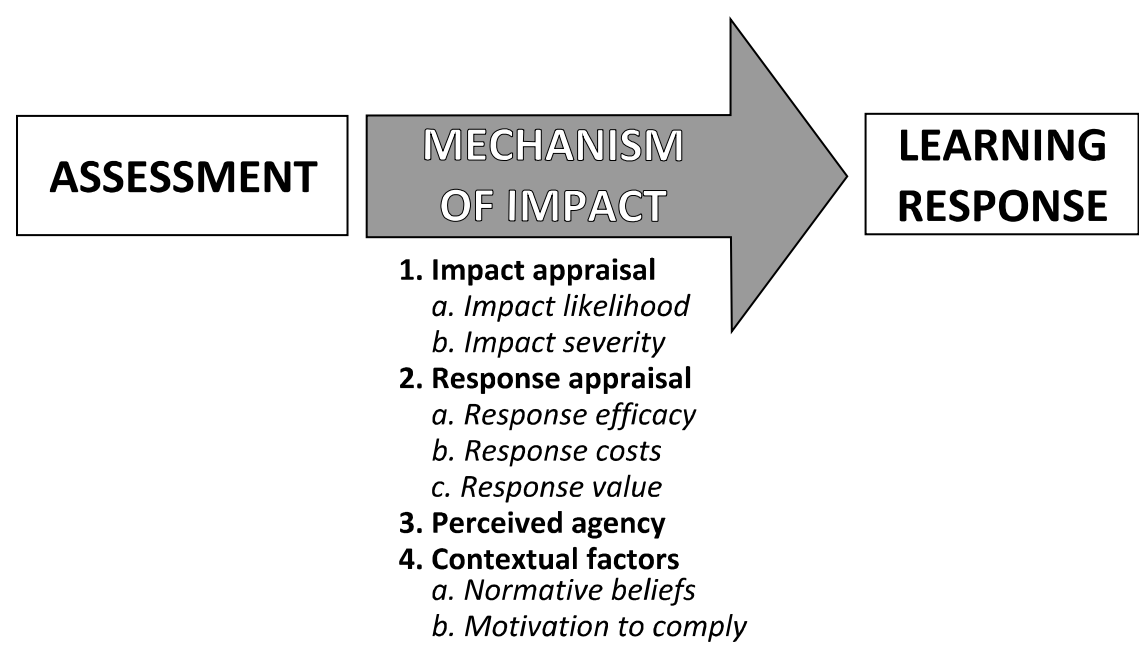

Figure 1. Mechanism of impact of assessment on learning

Likelihood of impact.

For these respondents, the potential for assessment to impact their lives was an unvarying certainty, inescapable, given that assessment in each module determined progression within the program.

[Quote 1] You leave things out that you think they will not ask. So it's maybe big things or maybe important things that could save a patient's life one day, but you don't swot it because you have to pass the test now and that's a problem for me. (6(V)F65)

Magnitude of impact.

The magnitude of any (positive or negative) impact of assessment also influenced respondents' learning. This impact could be external, on progression towards goals like passing a year (cf. Quote 8) or being certified to practice medicine (cf. Quote 3). It could be internal e.g., generating anxiety (cf. Quote 5). Interestingly, the threat of failure loomed large for many respondents, notwithstanding the fact that most of them had never failed a module (Table 1 ).

[Quote 2] initially, I studied more, as sick as it may sound, it was really actually nice to learn new things. Now, it's more so that I know when I go and write exams, it's just for my own peace of mind too. One learns so that you know you are not going to fail. That's a big motivation. (2(V)F77) 
This cuts both ways, however. The lack of (or limited) consequences of other assessment e.g., in-module assignments that contributed but a small proportion of the class mark for the module, also impacted on respondents' learning. Where such assignments were used, respondents would ration their efforts and knowingly sacrifice the small number of marks on offer in the knowledge that effort spent on preparing for the end of module assessment would accrue greater rewards. This was the case even where respondents were interested in and/or enjoyed the assignments during the module. If the "reward" on offer was not great enough, they were less likely to make a concerted effort.

\section{Appraisal of response}

When contemplating assessment, respondents variously considered the efficacy of any given learning response in achieving a particular outcome, the costs of that response and the value of that response as measured against the respondent's personal goals and their conceptions of success and wellness. The learning response to assessment was typically not considered in isolation, but rather balanced against demands from and interests in other dimensions of respondents' lives.

\section{Response efficacy.}

Respondents adapted their learning behaviour in various ways - even to the point of adopting approaches dissonant with their longer term goals (cf. Quotes 1, 8) or detrimental to the quality of their learning (cf. Quote 5) - to meet what they perceived to be the demands of assessment. In some instances, respondents matched the type of learning to the type of assessment. They reported memorizing lists for assessment purposes, even though this meant deliberately not studying for insight e.g., not learning material like pathophysiology or in ways perceived to be beneficial to patient care.

[Quote 3] I can swot lists for tests, but I forget those again. And it... it frustrates me unbelievably much if I don't have insight.

INTERVIEWER: Why do you swot lists then?

RESPONDENT: Well, I must get the marks. You know you must pass your course to become a doctor. Whether you agree with what they asked or not. (10(V)M82)

In other instances, respondents reported calibrating the magnitude and distribution of effort based on past experience or the workload relative to the time available.

[Quote 4] I think you tend to stress more earlier on the course, so you, you maybe... I think you actually relax. You know you can get away with more later on, so you 
maybe start studying a little later. If you have experienced before that, okay, I can actually start at this stage and still be fine, then you... then you tend do it the next time in the same way. (4(V)F81)

Other respondents reported matching their learning response to their perceptions of what an examiner was likely to ask. Respondents were less likely to leave work out if they perceived assessors to be less predictable e.g., if assessors did not either focus on common conditions in test papers or repeat questions from one test to another. Respondents also reported being more likely to pay attention to "spots" if they did not have enough time to review relevant work before a test.

\section{Response costs.}

Costs could be incurred by responding, and not, to the demands of assessment.

Meeting the demands of assessment incurred costs internal to and external to the respondent. Internally, these included tension between the short term goal of success in assessment and longer term goals of delivering quality clinical care. Respondents were sceptical that success in much of the assessment they were subjected to would correlate with good quality cognitive outcomes or future success as a clinician. They reported frustration resulting from wanting to learn to be good clinicians, but having to compromise both the type of content they learned and the way they learned that content in order to meet the short term goals of passing assessment (cf. Quotes 1, 3, 8). They were, however, pragmatic about the fact that if they do not pass the assessment and thus the year, there will be little point in knowing the material anyway. Respondents thus knowingly sacrificed long term benefit (better quality knowledge and being a better doctor) for short term gain (passing the assessment).

Respondents also reported adopting strategies to reduce stress associated with assessment:

[Quote 5] ... in our third year, we could progress [to the next year], so if you got 65, then you didn't need to go and write exams. Now, I cum'd all my theory modules at the end of the day... and so I didn't go and write the exams. And the one... there I go and get 65 on the nose. Then my parents said "are you going to do the exam". Then I said to them "no, I've got 65 . I'm going to progress". I'm not prepared to just, so that it will stand on paper that I cum'd that thing too, now put myself through all that stress of going to learn again and write an exam again. ... to go through the work again another time is, I suppose, always advantageous, but at that time, the pros and cons were just for me... it was just not that important to me. (8(V)F81)

Emotional costs accrued from not responding to assessment. The anxiety related to assessment was a driver of when respondents started paying increasing attention to 
their learning rather than other aspects of their lives. As assessment became more imminent, so respondents' anxiety levels increased, to a point where the anxiety acted as one influence on the distribution of their learning efforts (cf. Quote 4).

[Quote 6] I think if there is no assessment, you won't learn, because that is basically what it's about in medicine. You have a four week module, for example, and you know the first week that you must get an overview of the work and then you know when your stress mechanism starts to kick in, you must now start learning and then you start learning.

INTERVIEWER: What makes you stress?

RESPONDENT: I feel if I didn't go through all the work properly... I won't pass the test. I always feel like that. I know it's sometimes a bit in you somewhere... you only have to learn up to three quarters of the work but I feel if I didn't learn all the work and am satisfied with what I did that there is a possibility that could fail and I don't want to do that. (9(V)F83)

Externally, costs accrued to other assessment tasks (as described above) and to nonlearning activities. Costs accrued to non-learning activities from the unrelenting nature of the workload and from the periodic peaks in workload associated with frequent end-of-module assessment. Respondents reported wanting a break (cf. Quote 5), both mentally and to allow attention to other areas of their lives, and taking this even at the cost of allowing work to accumulate beyond the point where they would be able to deal with it all prior to assessment, and consequently have to engage in compensatory tactics to ensure success.

[Quote 7] ... you get to the stage of like, when you feel you've worked hard on your last clinical block and you feel like relaxing, socializing, then you see you've got a test. The first week of the module: not a good way to start. But I mean it definitely makes you start earlier. (4(V)F81)

\section{Value attached to expected outcome}

Learning responses were variously geared to ensuring respondents earned the "reward" of passing assessment (cf. Quotes 1,8) or avoided the "punishment" of failing (cf. Quotes 2, 6, 9), depending on their goal orientations. (While goal orientations were not formally determined, it was clear from interview data that various respondents displayed perform approach, perform avoid and mastery approach orientations (Pintrich, 2003)). Some articulated more specific goals, like achieving a pass with a certain score.

Respondents reported experiencing tension between different course-related goals e.g., successfully negotiating assessment and being well prepared for patient care. 
As assessment loomed, the goal of passing attained sufficient value that respondents reported learning in ways that were dissonant with their goal of becoming a good clinician (cf. Quotes 1, 3).

[Quote 8] ... as far as assessment goes, I will easily go and look at an old question paper or two or so, tips that other students give and based on that, I will go... go learn, focus on certain things. And, to my own detriment for the day that clinical comes, skip some things, so then I didn't emphasize those, but when you're in a corner... when you are calmly underway, then you feel "I must just swot... I want to swot to be a good doctor", but when you are in a corner, then you swot to make one exam, because you know... Yes, the pressure is pretty high some days, because then you know that your whole year can hinge ... on this one exam. In theory, you can plug your year... so [laughs] then some days all the good intentions go out the window. (7(IV)M72)

However, becoming a good clinician became a more prominent goal as respondents entered their fifth year of study and the 18 month student internship, which started in semester 10 of the program, loomed.

[Quote 9] In the beginning, [my main motivation to swot] was a fear "I'm going to fail". Crumbs, I... I firmly believed I wasn't going to make my first year. So, it's really just that drive to go and sit. But now it's just... I... especially now in the later stages, not just for myself that I... but also for my patients that I'll work with one day. So... I, I... owe it to them that... that I must know that I must do the best that I can and I owe it to them to be a good doctor one day. (5(V)M73)

The value accorded assessment was thus not fixed across time and waned somewhat as students became more senior. For fifth-year students, the imminence of becoming more involved in patient care as student interns became an increasingly prominent factor in their learning. However, they still felt themselves forced to learn in ways that were at odds with achieving this goal. Thus, the looming student internship heightened the tension respondents experienced between pragmatically having to learn in ways that will help them pass exams, and idealistically learning what they believe will be useful to help them care for patients.

In addition to negotiating the tension between these course-related goals, at any given time, respondents also weighed the costs of responding, or not, to assessment against attending to the many other imperatives and interests in their lives. Respondents' interest in, and value attached to, any one of these fluctuated constantly, generating a dynamic, ever-changing motivational mosaic. However, each time assessment loomed, the value attached to learning relative to other activities typically grew (cf. Quote 7). 
[Quote 10] ...the first week, if I don't understand something, then I go back and I'll again... go and get the hang of it. While other swotting thingeys, I won't in my first week. I'll go and put in an hour or two hours each day. Then the second week, then I'll concentrate more on my sport as a... And then in the second week, then one starts picking up a bit. There will be days, say like a Tuesday, then you'll take off and maybe go watch a movie or so, but you pick it up a bit. In the third week, then you start about four hours or so. And then from that... you already start... the second week's weekend, you already start putting in a bit. The first weekend, I don't really put in. And then the third weekend, then you start, from there, you start putting in hard. (5(V)M73)

[Quote 11] I don't know how else... how else one can do it, because there is just not enough time. How, even if you start swotting on the first day of the module, which never happens... You always say to yourself "I've worked so hard now, so I'm going to take the first week off now". And then... one sees one week of four has passed and then the second week starts and then you must already catch up the first week's work. (6(V)F65)

Respondents' interest in the topic of assessment also played a role in determining the amount of effort they devoted to it, particularly with small assignments during modules. The more interested they were in the topic, the more effort they were likely to devote time and effort to the task.

\section{Perceived self-efficacy}

A sense of self-efficacy has to do with the perception of being able to exert some control over a situation, even in the face of adversity. Respondents reported developing a sense over time of what they were able to achieve academically in any given time frame, and being able to calibrate the magnitude, distribution and nature of their learning efforts to achieve their predetermined goals when being assessed (cf. Quotes 4, 6).

[Quote 12] You know how long it takes you to learn something, when you must start waking up and you know when you are behind. And you know what your abilities are and how much you must do to... to be able to get to the test. $(8(\mathrm{~V}) \mathrm{F} 81)$

Various factors challenged respondents' perceived self-efficacy in relation to assessment, including unfamiliar question formats, unpredictable assessors, work overload and modules with a reputation of being difficult. This resulted in respondents adopting compensatory tactics like spotting and memorizing rather than studying for understanding. 


\section{Contextual factors}

The most important contextual factors in respondents' context were various referents. Referents, people whose opinion an individual values, play an important role in influencing intent and behaviour. They provide normative beliefs against which an individual can calibrate their behaviour, if so motivated. For respondents, two key groups of referents were lecturers and other students. Lecturers served as referents both directly and indirectly. Students could include both peers of the respondent and students who previously successfully negotiated the particular year of study. Some respondents clearly fell in the category of cue seekers as described by Miller and Parlett (1974). Others were cue conscious and became more so the greater the degree of trouble they perceived themselves to be in.

\section{Normative beliefs.}

Respondents actively sought out cues as to what lecturers believed to be important and therefore more likely to feature in assessment.

[Quote 13] one gets a reasonable idea in later years what the lecturers think is important. So, if I can, I will swot everything that there is to swot, but if the time gets a bit too little, then I take... not chances, but then I concentrate more on the things that to me are clearly more important. (2(V)F77)

On the one hand, respondents reported taking cues about what content to learn from the broader configuration of the curriculum. They reasoned that, given the extent of material that could potentially be covered in any given module, material that lecturers chose to focus on and include in lectures was likely to be of greater relevance to clinical practice than other material and also, therefore, more likely to feature in assessment. Within this "set" of information, they focused more on a subset of information defined by the fact that, say, three lectures were devoted to a particular topic. In this way, respondents defined for themselves what they believed to be "most assessable material".

[Quote 14] My theory is that a lecturer will not ask me something in an exam that he did not go to the trouble of mentioning in class. (7(IV)M72)

[Quote 15] ... if you paid attention in class, because in the 45 minutes, they cannot do the whole pack of notes. So, they touch on certain topics. And you know that, ten-to-one, the overwhelming majority will come out of the things they touched on in the lecture. $(8(\mathrm{~V}) \mathrm{F} 81)$

Respondents also reported attending class to glean more nuanced information about what the lecturer considered important with a view to deciding what content to focus on when learning and refining what they considered to be "most assessable 
material". This went beyond direct cues like "I won't ask this in the exam" or "Expect this in either the test or the exam". Respondents also attended lectures to discover what material lecturers subtly emphasized while lecturing. This included taking cues from how work was presented.

[Quote 16] ... obviously you have the past papers, but I mean we also have... I mean, the way that classes are presented. The professor said the whole time how important the principles are and he spent a great deal of time on these principles. You must understand, he said again and again, "listen, doses and such stuff is the type of thing you'll be asked in your [student intern] year. Now we want you to understand the principles and understand how stuff works". So I think it became more apparent in the way classes were presented. ... I mean, if the lecture goes on with a guy that puts up PowerPoint's that click, click, click, click, click and here comes a bunch of information, the next slide. You know, he's not really going to test your insights, because he didn't try and explain the concepts to you at all. He just simply gave you facts. So you can just expect that the paper will be factual. (10(V)M82)

Respondents also sought indirect guidance from lecturers by consulting past papers (cf. Quotes 8, 16) . Some respondents did this proactively i.e., at the start of their studies in a module. This was done to gather information about the type of questions asked so as to understand what type of content to focus on and not. Other respondents reported consulting past papers when they were in a pinch and they realized they could not learn all the material they had hoped or planned to. They did this so as to adapt their learning plans.

In some cases, this strategy allowed respondents to make definite choices about including or excluding content from their learning. In some cases, no guidance could be obtained from lecturers or past papers to focus studies. No "spots" were evident. For cue-seeking students, this resulted in high (though typically not debilitating) levels of anxiety.

Many respondents also sought or took cues and guidance from fellow students (cf. Quote 8) both in their class and from more senior classes, even acknowledging that the reliability of information from this source varied. In some instances, this was proactive and related to the workload or degree of difficulty of the work and therefore the amount and nature of effort required in and out of class to succeed in assessment. In other instances, it related to identifying work to focus on and leave out, both ahead of time and in the final hours before an assessment.

Motivation to comply with normative beliefs.

Many respondents' motivation to comply with normative beliefs increased proportionally to their perception of the decreasing likelihood of success in assessment (cf. 
Quote 8). As mentioned above, it was also evident that some respondents' motivation to comply with the perceived beliefs of lecturers or fellow students lessened somewhat as the student internship became more imminent.

\section{Negative cases}

As part of the process of analysis, data were scrutinised for evidence of cases which gave evidence that this mechanism was not a valid explanation of the link between assessment and learning. There were cases where students clearly were strongly focussed on their upcoming professions. The fifth-year respondents clearly were far more aware of learning for the purposes of caring for patients than their fourth year counterparts. The imminence of their student internship played a great role in this regard. Some respondents also seemed to have a more professional orientation in general or to be learning for the love of learning. However, it was striking how modulating factors like the imminence of assessment and the prevailing workload rode roughshod over such orientations. Even in the respondents with the most strongly established learning orientations of this nature, there was clear evidence that imminence, as a modulating factor, overrode their intrinsic orientation and that elements of the proposed mechanism came into play. Impact appraisal resulted in their abandoning their preferred learning activities in favour of strategies like, for example, memorising lists that would bring success in assessment, which success held the key to their progressing to the next stage of the course and being able to provide care for patients, their actual goal (as opposed to merely passing the exam). They also abandoned learning material they believed was relevant to patient care in favour of learning material they believed was irrelevant to patient care but relevant to achieving success in the upcoming assessment. Ultimately, then, there were no cases where some dimensions of this mechanism were not at play or where an alternate mechanism could be identified as the dominant factor at play.

\section{Discussion}

The purpose of this exploratory study was to probe the mechanisms by which assessment impacts on learning, focusing on how various dimensions of summative assessment of theory bring about such influence as they exert on various dimensions of learning. What is proposed here is a theoretical framework to explain why students respond to assessment in the ways that they do and not merely what their response is.

The factors described in this study do not form a simple target for intervention. Not all of these factors are in play for any given student at any given time, nor are the 
factors in play for any given student constant across time and context. Even if the same factors are in play for two students, the intensity of that impact may vary based on personal or other contextual influences individual to each. This serves to underline that "the social and cultural contexts of the phenomenon studied are crucial for understanding the operation of causal mechanisms" (Maxwell, 2004a: 6). To complicate matters even further, as Gebhardt and Maes (2001) caution in the context of health behaviour, not all behaviour is the result of a considered response to the factors inducing the behaviour. Hence, when assessment is manipulated to influence learning, students may initially act out established patterns of behaviour rather than making the effort to make considered, deliberate changes. This might go part way to explaining the lack of desirable impact of thoughtfully designed assessment interventions.

It also bears emphasising that assessment is typically not a single, homogeneous entity to which students respond. Each module or course makes its own demands of students, often independently of rather than in synchronised fashion with others. Ultimately, to have an impact on as many dimensions of learning of as many students as possible, it will be necessary to manipulate multiple dimensions of assessment i.e., assessment systems, rather than tweak individual assessment events. Yet not taking this complexity into account will result in failed efforts to positively influence learning using assessment. That said, what do these results suggest about designing assessment to enhance quality learning?

Assessment that is intended to impact learning should have consequences, be those consequences on students' marks and progression or on other factors e.g., their esteem in the eyes of fellow students as may be the case with project presentations or peer assessment or their sense of agency as may be the case with feedback. Furthermore, any attempt to manipulate assessment to influence learning has to be considered against the backdrop of all assessment in the system - particularly high stakes, summative assessment - that will also be impacting on students' learning.

The degree of impact of any assessment activity will probably be strongly correlated with the magnitude of the severity of consequences associated with it. Introducing feedback on a one-of-a-kind assignment contributing $10 \%$ of a student's grade is likely to be a less successful intervention than changing the level of cognitive challenge from recall to problem-solving in a multiple choice assessment contributing $50 \%$ of a student's grade.

Assessment should be designed in such a way that when students make their appraisal of the efficacy of their learning response, that appraisal leads them to learn in ways we as academics believe they should be learning. Evidently, Newble \& Jaeger (1983) and Frederiksen (1984) were able to bring about just such changes. In 
theory modules, using a mixed bag of longer and shorter questions types would force students to engage differently with learning material, both in terms of what they learn and in terms of how they learn. They would be unable to simply leave out work based on the length or type of questions to be asked. Having one longer (e.g., 20 mark) question per assessment mixed with shorter questions should lead to qualitative differences in students learning. Clearly, such a design would also have to be weighed against various other, including psychometric and pragmatic, considerations (van der Vleuten, 1996).

The costs to students of any given learning response should not be too high. Where the demands of an assessment system become too onerous, the cost-benefit analysis will lead students to find short cuts. One thinks here of the introduction of portfolios for assessment. This is based on sound educational grounds, but does not always lead to a salubrious impact on learning (Driessen, van Tartwijk, van der Vleuten, \& Wass, 2007).

Equally, assessment tasks that challenge students' sense of agency by virtue of being unknown or complex, or based on material too complex (van Etten et al., 1997) or too voluminous to engage with meaningfully in the limited time available within an academic module, will be unlikely to have a positive impact on student learning.

Finally, the impact of the "myths and legends" about assessment that swirl around a module and/or a lecturer should not be lost from sight. The university where no volumes of past examination papers are passed from one generation of students to the next is likely a rare place indeed. These form the basis of analyses of content and style that inform the learning of many a student. As such, they should be brought out of the shadows and incorporated openly into the assessment system.

There are some limitations inherent in this work, largely related to the methodology employed. One of the innate dangers when utilizing in-depth interviews with individual respondents is that respondents cannot be assumed to have complete knowledge about the impact of assessment on learning, or that their accounts was unbiased by their interpretation of their experiences or the situations to which they refer, or the situation of the interview (Cohen, Manion, \& Morrison, 2000). However, care was taken to get respondents to describe and explore their actual responses in various situations they had experienced over time and to minimise the impact of the situation of the interview. Furthermore, data saturation was reached both during interviews and during data analysis and we are confident that the constructs identified are exhaustive for this group of respondents.

A second limitation is that all respondents volunteered to participate in the study. In keeping with other studies, there was a greater proportion of respondents with 
higher average scores than the classes from which they were drawn (Callahan, Hojat, \& Gonnella, 2007; N. J. Entwistle \& Entwistle, 1991). This could have resulted in a greater proportion of insightful comments, but possibly over-represented well organised study strategies. In contrast to Callahan et al's findings, our respondents included a greater proportion of women. Given that gender may correlate with approaches to study (Duff, 2002), further study of the role of gender in this mechanism is warranted. Overall, however, as the purpose of this study is the elucidation of a process rather than generalizability, neither of these factors is considered a drawback.

How credible are our findings as a causal explanation? Our study has certainly addressed many of the threats to causal inference identified by Maxwell (2004b). This framework is derived from the lived experiences of students in a complex, authentic educational system over time. Our observation of causal processes is admittedly indirect by way of interviews. Nonetheless, even though interviews were conducted at one point in time, we explored the responses of respondents to multiple different assessment situations across their years of study. Similarities and differences between constructs and relationships between constructs were recognisable across contexts for given respondents and across respondents. Echoes of these constructs and relationships are also discernible in published literature (see below). As noted earlier, we were unable to find discrepant data or negative cases in our data that would challenge the proposed framework. Finally, we have informally solicited responses to this data from audiences in the health sciences and other disciplines in South African and international settings (e.g., Cilliers et al., 2008; Cilliers, Schuwirth, Adendorff, Herman, \& van der Vleuten, 2009). Participants have invariably acknowledged the findings to represent a "recognisable reality", both from the perspective of their own experience as learners and that as lecturers.

Does this mechanism have currency beyond the setting in which it has been elucidated i.e., an environment that uses high stakes assessment, repeatedly, as a means of advancing medical students at one South African university through the curriculum? Clearly the research design does not hold generalizability as its intent. Nonetheless, there are some tempting clues that we believe indicate that exploring this mechanism in other settings is warranted. When interpreted in light of this mechanism, findings reported in other literature generated from work done in various non-medical contexts in Scotland and the United States (Becker et al., 1968; Frederiksen, 1984; Miller \& Parlett, 1974; Snyder, 1971) give evidence of the mechanism being in play in other contexts. In fact, in contrast to the setting of this present work where the curriculum had been designed specifically so that students only studied one module at any given time, these other reports evidence how the mechanism 
plays out in settings where students have to juggle demands from multiple courses concurrently.

It is also anticipated that this model might be useful beyond the context of summative assessment. One of the conundrums with using feedback is that whilst it has been found to potentially have a powerful impact on student learning (Black \& Wiliam, 1998), it is often missed or misunderstood by students (see Gibbs \& Simpson, 2004 for examples). It is tempting to speculate that applying the lens of impact appraisal and response appraisal to some of the findings of research on feedback could shed some light on these phenomena. It is interesting to note that feedback from lecturers did not feature as a factor influencing learning in this study.

As Ramsden (1992, p. 68) pointed out: "Unsuitable assessment methods impose irresistible pressures on a student to take the wrong approaches to learning tasks". With a better understanding of how assessment impacts on student learning, it will hopefully be possible to start exploring how assessment can be better utilized to bring about meaningful student learning and remedy this situation. Crucial links in ensuring that assessment is utilized more effectively will include the academics who assess students, and administrators who increasingly decide on the mix of demands - assessment-related and otherwise - to which academics should be answerable. Understanding these cogs in the greater academic machine will hopefully ensure that we are not still lamenting the deplorable impact of assessment on learning some decades hence. 


\section{References}

Airasian, P. W. (1988). Measurement driven instruction: A closer look. Educational Measurement: Issues and Practice, $7(4), 6-11$.

Alderson, J. C., \& Banerjee, J. (2001). Language testing and assessment (part 1). Language Teaching, 34(4), 213-236.

Alderson, J. C., \& Wall, D. (1993). Does washback exist? Applied Linguistics, 14(2), 115-129.

Bailey, K. M. (1996). Working for washback: A review of the washback concept in language testing. Language Testing, 13(3), 257-279.

Bartholomew, L. K., Parcel, G. S., Kok, G., \& Gottlieb, N. H. (2001). Chapter 6. Selecting theory based intervention methods and practical strategies Intervention mapping: Designing theory-based health promotion programmes. Mountain View, California: Mayfield Publishing Company.

Becker, H. S., Geer, B., \& Hughes, E. C. (1968). Making the grade: The academic side of college life. New York: John Wiley \& Sons, Inc.

Becker, H. S., Geer, B., Hughes, E. C., \& Strauss, A. (1961). Boys in white. Student culture in medical school. Chicago: University of Chicago Press.

Biggs, J. B. (1987). Student approaches to learning and studying. Hawthorn, Australia: Australian Council for Educational Research Ltd.

Biggs, J. B. (1996). Assessing learning quality: Reconciling institutional, staff and educational demands. Assessment \& Evaluation in Higher Education, 21(1), 5-16.

Black, P., \& Wiliam, D. (1998). Assessment and classroom learning. Assessment in Education: Principles, Policy \& Practice, 5(1), 7-74.

Boud, D. (1995). Assessment and learning: Contradictory or complementary? In P. Knight (Ed.), Assessment for learning in higher education (pp. 35-48). London: Kogan Page.

Boud, D., Cohen, R., \& Sampson, J. (1999). Peer learning and assessment. Assessment \& Evaluation in Higher Education, 24(4), 413-426.

Broekkamp, H., \& van Hout-Wolters, B. H. A. M. (2007). Students' adaptation of study strategies when preparing for classroom tests. Educational Psychology Review, 19(4), 401-428.

Bunge, M. (2004). How does it work? The search for explanatory mechanisms. Philosophy of the Social Sciences, 34(2), 182-210.

Callahan, C. A., Hojat, M., \& Gonnella, J. S. (2007). Volunteer bias in medical education research: An empirical study of over three decades of longitudinal data. Medical Education, 41(8), 746-753.

Charmaz, K. (2006). Constructing grounded theory: A practical guide through qualitative analysis. London: Sage Publications Ltd.

Cilliers, F. J., Schuwirth, L. W. T., Adendorff, H. J., Bitzer, E. M., Herman, N., \& van der Vleuten, C. P. M. (2008). The impact of summative assessment of theory on how medical students learn. Paper presented at the AMEE Conference, Prague, Czech Republic.

Cilliers, F. J., Schuwirth, L. W. T., Adendorff, H. J., Herman, N., \& van der Vleuten, C. P. M. (2009). Assessment impacts on learning, you say? Please explain how. The impact of summative assessment of theory on how medical students learn. Paper presented at the Annual Conference of the Society for Research into Higher Education, Celtic Manor, Wales.

Cohen, L., Manion, L., \& Morrison, K. (2000). Research methods in education (5th ed.). London: RoutledgeFalmer.

de Corte, E. (2007). Learning from instruction: The case of mathematics. Learning Inquiry, 1(1), 19-30.

de Corte, E., Verschaffel, L., Entwistle, N. J., \& van Merriënboer, J. J. G. (2003). Powerful learning environments: Unravelling basic components and dimensions (1st ed.). Oxford: Pergamon.

Dey, I. (1993). What is qualitative analysis? Qualitative data analysis (pp. 31 - 54): Routledge, USA and Canada.

DiCicco-Bloom, B., \& Crabtree, B. F. (2006). The qualitative research interview. Medical Education, 40(4), 314-321. 
Dörnyei, Z. (2000). Motivation in action: Towards a process-oriented conceptualisation of student motivation. British Journal of Educational Psychology, 70(4), 519-538.

Driessen, E., van Tartwijk, J., van der Vleuten, C. P. M., \& Wass, V. (2007). Portfolios in medical education: Why do they meet with mixed success? A systematic review. Medical Education, 41(12), 1224-1233.

Duff, A. (2002). Approaches to learning: Factor invariance across gender. Personality and Individual Differences, 33(6), 997-1010.

Elton, L. (1987). Teaching in higher education: Appraisal and training. London: Kogan Page.

Elton, L. R. B., \& Laurillard, D. M. (1979). Trends in research on student learning. Studies in Higher Education, 4(1), 87-102.

Entwistle, A. C., \& Entwistle, N. J. (1992). Experiences of understanding in revising for degree examinations. Learning and Instruction, 2(1), 1-22.

Entwistle, N. J., \& Entwistle, A. C. (1991). Contrasting forms of understanding for degree examinations: The student experience and its implications. Higher Education, 22(3), 205-227.

Entwistle, N. J., \& Entwistle, A. C. (2005). Revision and the experience of understanding. In F. Marton, D. Hounsell \& N. J. Entwistle (Eds.), The experience of learning: Implications for teaching and studying in higher education (3rd (Internet) edition ed., pp. 145-155). Edinburgh: University of Edinburgh, Centre for Teaching, Learning and Assessment.

Fransson, A. (1977). Qualitative differences in learning. 4. Effects of intrinsic motivation and extrinsic test anxiety on process and outcome. British Journal of Educational Psychology, 47(3), 244-257.

Frederiksen, N. (1984). The real test bias: Influences of testing on teaching and learning. American Psychologist, 39(3), 193-202.

Gebhardt, W. A., \& Maes, S. (2001). Integrating social-psychological frameworks for health behavior research. American Journal of Health Behavior, 25(6), 528-536.

Gibbs, G., \& Simpson, C. (2004). Conditions under which assessment supports students' learning. Learning and Teaching in Higher Education, 2004-05(1), 3-31.

Gijbels, D., Coertjens, L., Vanthournout, G., Struyf, E., \& Van Petegem, P. (2009). Changing students' approaches to learning: A two-year study within a university teacher training course. Educational Studies, 35(5), 503-513.

Glover, J. A. (1989). The "testing" phenomenon: Not gone but nearly forgotten. Journal of Educational Psychology, 81(3), 392-399.

Janssens, S., Boes, W., \& Wante, D. (2002). Portfolio: Een instrument voor toetsing en begeleiding. In F. J. R. C. Dochy, L. Heylen \& H. Van de Mosselaer (Eds.), Assessment in onderwijs (pp. 203-224). Utrecht: LEMMA.

Jones, H. E. (1923). Experimental studies of college teaching: The effect of examination on the permanence of learning. Archives of Psychology, 10, 1-70.

Joughin, G. (2007). Student conceptions of oral presentations. Studies in Higher Education, 32(3), 323336.

Kvale, S. (1996). Interviews: An introduction to qualitative research interviewing. Thousand Oaks, California: Sage Publications, Inc.

Laurillard, D. M. (1979). The processes of student learning. Higher Education, 8(4), 395-409.

Lundeberg, M. A., \& Fox, P. W. (1991). Do laboratory findings on test expectancy generalize to classroom outcomes? Review of Educational Research, 61(1), 94-106.

Madaus, G. F. (1988). The distortion of teaching and testing: High-stakes testing and instruction. Peabody Journal of Education, 65(3), 29-46.

Maxwell, J. A. (2004a). Causal explanation, qualitative research, and scientific inquiry in education. Educational Researcher, 33(2), 3-11.

Maxwell, J. A. (2004b). Using qualitative methods for causal explanation. Field Methods, 16(3), 243-264.

Meyer, G. (1936). The effect of recall and recognition on the examination set in classroom situations. Journal of Educational Psychology, 27(2), 81-99. 
Miles, M. B., \& Huberman, A. M. (1994a). Making good sense - drawing and verifying conclusions Qualitative data analysis: An expanded sourcebook (2nd ed., pp. 245-287). Thousand Oaks: Sage Publications, Inc.

Miles, M. B., \& Huberman, A. M. (1994b). Within-case displays: Explaining and prediciting Qualitative data analysis: An expanded sourcebook (2nd ed., pp. 143-171). Thousand Oaks: Sage Publications, Inc.

Miller, C. M. L., \& Parlett, M. (1974). Up to the mark: A study of the examination game. London: Society for Research into Higher Education.

Newble, D. I., \& Jaeger, K. (1983). The effect of assessment and examinations on the learning of medical students. Medical Education, 17(3), 165-171.

Parlett, M. (1969). Undergraduate teaching observed. Nature, 223(5211), 1102-1104.

Pintrich, P. R. (2003). A motivational science perspective on the role of student motivation in learning and teaching contexts. Journal of Educational Psychology, 95(4), 667-696.

Ramsden, P. (1984). The context of learning. In F. Marton, D. Hounsell \& N. J. Entwistle (Eds.), The experience of learning (pp. 144-164). Edinburgh: Scottish Academic Press.

Ramsden, P. (1992). Learning to teach in higher education. London: Routledge.

Ramsden, P. (2005). The context of learning in academic departments. In F. Marton, D. Hounsell \& N. J. Entwistle (Eds.), The experience of learning: Implications for teaching and studying in higher education (3rd (Internet) edition ed., pp. 198-216). Edinburgh: University of Edinburgh, Centre for Teaching, Learning and Assessment.

Roediger, H. L., III, \& Karpicke, J. D. (2006). Test-enhanced learning. Psychological Science, 17(3), 249-255.

Ross, M. E., Green, S., Salisbury-Glennon, J. D., \& Tollefson, N. (2006). College students' study strategies as a function of testing: An investigation into metacognitive self-regulation. Innovative Higher Education, 30(5), 361-375.

Ross, M. E., Salisbury-Glennon, J. D., Guarino, A., Reed, C. J., \& Marshall, M. (2003). Situated selfregulation: Modeling the interrelationships among instruction, assessment, learning strategies and academic performance. Educational Research and Evaluation, 9(2), 189-209.

Sambell, K., \& McDowell, L. (1998). The construction of the hidden curriculum: Messages and meanings in the assessment of student learning. Assessment \& Evaluation in Higher Education, 23(4), 391-402.

Scouller, K. M. (1998). The influence of assessment method on students' learning approaches: Multiple choice examinations versus assignment essay. Higher Education, 35, 453-472.

Segers, M., \& Dochy, F. J. R. C. (2006). Introduction enhancing student learning through assessment: Alignment between levels of assessment and different effects on learning. Studies in Educational Evaluation, 32(3), 171-179.

Snyder, B. R. (1971). The hidden curriculum. New York: Alfred A. Knopf.

Tang, K. C. C. (1994). Effects of modes of assessment on students' preparation strategies. In G. Gibbs (Ed.), Improving student learning - theory and practice (pp. 151-170). Oxford: Oxford Centre for Staff Development, Oxford Brookes University.

Thomson, K., \& Falchikov, N. (1998). 'Full on until the sun comes out': The effects of assessment on student approaches to studying. Assessment \& Evaluation in Higher Education, 23(4), 379-390.

van der Vleuten, C. P. M. (1996). The assessment of professional competence: Developments, research and practical implications. Advances in Health Sciences Education, 1(1), 41-67.

van Etten, S., Freebern, G., \& Pressley, M. (1997). College students' beliefs about exam preparation. Contemporary Educational Psychology, 22(2), 192-212.

Vermunt, J. D. (1996). Metacognitive, cognitive and affective aspects of learning styles and strategies: A phenomenographic analysis. Higher Education, 31(1), 25-50. 


\title{
CHAPTER 3
}

\author{
A Model of the \\ Pre-assessment Learning Effects \\ of Summative Assessment \\ in Medical Education
}




\begin{abstract}
It has become axiomatic that assessment impacts powerfully on student learning. However, surprisingly little research has been published emanating from authentic higher education settings about the nature and mechanism of the pre-assessment learning effects of summative assessment. Less still emanates from health sciences education settings. This study explored the pre-assessment learning effects of summative assessment in theoretical modules by exploring the variables at play in a multifaceted assessment system and the relationships between them. Using a grounded theory strategy, in-depth interviews were conducted with individual medical students and analysed qualitatively. Respondents' learning was influenced by task demands and system design. Assessment impacted on respondents' cognitive processing activities and metacognitive regulation activities. Individually, our findings confirm findings from other studies in disparate non-medical settings and identify some new factors at play in this setting. Taken together, findings from this study provide, for the first time, some insight into how a whole assessment system influences student learning over time in a medical education setting. The findings from this authentic and complex setting paint a nuanced picture of how intricate and multifaceted interactions between various factors in an assessment system interact to influence student learning. A model linking the sources, mechanism and consequences of the pre-assessment learning effects of summative assessment is proposed that could help enhance the use of summative assessment as a tool to augment learning.
\end{abstract}

\title{
Abbreviations
}

CPA: cognitive processing activities

MRA: metacognitive regulation activities

HE: higher education

HSE: health sciences education

LESA: learning effects of summative assessment

SA: summative assessment

An abridged version of this chapter was published as:

Cilliers, F. J., Schuwirth, L. W. T., Herman, N., Adendorff, H., \& van der Vleuten, C. P. M. (2012). A model of the pre-assessment learning effects of summative assessment in medical education. Advances in Health Sciences Education, 17(1), 39-53. 


\section{Introduction}

\section{Background}

Summative assessment i.e., assessment administered in consequential test conditions (Sundre \& Kitsantas, 2004) carries inescapable and profound consequences for students. Such assessment, possibly more than any other form of assessment and perhaps more than any other aspect of instructional design, defines a major component of the impact of the learning environment on student learning. Becker, Geer and Hughes (1968) and Snyder (1971) provided evidence of the pervasive influence of assessment on students in higher education (HE) settings. This suggests that summative assessment is potentially a powerful tool with which to (positively) influence student learning. However, while better utilization of assessment to influence learning has long been a goal in $\mathrm{HE}$, it is not one that has been achieved with any great measure of success (Case \& Gunstone, 2003; Gijbels, Coertjens, Vanthournout, Struyf, \& Van Petegem, 2009; Heijne-Penninga, Kuks, Hofman, \& CohenSchotanus, 2008; Nijhuis, Segers, \& Gijselaers, 2005).

It is widely accepted that the impact of assessment on student learning is well documented. However, an extensive search of the literature in various fields e.g., HE, health sciences education (HSE), educational psychology, cognitive psychology, assessment and language testing has revealed that the literature about the learning effects of summative assessment in authentic HE settings is actually quite fragmentary. Assessment method $\mathrm{X}$ is compared with assessment method $\mathrm{Y}$ or dimension $\mathrm{A}$ with dimension $B$, more often in controlled experimental settings than in authentic field settings (e.g., Agarwal, Karpicke, Kang, Roediger, \& McDermott, 2008; Feldt, 1990; Son \& Kornell, 2009; Thiede, 1996; Williams, Pollack, \& Ferguson, 1975). Many papers offer descriptive rather than explanatory findings. Work emanating from different settings - university, college, secondary and even elementary school - is cited together (e.g., Biggs, 1998; Crooks, 1988; Natriello, 1987; Roediger \& Karpicke, 2006).

It is a challenge to synthesize a coherent account to explain the learning effects of summative assessment in HE settings, even more so for HSE settings, where literature on the topic is sparser. If we accept that summative assessment does, indeed, strongly influence student learning, it is imperative we harness this force and purposively utilize it to help create powerful learning environments (de Corte, Verschaffel, \& Masui, 2004). Yet it appears that too little is known about the nature of the impact of such assessment on student learning to meaningfully harness its power. 


\section{Typology of learning effects of assessment}

Dochy et al (2007) distinguish pre-, post- and pure assessment effects. Preassessment effects impact learning before assessment takes place and are typically addressed in literature on exam preparation (Broekkamp \& van Hout-Wolters, 2007; van Etten, Freebern, \& Pressley, 1997) and test expectancy (d'Ydewalle, Swerts, \& De Corte, 1983; Feldt \& Ray, 1989; Hakstian, 1971). Post-assessment effects impact after assessment and include effects on the outcomes of student learning i.e., student achievement or performance. These are typically addressed in literature referring to feedback (Black \& Wiliam, 1998; Gibbs \& Simpson, 2004) and other studies of the relationship of assessment with student achievement (Bangert-Drowns, Kulik, \& Kulik, 1991; Bol, Warkentin, Nunnery, \& O'Connell, 1999; Feldt, 1990; Sundre \& Kitsantas, 2004). Pure assessment effects impact during assessment and are reported more rarely (Tillema, 2001). The testing effect (Agarwal et al., 2008; Carpenter, Pashler, Wixted, \& Vul, 2008; McDaniel, Anderson, Derbish, \& Morrisette, 2007; Roediger \& Karpicke, 2006) could be classified as a pure or a post assessment effect depending on whether the effect on the learning process or subsequent achievement is considered.

\section{Pre-assessment Learning Effects of Summative Assessment}

Our interest is in the pre-assessment effects of summative assessment on student learning behaviours. More specifically, we are interested in summative assessment in theoretical modules in authentic educational settings. Given the paucity of HSE literature on the topic, most literature reviewed will be from HE literature, focusing on studies conducted in authentic educational settings. Two major sets of effects can be distinguished i.e., those related to perceived task demands and those related to the design of the assessment system.

\section{Effects related to perceived task demands}

Learning is influenced by students' perceptions of the demands of an assessment task. Perceptions of task demands may accrue from explicit and implicit information from lecturers, information from fellow students, old test and exam papers and students' own experience of assessment (including assessment formats and specific assessor's expectations) (Entwistle \& Entwistle, 1991; Frederiksen, 1984b; van Etten et al., 1997). These perceptions can differ from one student to the next (Sambell \& McDowell, 1998; Scouller, 1998; Scouller \& Prosser, 1994; Segers, Gijbels, \& Thurlings, 2008; Segers, Nijhuis, \& Gijselaers, 2006; Tang, 1994). Two types of demands may be distinguished i.e., content and processing demands. 


\section{Content demands}

Content demands relate to the knowledge required to respond to an assessment task (Broekkamp \& van Hout-Wolters, 2007). The resources students utilize to prepare for assessment are influenced by the perceived demands of both the assessor and of the assessment task (Entwistle \& Entwistle, 1991; Frederiksen, 1984b; Newble \& Jaeger, 1983; Säljö, 1979). Students are more likely to take notes in lectures when "exams were driven by lecture content" (van Meter, Yokoi and Pressley as cited in van Etten et al., 1997, p. 194). The selection of what to learn is influenced by the perceived demands of the assessment task, with students covering more content for selected response items than for constructed response items (Sambell \& McDowell, 1998). Elton and Laurillard (as cited in Boud, 1990) reported that

assessment encourages students to focus on those topics that are assessed at the expense of those that are not. ...if students want to get good marks, they focus on these aspects at the expense of others which might capture their interest. (p. 103)

Hakstian (1971) quotes various studies that found that students tend to focus on smaller units of information for selected response assessments than for essays, but found himself that students' learning (techniques; time on task) was no different when expecting an objective test, an essay or both.

\section{Processing demands}

Processing demands relate to "skills required for processing ... knowledge in order to generate the requested response" (Broekkamp \& van Hout-Wolters, 2007, p. 409). Students' approach to learning is influenced by the perceived demands of the assessor (Ramsden, 1979) and of the assessment task. Constructed response items and open-ended assessments are more likely to engender a transformative or deep approach to learning and selected response items and closed assessments more likely to arouse a reproductive or surface approach to learning (Laurillard, 1984; Ramsden, 1979; Sambell \& McDowell, 1998; Sambell, McDowell, \& Brown, 1997; Scouller, 1998; Tang, 1994; Thomas \& Bain, 1984; van Etten et al., 1997; Watkins, 1982). Short essay tests and short-answer exams elicited more surface approaches and assignments deeper approaches to learning (Tang, 1991 (cited in Biggs, 1996, p. 10); 1994; Thomas \& Bain, 1984). Contrary to expectation, however, closed-book tests were found to promote a deep approach to learning more than open-book tests (Heijne-Penninga et al., 2008).

Reporting on various studies, Marton and Säljö (1984) also relate how students adapt their learning to meet their perception of the demands posed by the type of questions they will be asked. Interestingly, students who perceived constructed response items to assess higher levels of cognitive functioning were more likely to adopt transformative approaches to learning, even though the items in question 
were adjudged to only assess facts or perhaps comprehension. The converse was not true (Scouller \& Prosser, 1994). Sambell, McDowell and Brown (1997) reported that where students perceived essay questions to require simply lifting information from books, learning was not transformative. Tang (1994) reported that where students who were intrinsically motivated to understand content perceived an assessment to require memorization, they would memorize facts after having first understood them.

Tang (1994) speculated that students' degree of familiarity with an assessment method influenced their approach to learning, while Watkins and Hattie (cited by Scouller, 1998) speculated that past success with surface strategies may encourage a perception that "deep level learning strategies are not required to satisfy examination requirements" (p. 454).

\section{Effects related to the design of the assessment system}

The mere fact of assessment motivates students to learn and therefore influences the quantum of effort expended on learning (van Etten et al., 1997). The amount of time students spend studying increases, up to a point, as the volume of material and, independent of that, the degree of difficulty of the material, to be studied, increases (van Etten et al., 1997). High workloads also drive students to be more selective about what content to engage with and to adopt low level cognitive processing tactics (Entwistle \& Entwistle, 1991; Ramsden, 1984; van Etten et al., 1997). The scheduling of assessment in a course and across courses impacts the distribution of learning effort, as do competing interests e.g., family, friends and extracurricular activities (Becker et al., 1968; Miller \& Parlett, 1974; Snyder, 1971; van Etten et al., 1997).

\section{Theoretical underpinnings}

Little previous work has invoked theory when discussing the learning effects of assessment. There is equally a dearth of models - whether or not supported by empirical evidence - offering insight into why assessment has the impact that it does. Becker, Geer \& Hughes (1968) constructed a 'perspective', the grade point average perspective, to explain the pervasive impact of assessment in their setting. Others (Ross, Green, Salisbury-Glennon, \& Tollefson, 2006; Ross, Salisbury-Glennon, Guarino, Reed, \& Marshall, 2003; Sundre \& Kitsantas, 2004; van Etten et al., 1997) have looked to self-regulation theory when discussing the link between assessment and learning. Alderson and Wall (1993) posited that motivation may play a role, but little empirical evidence supports either this contention, their hypotheses about, or a model (Bailey, 1996) of, washback in the language teaching and testing literature. Broekkamp and van Hout-Wolters (2007) derived a model from extensive (largely 
school-based) literature to explain students' adaptation of study strategies when preparing for classroom tests. None of these models has provided a satisfactory explanation of the learning effects of assessment, however.

Extant literature provides - with few exceptions - fragmented data about assessment-related sources of impact and their pre-assessment learning effects. Indeed, many of the studies cited did not set out to investigate the learning effects of assessment as such. The purpose of this study was to extend what is known about the pre-assessment learning effects of summative assessment in theoretical modules in a HSE setting by exploring the variables at play in an authentic, multifaceted assessment system and the relationships between them. Specifically, the study aimed to obtain answers to three questions: What facets of summative assessment in theoretical modules impact on student learning? What facets of student learning are influenced by such assessment? and In what way do these factors impact on student learning? Having ascertained that, the intention was to propose a model explaining the pre-assessment learning effects of summative assessment of theory. To do this, a qualitative approach was adopted, based on in-depth interviews with senior medical students.

\section{Methods}

\section{Context}

This study was conducted at a South African medical school. Students followed a sixyear curriculum. Most entered the program directly from school, having completed a national matriculation examination at the end of five years of secondary schooling. The program was modular. Phases One and Two, the first three semesters, comprised only theoretical modules, focused on preclinical sciences. Phase Three, semesters four to nine, comprised alternating clinical theory and clinical practice modules. Phase Four, semesters 10 to 12 , comprised clinical practice modules only. Study guides that included outcomes and information on assessment were provided for each module. Students had to successfully negotiate each module during the year to gain entrance to the end-of-year examination in that module. They had to pass the examination in each module to progress to the next year of study. Students who failed a module had to repeat the module. While they could repeat multiple modules in a repeat year, they could only repeat one year of study during the program. If they failed during a subsequent year of study, they exited the program. Attrition in the program was approximately $25 \%$ overall and was highest during years one and two. 


\section{Data Collection and Analysis}

Ethical approval for this study was obtained from an institutional research ethics board. Respondents were informed about the nature of the study, invited to participate and informed consent for study participation and later access to respondents' academic records elicited using an information sheet and informed consent document.

Our ultimate purpose was to propose a model explaining the pre-assessment learning effects of summative assessment. Model construction is often approached using a variance theory approach. Such mathematical modelling typically yields descriptions of whether one construct (of a typically limited number) is related to another, but often not how. In contrast, a process theory approach (Maxwell, 2004) can offer insight into how events and processes in complex systems are connected. Having no adequate model to use as a point of departure for an alternate research strategy, this study is informed by the latter approach. We adopted grounded theory as our research strategy. We made a deliberate decision to start with a clean slate and utilized in-depth interviews (Charmaz, 2006; DiCicco-Bloom \& Crabtree, 2006; Kvale, 1996) for data collection. While findings may confirm existing literature, this approach also offers the advantage of potentially discovering constructs and relationships not previously described.

Interviews were thus not structured beyond exploring three broad themes within each i.e., how respondents learned, what assessment they had experienced and how they adapted their learning to assessment. Each interview was allowed to develop its own direction within the broad confines of the theme of study. That said, specific examples of, and detailed information about, the facets of assessment to which respondents adapted their learning and the facets of learning that they adapted in response to assessment, were sought throughout, using probing questions where appropriate.

When new themes emerged in an interview, these were explored in depth. Not only was evidence sought in subsequent interviews to confirm the existence and nature of emerging constructs. New issues that emerged from preliminary data analysis (see below) were followed up. Evidence was also sought to disconfirm the existence of emergent constructs and relationships. Interviews explored respondents' experience of learning and assessment across the entire period of their university studies up to that point, not just at the time of the interview.

Interviews were conducted with 18 medical students (Table 1) in their fourth and fifth years of study. All interviews were conducted by the same investigator, an educational adviser involved in curriculum reform in the faculty who interacted primarily with lecturers. All students in the fourth $(\mathrm{N}=141)$ and fifth $(\mathrm{N}=143)$ year 
classes were invited to participate in the study. Each class was addressed once about the study and all students subsequently sent an individual email reminder, inviting them to participate. Thirty-two students volunteered to participate in interviews. Interviews were scheduled based on the availability of students, at a time and place of their preference and were conducted in Afrikaans or English based on respondent preference. In keeping with the grounded theory strategy that was used, data analysis (see below) commenced even as interviews proceeded. Later interviews were informed by initial analysis of earlier interviews. Notwithstanding the individualized nature of the interviews, each of which lasted approximately 90 minutes, no new findings emerged during data collection subsequent to interview 14. After interview 18 , the remaining volunteers were thanked but not interviewed.

Table 1. Summary of characteristics of respondents based on year of study, gender and academic performance across all six years of study.

Respondents are identified using the following notation: 12(V)F61(1). The first figure indicates respondent number; the Roman numeral in parentheses their year of study; the letter their gender; the next figure their average mark across all six years of study (obtained some time after the interviews); and the last parentheses indicate the number of modules (if any) that the respondent failed across all years of study.

\begin{tabular}{|c|c|c|c|c|}
\hline \multirow[b]{2}{*}{ YEAR OF STUDY } & \multirow[b]{2}{*}{ GENDER } & \multicolumn{3}{|c|}{ AVERAGE MARK } \\
\hline & & $<70 \%$ & $70-79 \%$ & $\geq 80 \%$ \\
\hline \multirow{3}{*}{4} & $\mathrm{~F}$ & 13(IV)F69 & & \\
\hline & \multirow{2}{*}{$M$} & & 7(IV)M72 & \\
\hline & & & 16(IV)M79 & \\
\hline \multirow{6}{*}{5} & \multirow{4}{*}{$\mathrm{F}$} & $6(\mathrm{~V}) \mathrm{F} 65$ & $2(\mathrm{~V}) \mathrm{F} 77$ & $4(V) F 81$ \\
\hline & & 12(V)F61(1) & 11(V)F71(1) & $8(V) F 81$ \\
\hline & & 15(V)F63(3) & & $9(V) F 83$ \\
\hline & & 17(V)F65 & & $18(\mathrm{~V}) \mathrm{F} 86$ \\
\hline & \multirow{2}{*}{ M } & 3(V)M67 & 5(V)M73 & 1(V)M80 \\
\hline & & & 14(V)M78 & 10(V)M82 \\
\hline
\end{tabular}

All interviews were audio recorded and transcribed verbatim, generating close to 1000 pages of transcripts. Prior to undertaking coding, each interview was reviewed as a whole, along with field notes. In keeping with grounded theory, data analysis was inductive rather than being based on a predetermined e.g., literaturebased coding framework, and iterative. Emerging constructs and relationships were constantly compared within and across interviews and refined (Charmaz, 2006; Dey, 1993; Miles \& Huberman, 1994). Initial open coding was undertaken by one investigator, subsequent development, revision and refinement of categories and linkages through discussions between the team members. The vast majority of the consequences of assessment for learning were initially categorized as relating to the choice to learn, learning effort and persistence in the face of adversity or distraction. As regards effort, the quality, quantity and distribution of learning effort were 
all influenced by assessment. As data analysis progressed, it became evident that the consequences of impact related to well-described constructs in the domains of cognitive processing activities or to metacognitive regulation activities (Garcia, McCann, Turner, \& Roska, 1998; Pintrich, 1999; Vermunt, 1998; Vermunt \& Verloop, 1999). The codebook was revised and focused coding of the entire dataset undertaken. No new constructs emerged from the analysis of interviews 13-18.

\section{Results}

Analysis revealed three sources of impact and two learning effects of summative assessment in this setting. The three sources of impact were task demands, the imminence of assessment - i.e., temporal proximity to assessment - and system design. Task demands influencing learning included information about task type, cues from lecturers, past papers and the student grapevine - the informal communication networks between students - and the nature of the material to be learned for assessment. Aspects of the design of the assessment system that influenced learning included the prevailing workload and the pattern of scheduling of assessment.

Learning effects of assessment accrued to respondents' cognitive processing activities (CPA) and metacognitive regulation activities (MRA). In some instances, assessment resulted in respondents choosing to adopt only superficial CPA, limited to selection or rehearsal of content. In other instances, respondents chose to adopt deeper CPA like elaborating and organizational strategies involving outlining, relating and structuring activities. As regards MRA, assessment influenced respondents' choice to learn i.e., the allocation of effort to learning (rather than other aspects of their lives). It influenced the quantity of effort and the distribution of effort, both across time and between topics. It influenced the choice of resources to source and utilize and the choice of content to learn (and, equally importantly, not to learn). Assessment influenced monitoring and adjustment strategies and respondents' persistence with learning.

Two things were striking about the relationships between the sources of impact and learning effects of assessment. The first was that there was not a simple one-to-one relationship between factors, but rather an interwoven $\mathrm{N}$-to- $\mathrm{N}$ relationship (Table 2). Any given facet of assessment influenced various facets of learning. Any given facet of learning was influenced by various facets of assessment. 


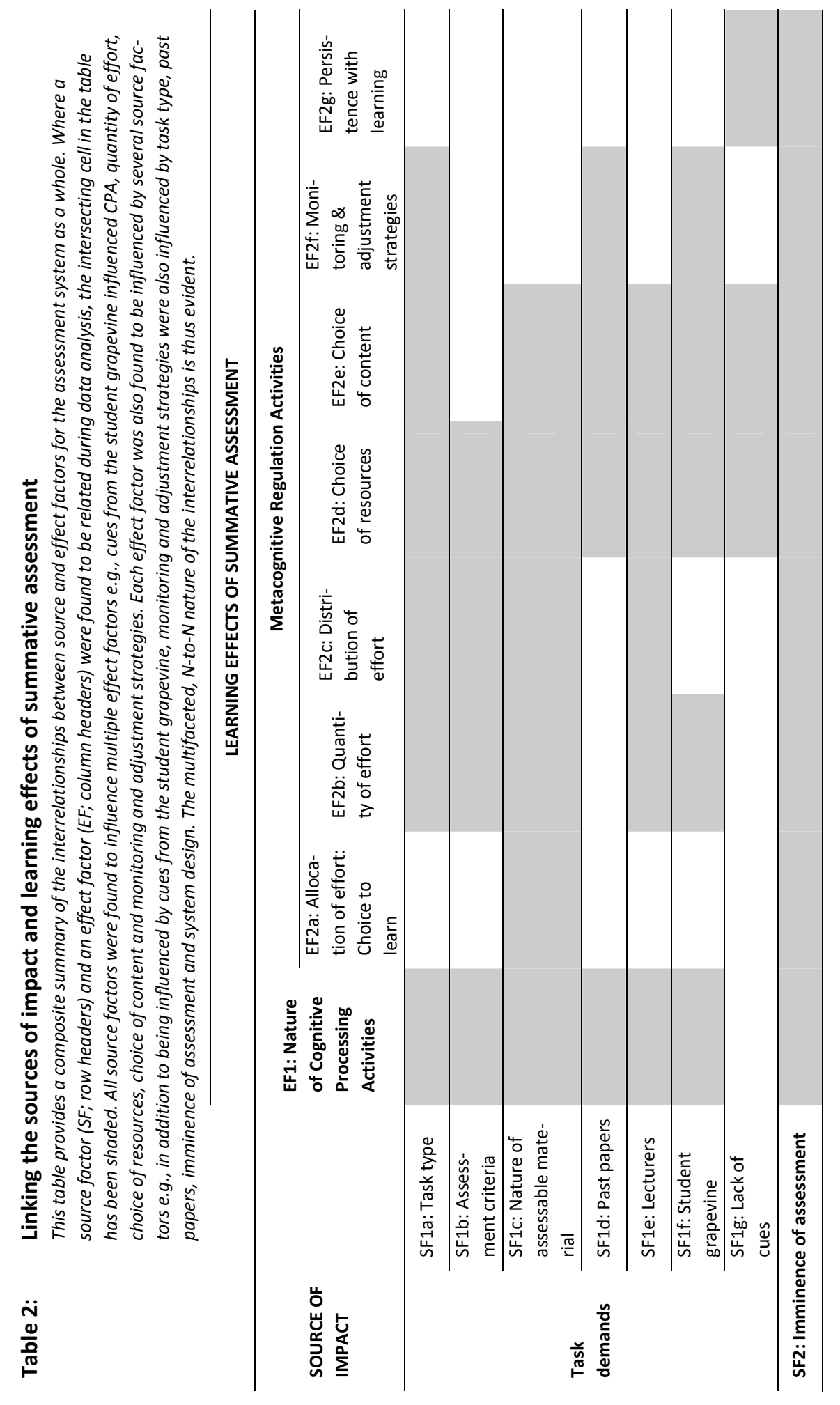




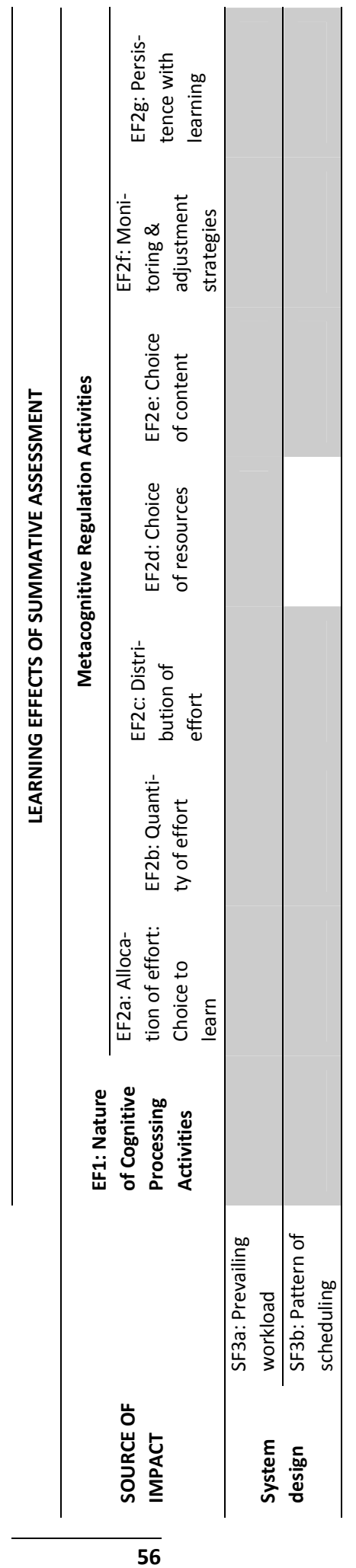


The second striking thing about the relationships was that they were variable. At the level of the individual respondent, different sets of interactions were found to be at play for different respondents in the same assessment context and for the same respondent in different assessment contexts. Responses were powerfully modulated by contextual variables like the imminence of assessment and the prevailing workload.

From Table 2, it is evident that six sets of relationships were most prominent: 1 ) the nature of CPA was influenced by most sources of impact; 2 ) the choice of what resources to source and utilize was influenced by most sources of impact; 3) the choice of what content to learn was influenced by most sources of impact; 4) the imminence of assessment influenced all the effects of assessment; 5) the prevailing workload influenced all the effects of assessment; and 6) the pattern of scheduling influenced most of the effects of assessment. These six sets of relationships will now be described. Given the multifaceted inter-relationships that exist, we will, for the sake of clarity, follow the order of the factors adopted in Table 2 within each section. Then, a model describing the pre-assessment learning effects of summative assessment will be proposed.

\section{Nature of CPA (column EF1, Table 2)}

\section{Task type}

Respondents matched the nature of their CPA to the perceived processing demands of the task-type to be used in an assessment event. They inferred processing demands directly based on the item type to be used (e.g., multiple choice questions or long answer questions) or indirectly based on the complexity of the cognitive challenge posed. They were, for example, uniform in their response to widely used short answer questions requiring the reproduction of lists e.g., "List three causes of..." or "List five symptoms of...", even thinly disguised questions of this type presented with a clinical vignette (cf. Quote 6). They merely memorized and rehearsed information (cf. also Quote 16).

[Quote 1] Look, medicine is such that there isn't actually much to understand, you just have to know. ... Sometimes there is an application question or so but in general I'd say it's just ... focused on your ability to remember, to recall what you do in the notes. ... there are a few little things that you must understand, like the Physiology ... but as you progress it's mostly just "name two causes". (9(V)F83)

Respondents varied in how they gauged the demands of some assessment tasks, however. Furthermore, their perceptions were not necessarily a true reflection of the characteristics of the assessment event. One example of this was the varied 
characterizations by respondents of true-false questions used widely in Phase 2 of the program. Some respondents dismissed these assessments as simply requiring recognition of previously encountered facts and responded with low-level cognitive processing. These respondents reported trying to superficially read as much of the work as possible, preferably more than once, to enhance the chances of recognizing any given fact or concept. They often did not even utilize rehearsal activities to ensure adequate recall of facts. In contrast, other respondents identified these same true-false questions (and multiple choice items used by another department in Phase 3 of the program) as assessing at a higher cognitive level than any other assessments in the program. They adapted their CPA to achieve understanding of the material so as to be able to reason through the questions and utilized analysing, relating and structuring activities.

Another example of varied perceptions of task demands relates to long answer questions. Some respondents perceived these to demand understanding rather than memorization. Learning was geared towards being able to understand and apply principles, rather than memorize information, so as to enable respondents to reason their way through a response to a question rather than merely reproduce a memorized response. Respondents reported generating summaries or schemes to understand the relationship between different ideas or the logic of the development of an argument. Other respondents' perceived these same questions to simply demand recall of larger chunks of work, resulting in a formulaic, low-level learning response i.e., memorization of longer tracts of work accompanied by rehearsal.

\section{Assessment criteria}

Task demands were also inferred from how respondents' perceived assessment criteria to be applied. Where they perceived marking to be inflexibly done according to a predetermined memorandum, they were more likely to respond with rote memorization in an attempt to ensure exact reproduction of responses. This had the further impact of suppressing the inclination and efforts to apply material learned in one module, in another.

\section{Nature of assessable material}

Where material was perceived to be understandable and logical, respondents adopted higher order cognitive approaches to learning. Where material was less understandable or where the level of detail required to understand the logic was too deep, respondents were more likely to adopt superficial processing activities.

[Quote 2] ... [names subject] is not very logical. You cannot reason it out for yourself ... unless you go and look in super-depth ... at almost ... micro pathological level and ... I have neither the time nor the interest to go and do that. ... I guess it's to a large 
extent about motivation to really understand that work ... [names subject again] is pretty much for me, you know, I must pass it. That's all I felt about it. It's not something I particularly wanted to do well or wanted to understand. (10(V)M82)

\section{Cues from lecturers}

Cues were inferred from the way that lecturers presented material in class. If presentations entailed reciting lists of facts using a PowerPoint presentation rather than helping students develop their understanding of a topic, this cued memorization as a learning response.

[Quote 3] obviously you have the past papers, but I mean we also have... I mean, the way that classes are presented. ... if the lecture goes on with a guy that puts up PowerPoint's that click, click, click, click, click and here comes a bunch of information, the next slide. You know, he's not really going to test your insights, because he didn't try and explain the concepts to you at all. He just simply gave you facts. So you can just expect that the paper will be factual. (10(V)M82)

\section{Cues from student grapevine}

Cues obtained from peers identified certain modules as making higher order cognitive demands, others as requiring only extensive memorization of material. Respondents geared their CPA accordingly.

The influence of imminence of assessment and system design on CPA will be detailed in later sections.

\section{Choice of resources (column EF2d, Table 2)}

Much planning effort was devoted to identifying and obtaining resources most likely to contain material relevant to assessment e.g., past papers and copies of PowerPoint slides used by, or hand-outs provided by, lecturers, rather than textbook, internet or journal based material.

\section{Task type}

Some modules included small projects as part of their assessment. These projects did not always engage respondents due to limitations in the number of marks involved, respondents' interest in the topic or the perceived relevance of the topic. However, where respondents did report engaging with these projects, this resulted in a meaningful impact on learning. On the one hand, this entailed spending greater 'time on task', engaging with the topic at hand. On the other, this included selecting and utilizing resources respondents would not otherwise have used e.g., text books in the library, the internet generally and literature databases more specifically. 
In contrast, the perceived demands of most other assessment tasks used resulted in the utilization of less, rather than more diverse, types of learning material. Constructed response assessment other than small projects resulted in respondents being less likely to read widely in preparation for assessment. When selected response items were used, respondents often acquired and reviewed past papers as a resource (cf. Quote 7). This was done both for the purposes of guiding what content they selected to learn and monitoring any learning already undertaken.

\section{Cues from lecturers}

In some instances, lecturers were perceived as being tied to a particular resource e.g., a prescribed textbook, which respondents then focused on. Equally, use was often not made of textbooks as other resources were perceived to be more appropriate for assessment purposes.

[Quote 4] ... with [names module] that we did last year. They kind of said to us we don't want you to study from the lecture notes we want you to study from [the] prescribed textbook. And that's all fine and well saying that, but if we had studied from [names textbook], we wouldn't have passed the test. So, you know, they've got their questions in their notes and that's basically what you have to study to get through. (1(V)M80)

\section{Cues from student grapevine}

Cues obtained ahead of or early in the course of a module about the likely content of assessment influenced the resources respondents opted to use in preparation for assessment (cf. Quote 9).

The influence of imminence of assessment and prevailing workload on choice of resources will be detailed in later sections.

\section{Choice of content (column EF2e, Table 2)}

Various cues influenced both respondents' choices regarding what to learn and, equally, what to omit. Cues from different sources could reinforce one another. $A$ lack of cues also influenced respondents' choice of what to learn.

\section{Task type}

Respondents matched the content they selected to learn to information about task type. They actively sought out material they perceived could be asked in the particular format and did not study information they perceived could not. For shortanswer questions requiring them to list facts, they sought out and memorized mate- 
rial they perceived could be asked as a list. They also actively omitted material they perceived could not be asked as a list e.g., pathophysiology (cf. Quote 5). Depending on their personal goals with their studies, respondents also adopted various refinements within this strategy e.g., memorizing $50 \%$ or $60 \%$ of the items in a list, with the goal of achieving a predetermined mark.

Information about the number of marks devoted to each section of the work and the magnitude of questions e.g., two or five or $\mathbf{2 0}$ marks also influenced choice of content. If respondents knew there would be no question longer than, say, 10 marks in an assessment, they omitted tracts of work they perceived could only be part of a longer question. Similar reasoning informed decisions based on information they were given about the overall extent of assessment in a module. Knowing that an end-of-module assessment would count, for example, 100 marks, respondents gambled that lecturers, wanting to cover content as widely as possible, would be unlikely to focus 20 marks of that on just one topic and so omitted work that could only be asked (in their perception) in a question of that length.

[Quote 5] then like in Patho[logy] or take now Physiology, it's a big part and you know they cannot ask it, because there's too few marks to ask such a big piece and it's difficult to ask it, so you leave it out. ... Yes, say a question paper can count 200 marks at the most. Then an 80 mark one is not even so much. It was a long time ago that we has such a big paper - you know they can't just ask 20 marks just about one disease's pathophysiology. They are actually going to try and cover stuff as widely as possible, from every small thing, it's... So, at the end of the day, you leave pretty important stuff out for now to learn ridiculous lists of thingeys. ... You know you must get these little lists in your head, but at the end of the day, your insight in... in the whole story is... left out. Now if you know the pathophysiology, you can figure out almost anything. So, you leave out pretty important things because you don't have time to swot* them. ... [I learn lists] because that's what they ask. It's pretty much what they ask. You know then they will say, name five causes of this for me. Or list 10 differential diagnoses of this. You have to give lists. (6(V)F65)

* swot: study, especially intensively in preparation for an examination

\section{Past papers}

Past papers were used to determine not only what topics but also what kind of material to study or omit (cf. also Quotes 3, 9).

[Quote 6] what I will do is I will see a question paper, I browse through the whole paper, the whole paper is just five to ten point "listing" questions. They're not paragraph or insight or case-studies... Or the case studies are actually just again just to get the little lists out of you in another way... And so I will concentrate on that. If I page through that work and here is some or other description of a thing, l'll maybe 
skip over it, but you'll stop at a five or ten point list. Yes, then one just swots like that, you know, that is what will get you through. (7(IV)M72)

The tendency of any given assessor to utilize a particular question type or to repeat questions from one assessment event to another influenced the degree to which respondents utilized past papers to plan their learning and select material to learn.

[Quote 7] I think all the tests and exams that we encounter, or the vast majority of them, are very predictable firstly because it's the same person setting up the test year after year and there's easy access to past papers so you know what sort of questions there are going to be. So that's one way you prepare for the exam. You kind of know what sort of questions are coming and then as I said you know this is going to be a multiple choice paper and then you go back to previous papers and you have a look. These are the multiple-choice questions that were asked in the past years. This is the bank of multiple choice questions that they have to draw from and so you start focusing in on those exact questions and preparing yourself for those questions. ... when we were doing a lot of our [names module] with [names professor], you know he only sets multiple choice questions. You know that if you've been through the previous ten years question papers that the questions will come out of those papers because he has a certain core from which he can actually draw questions (1(V)M80)

\section{Lecturers}

Direct and indirect cues from lecturers influenced what content respondents opted to study.

Direct cues. These included general comments in class like "this will (or won't) be in the exam" and specific "spots" provided to students. The powerful influence of these cues was such that respondents attended to them even if they perceived the content identified as important to be irrelevant to later clinical practice.

[Quote 8] the lecturers do rather have a tendency to give spots and then I always feel, okay, I now know that question is going to get asked. I think it is a stupid question to ask, but I suppose it is going to get asked. Then I just go and swot that list before the time $(10(\mathrm{~V}) \mathrm{M} 82)$

Indirect cues. Respondents read much into what lecturers opted to cover in a module generally and in any given lecture more specifically. Respondents reasoned that given the vast amount of material lecturers could cover on any topic and the limited time available, the material lecturers opted to include in a module and a lecture must necessarily be "important". Importance was variously judged by the yardstick of relevance to clinical care or to assessment. The amount of time devoted to a topic in a module was also taken as a cue as to how much time to devote to that topic while studying. 
Indirect cues were also taken from the resources lecturers provided or utilized. These were perceived to delineate what should be known about a topic and therefore what was more likely to feature in assessment. Where lecturers utilized PowerPoint slides in class, respondents typically ensured they obtained copies of these slides.

Respondents did not take lecturer cues at face value, though. They evaluated any cues for coherence with other information e.g., as defined by the content of past papers and if there was a disjuncture between sources, the guidance of past papers was accorded more gravity.

\section{Student grapevine}

Respondents sought guidance about assessment from students that had already successfully negotiated the year they were currently in and from their peers. Cues obtained ahead of or early in the course of a module about the likely content of assessment influenced the content they opted to learn and to omit. Cues obtained from peers late in the course of a module in the run-up to assessment, particularly during examinations, included "spots" about topics likely to feature in assessment. This influenced the material they opted to learn in the days and hours before assessment, even if they considered the material covered by the "spots" to be irrelevant to their higher level goal of becoming a good clinician (cf. also Quote 8).

[Quote 9] ... as far as assessment goes, I will easily go and look at an old question paper or two or so, tips that other students give and based on that, I will go... go learn, focus on certain things. And, to my own detriment for the day that clinical comes, skip some things ... I will talk to guys that are a year or two years ahead of me, especially guys that are a year ahead of me, because the course is still much the same as what they had ... I will talk to them about how they experienced it ... if someone says "listen here, for that little test, they took that book, but at the back of the book there's a bunch of questions and they really just concentrated on the questions"... Then I'll maybe read the book too, but I will concentrate on the questions. (7(IV)M72)

\section{Lack of cues}

Where respondents could not obtain specific cues about what to expect in assessment, they were more likely to try and learn their work more comprehensively. If an assessor was known to not repeat questions from one assessment event to the next or to not give "spots" or ask "spotted" material, this made respondents less likely to focus on or omit any part of the assessable material. This also influenced the quantity of effort expended and the CPA respondents adopted, but all at the cost of increased respondent anxiety. 
The influence of imminence of assessment and prevailing workload on choice of content will be detailed in the next sections.

\section{Imminence of assessment (row SF2, Table 2)}

\section{Nature of CPA}

Imminence influenced the CPA respondents adopted. When assessment was more distant, respondents reported adopted higher order processing activities, whilst they reported opting for lower order activities like memorization and rehearsing as assessment became more imminent (cf. Quote 16).

\section{Allocation, quantity and distribution of effort}

Imminence influenced respondents' choices about how to expend their time and effort and to do so on learning. As assessment loomed ever closer, it influenced the absolute quantity of effort expended and the distribution of that effort. Respondents reported a dramatic escalation in effort in the period leading up to assessment.

Assessment generated its influence as one element of the motivational mosaic that characterized each respondent's life. It was evident that there was an interaction between motivational constructs at play in different arenas of respondents' lives e.g., academic, personal and family relationships, recreation, spiritual etc. Although this was not formally determined, some respondents clearly demonstrated characteristics compatible with strong interest and intrinsic motivation and a mastery goal orientation, others a strong performance-approach or performance-avoid goal orientation (Pintrich, 2003). However, almost without exception, the value of learning as a worthwhile endeavour upon which to expend effort grew as assessment - and its consequences - became ever more imminent. Other interests and imperatives were typically relegated to a back seat as assessment loomed. This was a powerful and pervasive influence of assessment.

\section{Choice of resources and content}

Concurrently, though, as assessment became more imminent, so the range of resources respondents utilized shrank. Imminence also influenced what content respondents selected to learn and to omit from those resources. Respondents sought and attended to cues at various stages of the academic year. Some sought assessment-related cues before a module to proactively guide their choice of content and the cognitive approaches they would adopt. Some sought cues in the run-up to assessment to monitor their learning or help adjust their planned learning by focusing on content perceived to be more likely to feature in assessment when they per- 
ceived themselves to be in trouble. Although this was not formally determined, it was evident that various respondents displayed characteristics congruous with descriptions of students as cue seekers, cue conscious and cue deaf (Miller \& Parlett, 1974). Cue-seeking behaviour and responsiveness to cues were powerfully modulated by the context, however. Both typically intensified as assessment grew more imminent and when respondents perceived themselves to be in trouble insofar as the workload had been become unmanageable (cf. Quotes 10,13). Even respondents who evidenced seemingly robust intrinsic motivation and a mastery goal orientation sought out and acted on cues.

[Quote 10] especially with things that were said to be important in class ... you know, maybe 10 points and they say "This is important". ... I ask myself a question, cover up the answers and write it out, see how many I can get. If I only get like five or six then I look through the stuff again. And I close it again, try it again ... until I can say, okay I know that. And then I move on. ... Depending how much time I have, if there's time to do that thoroughly with most of the things in my summary, I do, but if I'm running all out of time, then I look at the things that were specifically indicated to me as important and I cram those. (4(V)F81)

\section{Persistence}

As assessment loomed ever closer, it coaxed respondents to focus on and persist with their learning in the face of distractions. As the academic year progressed, assessment coaxed respondents to persist with their learning even as they grew academically fatigued and their academic motivation flagged.

All in all, imminence was a powerful modulator of preferred ways of learning.

\section{Prevailing workload (row SF3a, Table 2)}

Respondents' perception of the prevailing workload in a module was the result of the interplay between the absolute volume of "assessable material" to which they were exposed, the imminence of assessment and their perceptions of their ability to deal with any given workload. This varied across time. Most respondents perceived the volume of work associated with any given module to be beyond their capacity to deal with. Some modules were worse than others in this regard.

In some instances, the workload generated by exposure to large volumes of work was compounded by poor planning on the part of respondents, resulting in them being confronted with more work to cover prior to an assessment than they had time available for. In other instances, the rate at which lecturers made lecturergenerated hand-outs available was unevenly distributed across the module. This resulted in a large volume of hand-outs being made available relatively late in the 
course of a module, with a resultant spike in the workload in the lead-up to assessment.

\section{Nature of CPA}

Where workload was perceived as being manageable, higher order CPA were adopted. Where workload was perceived as unmanageable, even respondents who reported preferring to adopt higher order processing activities would utilize only lower order processing activities like selecting and rehearsing.

[Quote 11] I don't have a problem with memorizing stuff. But for me, at the end of the day, it's... it misses the point, because if you are going to swot like that just to pass a test, what will that help? ... Because I know, if you are not going to know it now, then you must know it in your [student intern] year and then you... you know you've actually just wasted your time if all you wanted was to just pass the test. But I mean, sometimes your time is just too little and you must just go and swot the stuff parrot-fashion, but I don't like doing it like that at all. (10(V)M82)

\section{Allocation, quantity and distribution of effort}

Respondents' perceptions of the prevailing workload influenced how they planned the allocation of their learning effort. This included the quantity of effort (the total 'time on task'), the distribution of effort across time (when to start learning and how much to learn each day) and the allocation of effort between studies and other aspects of their lives like recreation and personal and family relationships.

\section{Choice of resources}

The workload in the program generally inhibited the sourcing or utilization of resources other than those provided by lecturers in the form of lectures and lecturerelated hand-outs. Only where resources provided by lecturers were perceived to be inadequate, did respondents report sourcing and utilizing other resources, workload notwithstanding. Where workload became overwhelming, respondents reported skipping classes, privileging existing material to be learned over whatever learning material and other benefits they may have obtained from attending a few last classes in the lead-up to assessment.

\section{Choice of content}

Perceptions of prevailing workload strongly influenced the selection of content. Where workload was perceived as being manageable, respondents reported focusing on material they perceived to be important to their longer-term goals of patient care. They did this by selecting topics considered to be relevant to good clinical care 
and selecting material that would promote understanding and clinical reasoning rather than, for example, memorizing lists of facts without understanding why those facts were grouped. Where workload was perceived as unmanageable, respondents reported focusing on material they perceived to be more likely to ensure success in assessment, even if this selection was at odds with what they would have learned to satisfy their longer-term goals (cf. Quote 5). Workload also influenced the order in which different material was learned.

[Quote 12] ... the whole approach of four weeks for one large subject like [names module], it's a massive chunk of work and then you must swot so selectively about what you are going to leave out and it's not as though you leave out less important things. You leave things out that you think they will not ask. So it's maybe big things or maybe important things that could save a patient's life one day, but you don't swot it because you have to pass the test now and that's a problem for me. ... if you know you are going to be tested, you will just do the stuff that you are going to be tested on. (6(V)F65)

[Quote 13] ... it maybe sounds very idealistic, but it is something I really strive for, to think what a good doctor would know of this work. And I just always try to do all the work, despite knowing this is maybe not going to be asked in the test. But I always just reason, if I'm not going to swot this now, I know I'm not just going to go and swot this up for the joy of it when I have some free time. ... while I'm busy now, I can just as well swot this work, too. So, I try not to concern myself with spots, but if I'm really in trouble, yes, then I'll just hope for the best and go for the spots. ... [In trouble] is if I have too little time to go through all the work. Yes, it was especially in the early years when I didn't really know what the speed of things was... it happened rather regularly. In time, you realize you must just start swotting two weeks before the test to get through the work. (10(V)M82)

\section{Monitoring and adjustment}

While it ensured that respondents spent appropriate amounts of 'time on task', a high perceived workload enhanced the likelihood that respondents would seek and attend to cues from various sources. This could be accompanied by a disorganized approach to MRA. Instead of a systematic approach to a body of work, respondents reported disorganized approaches to selecting work to learn and abandoning monitoring and adjusting activities.

Prevailing workload, like imminence, thus exerted a powerful modulating effect on respondents' preferred ways of learning. 


\section{Pattern of scheduling (row SF3b, Table 2)}

\section{Allocation, quantity and distribution of effort}

The pattern of scheduling of assessment influenced respondents' distribution of effort both across time and between topics. As they mastered the rhythm of the assessment system (Snyder, 1971), so respondents calibrated the distribution and quantity of their learning effort to the demands of the system. The pattern of scheduling of assessment thus had the beneficial effect of ensuring that respondents planned regular periods of study, and spent 'time on task'. On the downside, however, even though they learned regularly, respondents reported adopting a periodic, rather than a continuous, pattern of study due to the pattern of assessment. In an effort to devote attention to other aspects of their lives, respondents reported devoting little or no effort to learning at the start of each module, even knowing that the volume of work ideally demanded on-going attention. Effort typically built from this low base and escalated dramatically in the period leading up to assessment.

[Quote 14] I think that because we write tests periodically, I swot periodically. ... I think [the block method] has definitely caused me to change from a person who worked continuously to a person who does the minimum for the first three weeks of every month and the maximum in the last week. ......one sometimes loses sight of the long term goal, because you are continuously confronted with short term goals, namely to pass this module. So it focuses me tremendously on the short term and like I say, the long term might get a bit neglected. (2(V)F77)

Some modules also made use of smaller assessments within the module, which encouraged respondents to start studying earlier than they otherwise would have in a new module.

[Quote 15] sometimes the modules do that. So it's a four weeks module and you have two weeks into the modules and then a test at the end. ... you get to the stage of like, when you feel you've worked hard on your last clinical block and you feel like relaxing, socializing, then you see you've got a test. The first week of the module: not a good way to start. But I mean it definitely makes you start earlier.

(4(V)F81)

The fact that the assessment system was designed in such a way that students were assessed at the end of a module and again at the end of the year was seen by respondents as being beneficial. The examination forced them to again allocate time and effort to learning for a particular module. Having to learn the work again allowed them to both reinforce and extend their existing knowledge and was considered to have a beneficial impact on the outcomes of their learning efforts. Writing examinations also allowed respondents to plan to compensate for not being able to 
deal with the prevailing workload at the time of the test and so influenced how respondents planned the distribution of their effort between different assessment events.

Another type of influence on the distribution of effort resulted from the fact that the modular system was designed in such a way that students wrote several examinations over a relatively short period of time at the end of the year. This tight schedule influenced how they planned to allocate their learning time during the period leading up to the examinations. Instead of just focusing on learning the material for the module they were busy with, they also planned to allocate time to revising work from other modules. This typically meant allocating more effort to studies than to other aspects of their lives.

\section{Persistence}

Regular, periodic assessment took its toll by leading to exhaustion yet also helped motivate respondents to persist with their learning despite growing fatigue as the academic year progressed. In some instances, though, the demands made of respondents by assessment were perceived as being relentless. Respondents reported yearning for time to spend on interests other than their studies - on friends, on family, on sport, on "becoming a person" again - yet assessment motivated them to persist and allocate time and effort to learning (cf. Quote 15).

\section{Disconfirming evidence and negative cases}

Throughout the process of analysis, we remained alert to disconfirming evidence or negative cases. There were no cases where the described sources and effects were not a fundamental part of how respondents described their learning response to assessment. There were instances where respondents' learning was not influenced by task demands, even though they perceived different assessment tasks to pose different demands. This was the exception rather than the rule, however, and other dimensions of the responses described above were discernible for these respondents. Patient care goals (see below) vied strongly with assessment for prominence in respondents' academic goal structures, particularly for the more senior students. However, as will be evident below, assessment ultimately trumped patient care in influencing the learning response.

\section{A Model of the Pre-assessment Learning Effects of Summative Assessment}

Clearly, the interrelationships between these factors are complex. However, it is now possible to propose a model that goes some way to explaining the preassessment learning effects of summative assessment of theory in this setting. The 
mechanism by which assessment impacts on learning in this context has previously been described (Cilliers, Schuwirth, Adendorff, Herman, \& van der Vleuten, 2010) and helps explain the variability of the relationships between sources of impact and effects of assessment. Combining that data with the data reported here allows the construction of the model proposed in figure 1.

This model indicates how various facets of summative assessment acted via various factors of the mechanism to bring about various pre-assessment learning effects. The interplay between these various factors can be visualized as a threedimensional matrix. In different scenarios, different sources and mechanisms combined in varying intensities to yield different sets of effects. Not all factors were active in all students at all times or, indeed, the same student at different times. Furthermore, different factors were in play for different students in any given context and often for the same student in different contexts. The nature of the interaction was influenced by what factors in the given student's motivational mosaic were at play at any given moment.

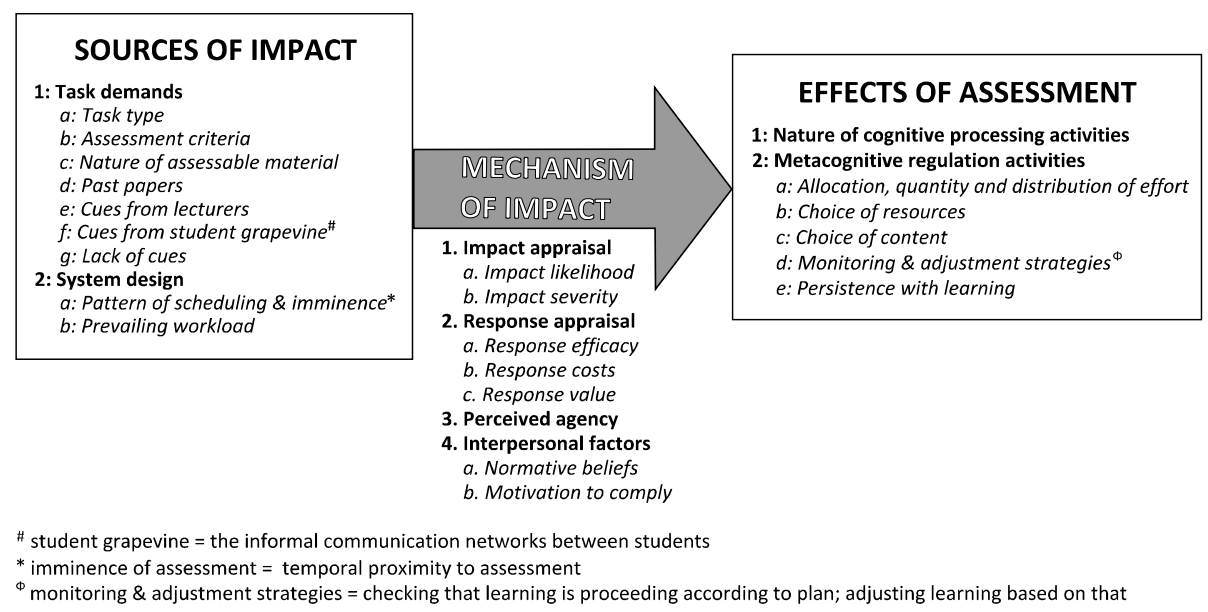

\section{Figure 1. A model of the pre-assessment learning effects of summative as- sessment}

The relationships in this model and the role that assessment plays against the backdrop of various other imperatives in respondents' lives are illustrated by the interplay between assessment and patient care goals as influences on respondents' learning. Throughout the interviews, it was striking how assessment vied with patient care for prominence in respondents' academic goal structures. As respondents progressed to their fifth year of study, patient care assumed increasing prominence, as the start of their student internship in semester 10 of the program loomed. The demands of these two tasks were often perceived to be in conflict, however (cf. also Quotes 5, 9, 11, 12). As described under the section on the imminence of assess- 
ment, patient care goals were typically overwhelmed by the demands of intercurrent and more imminent assessment. Respondents abandoned trying to understand principles both when under time pressure and when assessment was perceived to require memorization, even where the former approach was perceived as leading to more useful outcomes of learning for patient care in the longer-term than generating a short lived memory bank of facts:

[Quote 16] ... in the earlier years... say first, second and third year you were thinking more along the lines of... I must pass... I must get through this exam. ... But now, when I started hitting last year and this year you start thinking. I'm actually going to be a doctor. It's no good to me using a way to memorize these facts when I'm not going to be able to use it practically in my job one day. ... I've started trying to change the way I study...... the way I approach a module is trying to maybe within the first two or three weeks of a four week block, to understand... to understand the concepts more and to sit with the concepts and try to work the concepts out rather than just memorizing. And then it's unavoidable when it comes to the last week, last week and a half of a block ... You just try and cram - try and get as many of those facts into your head just that you can pass the exam and it involves... sadly it involves very little understanding because when they come to the test, when they come to the exam, they're not testing your understanding of the concept. They're testing "can you recall ten facts in this way?" ... And yes you know that I'm gonna be asked to recall five facts. So then you just learn five facts rather than trying to understand the core concepts. (1(V)M80)

Examining this quote through the lens of the model, it is evident that as assessment becomes more imminent ("when it comes to the last week, last week and a half of a block"), impact likelihood ("it's unavoidable") and impact severity ("just that you can pass the exam") are considered, along with response value (success in assessment increasing, patient care decreasing in value as assessment looms). These factors, together with task type ("they're not testing your understanding of the concept. They're testing 'can you recall ten facts in this way?") and response efficacy ("You just try and cram - try and get as many of those facts into your head just that you can pass the exam") considerations, generate an impact on the nature of CPA ("So then you just learn five facts rather than trying to understand the core concepts").

This quote illustrates the complexity of the interplay between source factors and effect factors to generate a learning effect. Other examples of the interplay between assessment and patient care goals further illustrate the model. Despite wanting to learn content that was relevant to patient care, respondents reported learning material for assessment purposes that they perceived to be of little value to them in the achievement of goals like providing quality patient care (cf. Quotes 8 \& 12 , which illustrate the interplay between cues about task demands from lecturers, 
prevailing workload, response efficacy and response value to influence choice of content). They memorized lists even if they believed that learning that material and in that fashion would not serve them well in a subsequent clinical rotation or in their future careers. Respondents also avoided learning pathophysiology despite believing that this was to the detriment of their longer-term goal of delivering quality patient care, in service of the shorter-term goal of passing the module (cf. Quote 5 , which illustrates the interplay between task demands and response efficacy to influence choice of content).

The impact of assessment on learning was such that respondents knowingly - if begrudgingly - sacrificed longer-term goals for short-term gain. The more immediate demands of assessment superseded the demands of longer-term goals, even in the face of an awareness of the potential importance of learning certain material to a "greater" goal i.e., the ultimate goal of patient care. This would presumably be true for all students except those with the very strongest of mastery goal orientations. Even respondents who seemed to have a mastery goal orientation were driven by the reward (Pintrich, 2003, p. 674) assessment offered to a selective goal pattern (Pintrich, 2003, p. 676). The utility value of learning lists and passing trumps interest or mastery goals. The imperative to pass seems to impose external regulation on the learning process and usurp a default tendency to internal regulation.

\section{Discussion}

The purpose of this study was to extend what is known about the pre-assessment learning effects of summative assessment in theoretical modules in a HSE setting by exploring the variables at play in an authentic, multifaceted assessment system and the relationships between them. The findings in this paper are derived from the assessment and learning experiences of respondents over a number of years, albeit collected at one time point. Not only have the influence of various individual assessment methods in a field setting been ascertained, this has been done in the context of other academic and non-academic influences in a "whole curriculum" setting. This is the first time this has been done for a health sciences education setting. Furthermore, being generated from the lived accounts of students, this work adds to a relatively limited body of literature on the learning effects of assessment emanating from authentic rather than controlled settings.

Our findings paint a nuanced picture of the range of factors at play. How various factors relate to one another and how the influence of those factors is modulated over time by factors in and outside of the assessment system and influenced by personal factors has been described. The influence on learning of the imminence of 
assessment, a newly described factor, is a case in point. Any work investigating the impact of assessment on learning needs to take cognizance of how near or far assessment looms for respondents in that study as responses are likely to vary based on this.

Together with other findings (Cilliers et al., 2010) it has been possible to propose for the first time a theoretical model not only describing what the pre-assessment learning effects of summative assessment are, but also explaining why students interact in the way that they do with assessment (Figure 1). It bears emphasizing that this model makes no claim for a solo role for summative assessment as a determinant of the outcomes of learning; instead, it emphasizes how summative assessment contributes to this prior to an assessment event and fleshes out the line linking assessment and learning in various other models (e.g., Biggs, 1978 fig. 1, p267; Ramsden, 2003 fig. 5.1, p82). However, given the profound consequences associated with summative assessment, there can be little doubt that these factors play a significant role in the overall picture.

Self-regulation theory has previously been invoked when discussing the link between assessment and learning (Ross et al., 2006; Ross et al., 2003; Sundre \& Kitsantas, 2004; van Etten et al., 1997). Our findings suggest that self-regulation does indeed play a role, but that it is part of a broader framework. Our findings also lend empirical support to some aspects of the model proposed by Broekkamp and van Hout-Wolters (2007) to explain students' adaptation of study strategies when preparing for classroom tests. Given that the model we propose is more comprehensive than others cited in this paper, we feel justified in our adoption of grounded theory as our research strategy. Had we used existing models as a point of departure, that may well have limited the scope of our findings and precluded the identification of the novel elements we report here. This highlights one of the strengths of exploratory qualitative research.

The model proposed here hopefully brings us one step closer to being able to utilize summative assessment more effectively to influence student learning in a positive way. These findings confirm that individual lecturers need to be cognizant of the powerful effect that summative assessment has on student learning when designing tests and exams. They also confirm that instructional designers need to be cognizant of this powerful influence when designing a curriculum and the perils of not incorporating summative assessment overtly as part of the instructional design. Individual assessment events need to be part of a coherent assessment program.

The complexity of the interrelationships between these various factors cannot be sufficiently emphasized. From the perspective of the student, it seems that each assessment event is an ill-structured problem (Frederiksen, 1984a) that students 
work to solve and that a common thread in their endeavours is the reduction of uncertainty. They try to characterize and make the most of the predictability of the system. Our findings that students' response to assessment is coloured by their perceptions (whether accurate or not) supports other findings regarding the role of student perceptions in their reaction to assessment (Segers \& Dochy, 2006; Segers et al., 2008).

This model provides a theoretical framework within which to contemplate the complex impact of assessment on student learning. The same student could react differently to different assessment tasks in different modules. Equally, different students could have different responses to the same assessment task. No single assessmentbased intervention is likely to affect all students' learning in the same way or to the same degree. Applying this model will not lead to simple interventions that dramatically enhance the power of the learning environment by enhancing the impact of assessment on student learning. However, what this model does offer is a means of understanding how and why assessment impacts on student learning. This should allow for the purposive and deliberate design and use of assessment as an integral part of the planning of the design of a learning environment to bring about the type of learning desired. This will allow curriculum designers to understand how to "rely on approaches and methods of assessment that fulfill their full potential to reinforce our educational goals" (Krupat \& Dienstag, 2009, p. 548). The model should also allow the systematic review of existing assessment tasks and systems for the purposes of "diagnosis" where problems arise or where assessment has undesirable impacts on student learning.

How, then, to utilize summative assessment to induce positive pre-assessment learning effects? While it is clear that every situation will need to be analysed on its own merits, these results do, perhaps, suggest some broad focus areas. It seems evident that if the intention is to influence students' cognitive processing activities, attention should be paid to the assessment methods used. Specifically, the level of cognitive challenge posed by those assessment methods rather than the assessment method as such is what is important. However, it is also important to manage students' perceptions of the demands of assessment, in addition to ensuring that assessment tasks pose appropriate demands. If the intention is to influence the content to which students attend, then the various cues in the system need to be managed and aligned. Attending to the prevailing workload and considering the influence of imminence can potentially influence a wide range of metacognitive regulation activities.

Along with other reports of disappointing results of attempts to influence learning using assessment (e.g., Gijbels et al., 2009; Heijne-Penninga et al., 2008), this report should serve as something of a cautionary tale to those who would wield assess- 
ment to influence learning. In the curriculum that preceded the one upon which this report is based, students studied multiple theoretical modules concurrently and wrote big summative tests on multiple modules at four pre-determined times during the year. This resulted in what was considered an undesirable pattern of learning i.e., little learning effort for two or three months, followed by binge-learning for a couple of weeks prior to the big tests. The modular design of the present curriculum had been introduced partly in the hope of inducing more continuous and effective (from the point of view of long term gain) learning. However, while students do allocate time to learning more frequently than in the past, the impact appears to have been simply the induction of shorter cycles of binge-learning than had characterized the previous curriculum.

Would the introduction of feedback into this system mitigate the profound impact that summative assessment has on learning in this system? One is tempted to speculate not, given the time lag for most modules between when feedback would be given (immediately after a module) and when it would be useful (for examinations in that module at the end of the year). For modules at the start of the academic year, this gap would be almost a year long. Furthermore, given the lack of relationship between assessment in one module and the next, feedback in one module would be of little benefit to students in a subsequent module. Furthermore, most theory modules are separated from the next by a clinical module of four weeks duration, which introduces an additional time lag between when feedback would be given and when it would be of benefit to students.

It could be argued that a severe limitation of this work is the fact that the findings are derived qualitatively and from only medical students in one South African setting. However, the findings of this work resonate with and indeed, further illuminate, findings reported elsewhere (Becker et al., 1968; Miller \& Parlett, 1974; Snyder, 1971; van Etten et al., 1997). This latter work derived from a range of types of university in the United States and Scotland and drew on students from a range of disciplinary backgrounds. This suggests the constructs and relationships described in this report exhibit a certain robustness across a variety of contexts.

Callahan, Hojat, and Gonnella (2007) caution about the potentially biasing influence of utilizing volunteers in research. Some of the characteristics of our respondents support these cautions. We had a higher proportion of more successful students than would be expected were the sample representative of the population from which they were drawn, and a higher proportion of women. However, given the exploratory nature of this work, this is not considered a drawback. Furthermore, the degree to which the findings in this report resonate with other reports, even those whose respondents were almost exclusively men, suggests some credibility to our findings. It should be emphasized, however, that we make no claims as to generali- 
zability. It will be crucial to explore various aspects of the proposed model in other settings.

Future directions for research include both validating the model and evaluating it in other educational contexts e.g., settings with assessment systems that make more use of formative assessment, settings concerned with the development and assessment of competence, with groups of students from other disciplines and with students from other institutions. There are also a multitude of individual relationships within this model that warrant more detailed scrutiny.

The focus when thinking about the impact of an assessment system of students' learning is often on formative assessment and/or the role of feedback on student learning. However, this study shows how overwhelming the impact of summative assessment on learning can be. However carefully the rest of the assessment system is designed, given the stakes of summative assessment, the latter will quite likely overwhelm other aspects of assessment if not designed in harmony with the overall system. 


\section{References}

Agarwal, P. K., Karpicke, J. D., Kang, S. H. K., Roediger, H. L., III, \& McDermott, K. B. (2008). Examining the testing effect with open- and closed-book tests. Applied Cognitive Psychology, 22(7), 861-876.

Alderson, J. C., \& Wall, D. (1993). Does washback exist? Applied Linguistics, 14(2), 115-129.

Bailey, K. M. (1996). Working for washback: A review of the washback concept in language testing. Language Testing, 13(3), 257-279.

Bangert-Drowns, R. L., Kulik, J. A., \& Kulik, C.-L. C. (1991). Effects of frequent classroom testing. Journal of Educational Research, 85(2), 89-99.

Becker, H. S., Geer, B., \& Hughes, E. C. (1968). Making the grade: The academic side of college life. New York: John Wiley \& Sons, Inc.

Biggs, J. B. (1978). Individual and group differences in study processes. British Journal of Educational Psychology, 48(3), 266-279.

Biggs, J. B. (1998). Assessment and classroom learning: A role for summative assessment? Assessment in Education: Principles, Policy \& Practice, 5(1), 103-110.

Black, P., \& Wiliam, D. (1998). Assessment and classroom learning. Assessment in Education: Principles, Policy \& Practice, 5(1), 7-74.

Bol, L., Warkentin, R. W., Nunnery, J. A., \& O'Connell, A. A. (1999). College students' study activities and their relationship to study context, reference course, and achievement. College Student Journal, 33(4), 608-622.

Boud, D. (1990). Assessment and the promotion of academic values. Studies in Higher Education, 15(1), 101-111.

Broekkamp, H., \& van Hout-Wolters, B. H. A. M. (2007). Students' adaptation of study strategies when preparing for classroom tests. Educational Psychology Review, 19(4), 401-428.

Callahan, C. A., Hojat, M., \& Gonnella, J. S. (2007). Volunteer bias in medical education research: An empirical study of over three decades of longitudinal data. Medical Education, 41(8), 746-753.

Carpenter, S. K., Pashler, H., Wixted, J. T., \& Vul, E. (2008). The effects of tests on learning and forgetting. Memory \& Cognition, 36(2), 438-448.

Case, J., \& Gunstone, R. (2003). Going deeper than deep and surface approaches: A study of students perceptions of time. Teaching in Higher Education, 8(1), 55-69.

Charmaz, K. (2006). Constructing grounded theory: A practical guide through qualitative analysis. London: Sage Publications Ltd.

Cilliers, F. J., Schuwirth, L. W. T., Adendorff, H. J., Herman, N., \& van der Vleuten, C. P. M. (2010). The mechanism of impact of summative assessment on medical students' learning. Advances in Health Sciences Education, 15(5), 695-715.

Crooks, T. J. (1988). The impact of classroom evaluation practices on students. Review of Educational Research, 58(4), 438-481.

d'Ydewalle, G., Swerts, A., \& De Corte, E. (1983). Study time and test performance as a function of test expectations. Contemporary Educational Psychology, 8(1), 55-67.

de Corte, E., Verschaffel, L., \& Masui, C. (2004). The clia-model: A framework for designing powerful learning environments for thinking and problem solving European Journal of Psychology of Education, $X I X(4), 365-384$.

Dey, I. (1993). What is qualitative analysis? Qualitative data analysis (pp. 31 - 54): Routledge, USA and Canada.

DiCicco-Bloom, B., \& Crabtree, B. F. (2006). The qualitative research interview. Medical Education, 40(4), 314-321.

Dochy, F., Segers, M., Gijbels, D., \& Struyven, K. (2007). Assessment engineering: Breaking down barriers between teaching and learning, and assessment. In D. Boud \& N. Falchikov (Eds.), Rethinking assessment in higher education: Learning for the longer term (pp. 87-100). Oxford: Routledge.

Entwistle, N. J., \& Entwistle, A. C. (1991). Contrasting forms of understanding for degree examinations: The student experience and its implications. Higher Education, 22(3), 205-227. 
Feldt, R. C. (1990). Test expectancy and performance on factual and higher-level questions. Contemporary Educational Psychology, 15(3), 212-223.

Feldt, R. C., \& Ray, M. (1989). Effect of test expectancy on preferred study strategy use and test performance. Perceptual and Motor Skills, 68(3 Pt 2), 1157-1158.

Frederiksen, N. (1984a). Implications of cognitive theory for instruction in problem solving. Review of Educational Research, 54(3), 363-407.

Frederiksen, N. (1984b). The real test bias: Influences of testing on teaching and learning. American Psychologist, 39(3), 193-202.

Garcia, T., McCann, E. J., Turner, J. E., \& Roska, L. (1998). Modeling the mediating role of volition in the learning process. Contemporary Educational Psychology, 23(4), 392-418.

Gibbs, G., \& Simpson, C. (2004). Conditions under which assessment supports students' learning. Learning and Teaching in Higher Education, 2004-05(1), 3-31.

Gijbels, D., Coertjens, L., Vanthournout, G., Struyf, E., \& Van Petegem, P. (2009). Changing students' approaches to learning: A two-year study within a university teacher training course. Educational Studies, 35(5), 503-513.

Hakstian, A. R. (1971). The effects of type of examination anticipated on test preparation and performance. Journal of Educational Research, 64(7), 319-324.

Heijne-Penninga, M., Kuks, J. B. M., Hofman, W. H. A., \& Cohen-Schotanus, J. (2008). Influence of openand closed-book tests on medical students' learning approaches. Medical Education, 42(10), $967-$ 974.

Krupat, E., \& Dienstag, J. L. (2009). Commentary: Assessment is an educational tool. Academic Medicine, 84(5), 548-550.

Kvale, S. (1996). Interviews: An introduction to qualitative research interviewing. Thousand Oaks, California: Sage Publications, Inc.

Laurillard, D. M. (1984). Learning from problem solving. In F. Marton, D. Hounsell \& N. J. Entwistle (Eds.), The experience of learning (pp. 124-143). Edinburgh: Scottish Academic Press.

Marton, F., \& Säljö, R. (1984). Approaches to learning. In F. Marton, D. Hounsell \& N. J. Entwistle (Eds.), The experience of learning (pp. 36-55). Edinburgh: Scottish Academic Press.

Maxwell, J. A. (2004). Causal explanation, qualitative research, and scientific inquiry in education. Educational Researcher, 33(2), 3-11.

McDaniel, M. A., Anderson, J. L., Derbish, M. H., \& Morrisette, N. (2007). Testing the testing effect in the classroom. European Journal of Cognitive Psychology, 19(4/5), 494-513.

Miles, M. B., \& Huberman, A. M. (1994). Making good sense - drawing and verifying conclusions Qualitative data analysis: An expanded sourcebook (2nd ed., pp. 245-287). Thousand Oaks: Sage Publications, Inc.

Miller, C. M. L., \& Parlett, M. (1974). Up to the mark: A study of the examination game. London: Society for Research into Higher Education.

Natriello, G. (1987). The impact of evaluation processes on students. Educational Psychologist, 22(2), 155-175.

Newble, D. I., \& Jaeger, K. (1983). The effect of assessment and examinations on the learning of medical students. Medical Education, 17(3), 165-171.

Nijhuis, J. F. H., Segers, M. S. R., \& Gijselaers, W. H. (2005). Influence of redesigning a learning environment on student perceptions and learning strategies. Learning Environments Research, 8(1), 67-93.

Pintrich, P. R. (1999). The role of motivation in promoting and sustaining self-regulated learning. International Journal of Educational Research, 31, 459-470.

Pintrich, P. R. (2003). A motivational science perspective on the role of student motivation in learning and teaching contexts. Journal of Educational Psychology, 95(4), 667-696.

Ramsden, P. (1979). Student learning and perceptions of the academic environment. Higher Education, 8(4), 411-427.

Ramsden, P. (1984). The context of learning. In F. Marton, D. Hounsell \& N. J. Entwistle (Eds.), The experience of learning (pp. 144-164). Edinburgh: Scottish Academic Press. 
Ramsden, P. (2003). Learning to teach in higher education (2 ed.). London: Routledge.

Roediger, H. L., III, \& Karpicke, J. D. (2006). The power of testing memory. Perspectives on Psychological Science, 1(3), 181-210.

Ross, M. E., Green, S., Salisbury-Glennon, J. D., \& Tollefson, N. (2006). College students' study strategies as a function of testing: An investigation into metacognitive self-regulation. Innovative Higher Education, 30(5), 361-375.

Ross, M. E., Salisbury-Glennon, J. D., Guarino, A., Reed, C. J., \& Marshall, M. (2003). Situated selfregulation: Modeling the interrelationships among instruction, assessment, learning strategies and academic performance. Educational Research and Evaluation, 9(2), 189-209.

Säljö, R. (1979). Learning about learning. Higher Education, 8(4), 443-451.

Sambell, K., \& McDowell, L. (1998). The construction of the hidden curriculum: Messages and meanings in the assessment of student learning. Assessment \& Evaluation in Higher Education, 23(4), 391-402.

Sambell, K., McDowell, L., \& Brown, S. (1997). 'But is it fair?': An exploratory study of student perceptions of the consequential validity of assessment. Studies in Educational Evaluation, 23(4), 349-371.

Scouller, K. M. (1998). The influence of assessment method on students' learning approaches: Multiple choice examinations versus assignment essay. Higher Education, 35, 453-472.

Scouller, K. M., \& Prosser, M. (1994). Students' experiences of studying for multiple choice question examinations. Studies in Higher Education, 19(3), 267-279.

Segers, M., \& Dochy, F. J. R. C. (2006). Introduction enhancing student learning through assessment: Alignment between levels of assessment and different effects on learning. Studies in Educational Evaluation, 32(3), 171-179.

Segers, M., Gijbels, D., \& Thurlings, M. (2008). The relationship between students' perceptions of portfolio assessment practice and their approaches to learning. Educational Studies, 34(1), 35-44.

Segers, M., Nijhuis, J., \& Gijselaers, W. (2006). Redesigning a learning and assessment environment: The influence on students' perceptions of assessment demands and their learning strategies. Studies In Educational Evaluation, 32(3), 223-242.

Snyder, B. R. (1971). The hidden curriculum. New York: Alfred A. Knopf.

Son, L. K., \& Kornell, N. (2009). Simultaneous decisions at study: Time allocation, ordering, and spacing. Metacognition and Learning, 4(3), 237-248.

Sundre, D. L., \& Kitsantas, A. (2004). An exploration of the psychology of the examinee: Can examinee self-regulation and test-taking motivation predict consequential and non-consequential test performance? Contemporary Educational Psychology, 29(1), 6-26.

Tang, K. C. C. (1991). Effects of different assessment procedures on tertiary students' approaches to studying. (PhD in Education PhD Dissertation), University of Hong Kong, Hong Kong.

Tang, K. C. C. (1994). Effects of modes of assessment on students' preparation strategies. In G. Gibbs (Ed.), Improving student learning - theory and practice (pp. 151-170). Oxford: Oxford Centre for Staff Development, Oxford Brookes University.

Thiede, K. W. (1996). The relative importance of anticipated test format and anticipated test difficulty on performance. Quarterly Journal of Experimental Psychology: Section A, 49(4), 901-918.

Thomas, P. R., \& Bain, J. D. (1984). Contextual dependence of learning approaches: The effects of assessments. Human Learning, 3, 227-240.

Tillema, H. H. (2001). Portfolios as developmental assessment tools. International Journal of Training and Development, 5(2), 126-135.

van Etten, S., Freebern, G., \& Pressley, M. (1997). College students' beliefs about exam preparation. Contemporary Educational Psychology, 22(2), 192-212.

Vermunt, J. D. (1998). The regulation of constructive learning processes. British Journal of Educational Psychology, 68, 149-171.

Vermunt, J. D., \& Verloop, N. (1999). Congruence and friction between learning and teaching. Learning and Instruction, 9, 257-280.

Watkins, D. (1982). Factors influencing the study methods of australian tertiary students. Higher Education, 11(4), 369-380. 
Williams, R. G., Pollack, M. J., \& Ferguson, N. A. (1975). Differential effects of two grading systems on student performance. Journal of Educational Psychology, 67(2), 253-258. 


\section{CHAPTER 4}

A Model of the Pre-assessment Learning Effects of Assessment is Operational in an Undergraduate Clinical Context 


\section{Abstract}

Background. No validated model exists to explain the learning effects of assessment, a problem when designing and researching assessment for learning. We recently developed a model explaining the pre-assessment learning effects of summative assessment in a theory teaching context. The challenge now is to validate this model. The purpose of this study was to explore whether the model was operational in a clinical context as a first step in this process.

Methods. Given the complexity of the model, we adopted a qualitative approach. Data from in-depth interviews with eighteen medical students were subject to content analysis. We utilised a code book developed previously using grounded theory. During analysis, we remained alert to data that might not conform to the coding framework and open to the possibility of deploying inductive coding. Ethical clearance and informed consent were obtained.

Results. The three components of the model i.e., assessment factors, mechanism factors and learning effects were all evident in the clinical context. Associations between these components could all be explained by the model. Interaction with preceptors was identified as a new subcomponent of assessment factors. The model could explain the interrelationships of the three facets of this subcomponent i.e., regular accountability, personal consequences and emotional valence of the learning environment, with previously described components of the model.

Conclusions. The model could be utilized to analyse and explain observations in an assessment context different to that from which it was derived. In the clinical setting, the (negative) influence of preceptors on student learning was particularly prominent. In this setting, learning effects resulted not only from the high-stakes nature of summative assessment but also from personal stakes, e.g. for esteem and agency. The results suggest that to influence student learning, consequences should accrue from assessment that are immediate, concrete and substantial. The model could have utility as a planning or diagnostic tool in practice and research settings.

Published as:

Cilliers, F. J., Schuwirth, L. W. T., \& van der Vleuten, C. P. M. (2012). A model of the pre-assessment learning effects of assessment is operational in an undergraduate clinical context. BMC Medical Education, 12: 9. 


\section{Background}

Even though the belief that assessment influences student learning is widely proclaimed, attempts in field settings to influence learning in desirable ways using assessment have not been very successful (e.g., Heijne-Penninga, Kuks, Hofman, \& Cohen-Schotanus, 2008). One reason may be that even thoughtfully conceived attempts are not informed by a sufficiently theoretically grounded understanding of how assessment influences learning.

While there is much literature relating assessment and learning, there is currently no satisfactory theory or model offering support to the "assessment for learning" endeavour. Calls have been made for a greater role for theory in researching assessment (Schuwirth et al., 2011) and in understanding what interventions work under which conditions (Gibbs, Durning, \& van der Vleuten, 2011). There has only recently been an attempt to formalize existing knowledge by classifying the learning effects of assessment (Dochy, Segers, Gijbels, \& Struyven, 2007). A distinction is drawn between pre-, pure and post-assessment learning effects that respectively impact learning before (e.g., study behaviour), during (e.g., portfolios, testing effect) and after (e.g., feedback) assessment.

A validated model explaining (rather than describing) how assessment influences learning could benefit the design of, and research into, assessment for learning. Self-regulation theory has been invoked to explain the effects of assessment (Ross, Green, Salisbury-Glennon, \& Tollefson, 2006; Ross, Salisbury-Glennon, Guarino, Reed, \& Marshall, 2003; Sundre \& Kitsantas, 2004; van Etten, Freebern, \& Pressley, 1997). Other empirical work resulted in the proposal of a "grade point average perspective" (Becker, Geer, \& Hughes, 1968), while a synthesis of literature resulted in a model explaining students' study strategies when preparing for classroom tests (Broekkamp \& van Hout-Wolters, 2007). None of these models or frameworks has been further validated, however.

Although not typically designed with learning aforethought, summative assessment strongly influences learning. We recently proposed a model explaining the preassessment learning effects of summative assessment (Cilliers, Schuwirth, Herman, Adendorff, \& van der Vleuten, 2012). According to the model (Figure 1), task demands and system design influence the quality and regulation of learning. These effects are mediated by a mechanism that involves impact appraisal, response appraisal, perceived agency and interpersonal factors. Thus, when contemplating an upcoming assessment event, students may consider the likelihood that assessment will impact them (positively or negatively) and what the magnitude of that impact is likely to be. They may consider the efficacy of any given learning response in bringing about a desired outcome, the costs of that learning response and how the desired or likely outcome relates to their values. Their perceptions of their ability to bring about a particular outcome may also influence their learning, as may their 
perceptions of the opinions of referents like lecturers and fellow students and their motivation to comply with those perceptions.

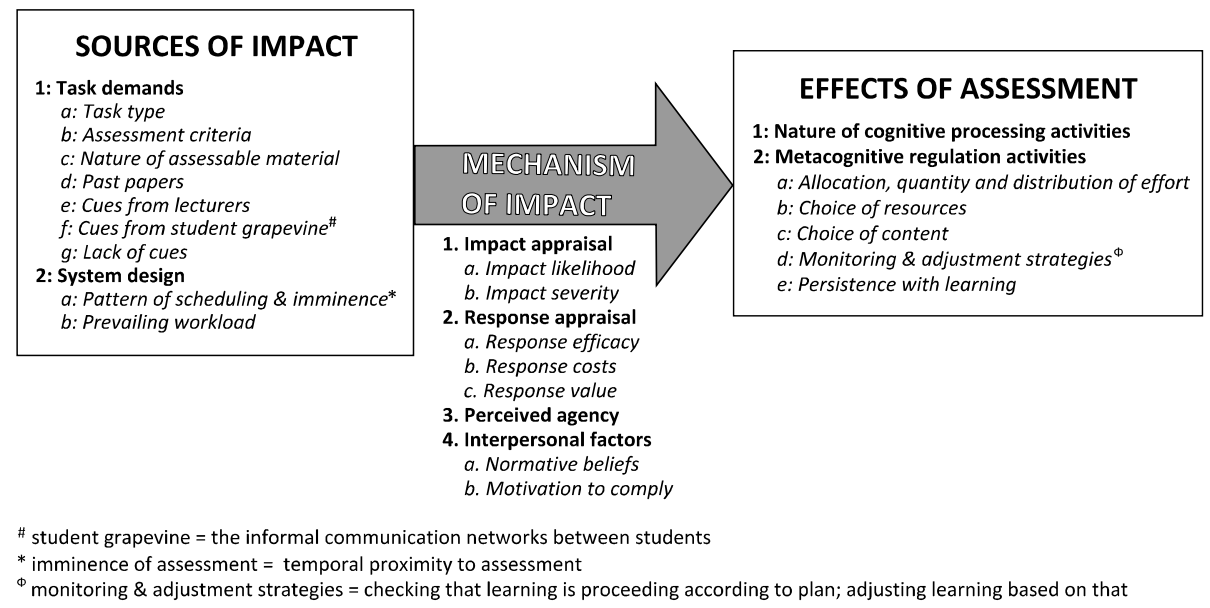

Figure 1 A model of the pre-assessment learning effects of summative assessment (Cilliers et al., 2012).

See Appendix: Additional Illustrative Quotes for more extensive information on the model. Descriptions of constructs are provided as are illustrative quotes for each.

The relationship between assessment factors, mechanism factors and learning effects is not a simple one-to-one-to-one relationship. In any given assessment context for any given student, one or more assessment factors will influence one or more aspects of learning, acting via one or more facets of the mechanism. Different students can react in different ways to any given assessment event, depending on what factors in their mosaic of academic and personal motivation enjoy prominence at that time. Equally, any one student can react in different ways to different assessment events, as factors enjoying prominence in their motivational mosaic wax and wane. See Additional File 1: Additional material_Illustrative quotes.pdf for more extensive information on the model.

Whilst this model is grounded in empirical data, it too has yet to be validated. Validation is necessary before any model can meaningfully inform the design of, or research into, the learning effects of assessment. The question now is whether the model can be shown to be valid outside of the immediate context in which it was derived and how to approach this.

To explore this, a clinical setting i.e., a different educational context to that in which the model was derived, held appeal. Furthermore, surprisingly little has been written about the impact of performance assessment in authentic field settings on student learning (Frederiksen, 1984; Newble \& Jaeger, 1983; Stillman, Haley, Regan, \& Philbin, 1991). When contemplating the use of assessment to influence learning in 
desirable ways, this lack is problematic for fields like the health sciences where performance assessment can comprise a substantial component of assessment.

A qualitative rather than a quantitative approach also seemed appropriate. There are too many variables and relationships to attempt validation using traditional quantitative means. Maxwell (Maxwell, 2004a, 2004b) argues that qualitative research is well suited to taking account of the integral role of context and mental processes in causal processes and understanding. He further argues that prerequisites for the use of experiments in service of understanding causality include welldeveloped theory that allows interpretation of the results and a manipulable, fairly simple process free from "temporal and contextual variability" (Maxwell, 2004a). Given the as yet tentative nature of the model, its complexity and the temporal and contextual variability of the relationships in the model, we opted for a qualitative approach at this stage in the development of the model.

Our research question was whether the model could be used to explain observations about the learning effects of assessment in a different context to that in which the model was derived. To do this, we undertook a qualitative study based on indepth interviews with senior medical students about the impact of assessment on their learning in a clinical setting.

\section{Methods}

\section{Context}

Respondents were South African medical students. Most students at this medical school enrolled directly after secondary school. From semesters four to nine of the six-year curriculum that they followed, students spent alternating four-week periods on clinical theory and clinical practice modules. Clinical theory modules entailed full-time classroom-based instruction on various aspects of clinical medicine. Most of these modules were system-based and multidisciplinary. Much of this instruction comprised lectures; project work and tutorials were less commonly used. Clinical practice modules entailed full-time instruction in clinical settings. Most of these modules were discipline-based. In most clinical practice modules, students worked from day-to-day with preceptors, often registrars. Interaction with consultants tended to be less frequent, sometimes once or twice a week during ward rounds and tutorials.

Students received study guides for each module that spelled out module outcomes and details of assessment. Each module was assessed summatively. Adequate performance in assessment in clinical theory modules gained students access to an end-of-year examination in that module. Students had to pass that examination to progress to the next year of study. Having negotiated assessment in a clinical theory module, typically on the last Friday of that module, students then started with their 
next clinical practice module on the following Monday. During semesters four to nine, there were no end-of-year examinations for clinical practice modules. Students had to pass assessment in clinical practice modules at the end of each module to progress to the next year of study. Assessment in the clinical practice setting usually comprised a continuous and an exit element. Continuous assessment varied. Students typically had to account for their learning on a daily basis by presenting to preceptors. On some modules, a "ward mark" was awarded based on criteria like punctuality, enthusiasm etc. This mark was usually awarded by the consultant, rather than the registrar, however. Some modules utilized case studies or project work for assessment. Exit assessment at the end of a module often entailed an OSCE, an oral or a clinical case. Having completed a clinical practice module, students would start the next clinical theory module on the following Monday.

\section{Data collection and analysis}

Data was collected by conducting in-depth, unstructured, face-to-face interviews with individual medical students. Respondents determined the venue for and language (Afrikaans or English) in which interviews were conducted. Each interview lasted about 90 minutes, was audio-recorded and transcribed in full. Each respondent was interviewed once. All interviews were conducted by the same author, an educational adviser fluent in English and Afrikaans, with medical and educational qualifications and training in qualitative interviewing. He worked in the faculty but had little day-to-day interaction with students.

Interviews first explored how respondents learned and how they had been assessed across the course of their studies and then how they adapted their learning in response to assessment. The influence of assessment on learning in a theory teaching context was explored first, then that in a clinical teaching context. Interviews were not structured beyond addressing these three issues in these two contexts. Furthermore, in keeping with the grounded theory design of the study, later interviews were informed and influenced by preliminary data analysis of earlier interviews.

Respondents were asked throughout to provide concrete examples to illustrate how assessment influenced their learning. The influence of assessment on learning was thus explored in various and different contexts and across time, although data was collected at one time point. The dataset comprised over 700 pages of transcriptions.

Previously, an inductive analysis of the dataset was undertaken, utilizing the principles of grounded theory (for details, see: Cilliers, Schuwirth, Adendorff, Herman, \& van der Vleuten, 2010; Cilliers et al., 2012). This initial analysis drew only on those portions of the interviews relating to assessment in theoretical modules and yielded the model described earlier (Figure 1). For the current study, the dataset was analysed utilizing the code book developed during the previous phase of analysis, but now focusing on only those portions of the interviews relating to assessment in 
clinical practice modules. This data had not been included in the initial analysis and was thus being analysed for the first time for this study.

Atlas.ti was used to facilitate this process. We remained alert throughout analysis to data that might not conform to the coding framework and open to deploying inductive coding as needed. Initial analysis was undertaken by one investigator. Results were subsequently refined and finalized during repeated discussions between all three team members.

Respondents had been recruited by addressing and then emailing the fourth $(n=141)$ and fifth ( $N=143)$ year classes, inviting volunteers to participate in the study. Thirty-two students volunteered for interviews. Interviews were conducted with the first 18 students who volunteered (Table 1). The remaining volunteers were thanked but not interviewed. This decision was taken when no new data emerged after interview 14, despite later interviews being individualized to explore constructs emerging from preliminary analysis, which analysis was initiated whilst interviews were still being undertaken. During initial analysis, no new constructs emerged after interview 12.

Table 1 Summary of respondent characteristics based on year of study, gender and academic performance across all 6 years of study

*: Respondent failed one/more modules during their studies

\begin{tabular}{|c|c|c|c|c|}
\hline \multirow[b]{2}{*}{$\begin{array}{l}\text { YEAR OF } \\
\text { STUDY }\end{array}$} & \multirow[b]{2}{*}{ GENDER } & \multicolumn{3}{|c|}{ AVERAGE MARK } \\
\hline & & $<70 \%$ & $70-79 \%$ & $\geq 80 \%$ \\
\hline \multirow{3}{*}{4} & $\mathrm{~F}$ & Resp13 & & \\
\hline & \multirow{2}{*}{ M } & & Resp7 & \\
\hline & & & Resp16 & \\
\hline \multirow{6}{*}{5} & \multirow{4}{*}{$\mathrm{F}$} & Resp6 & Resp2 & Resp4 \\
\hline & & Resp12* & Resp11* & Resp8 \\
\hline & & Resp15* & & Resp9 \\
\hline & & Resp17 & & Resp18 \\
\hline & \multirow{2}{*}{$M$} & Resp3 & Resp5 & Resp1 \\
\hline & & & Resp14 & Resp10 \\
\hline
\end{tabular}

An institutional research ethics board granted ethical approval for the study. Informed consent was obtained from respondents for participation in the study and later access to their study records.

\section{Results}

All major components of the model were evident in the clinical context. Relationships between components could all be related to the model. These findings will be summarized briefly below. 
One new source factor was found to be operating as a subcomponent of task demands i.e., interaction with preceptors. The model was utilized as a lens to scrutinize the interrelationships of this new subcomponent with previously described components. These results will be reported in greater detail to illustrate how the model operated in the clinical context.

\section{An overview of findings}

\section{Assessment factors and learning effects}

Task demands and system design were discernible as assessment factors, the nature of cognitive processing activities and metacognitive regulation activities, as learning effects of assessment. The relationships between assessment factors and learning effects are summarized in Table 2 and compared to findings emanating from theoretical modules.

There were a few notable differences between findings from the two settings. In keeping with the nature of clinical assessment, past papers did not feature as a subcomponent of task demands in the clinical context. Fewer sources of impact influenced monitoring and adjustment strategies or persistence with learning in the clinical context. One new assessment factor was found to be operating as a subcomponent of task demands i.e., interaction with preceptors.

\section{Mechanism}

All four components of the mechanism of impact were discernible in the clinical context. Examples will be given in the next section.

\section{A new subcomponent illustrates the operation of the model}

Three facets of respondents' interaction with preceptors influenced their learning via the components of the mechanism. These were regular accountability to preceptors, personal consequences that could accrue from these interactions and the emotional valence of the learning environment. Response appraisal was largely geared towards addressing these issues, rather than achieving an academic result. The operation of the model will be described for each of these facets rather than for the subcomponent "interaction with preceptors" as a whole. Model constructs will be highlighted in a bold font. The type of model component will be indicated as follows: $\mathrm{AF}=$ assessment factor; $\mathrm{MF}=$ mechanism factor; $\mathrm{LE}=$ learning effect. 


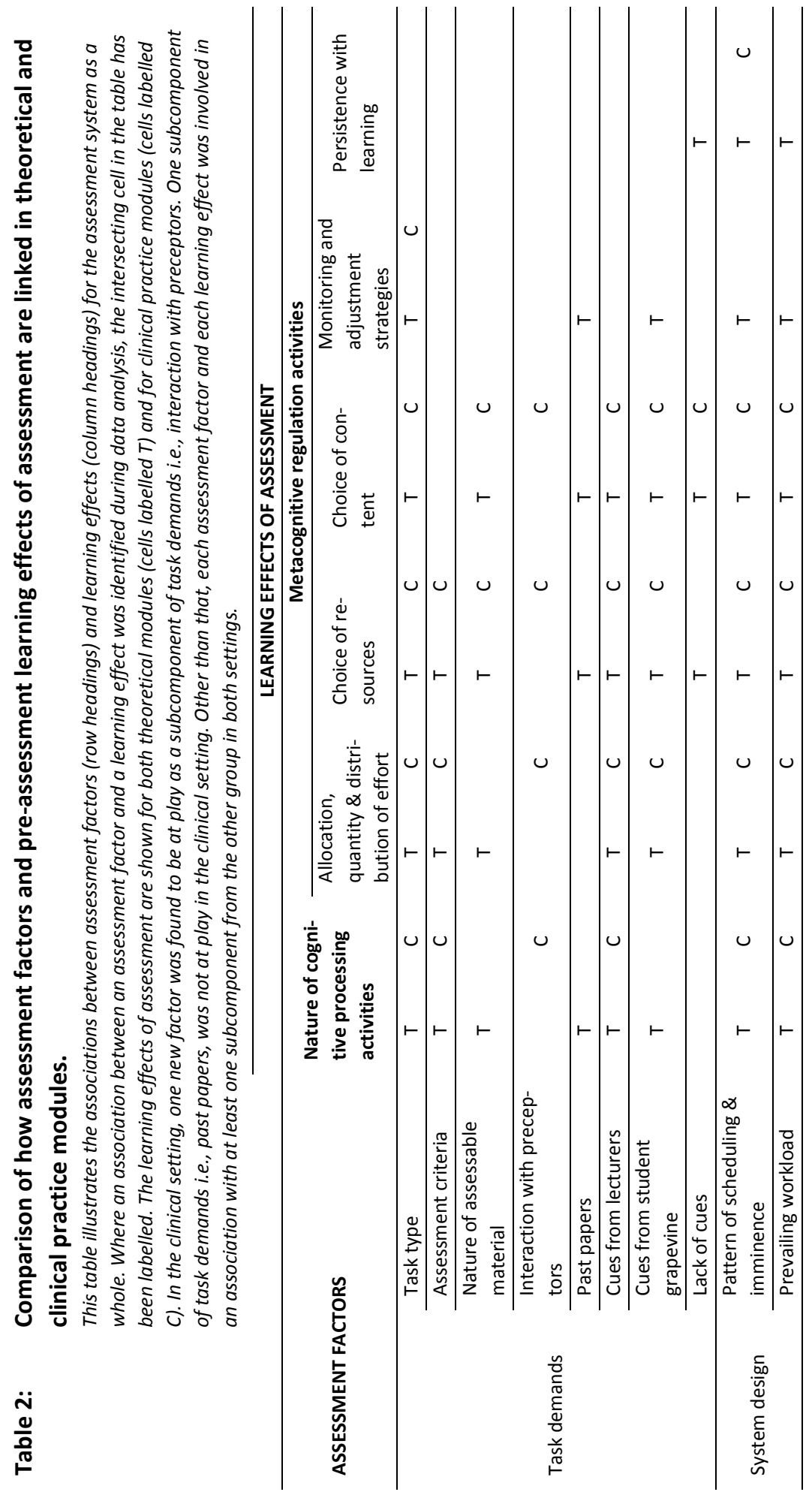




\section{Regular accountability}

Respondents allocated daily effort to learning (LE:allocation of effort) from the start (LE:distribution of effort) of a clinical practice module because consequences (MF:impact likelihood) were constantly imminent (AF:imminence), as they presented information on and had to answer questions about patients.

[Quote 1] a large class is where it's one doctor for 180 ... [the chances] that you will now be asked are very small... whereas in clinical, you cannot really hide ... you must say something (Resp14)

Respondents' learning was influenced more by the immediate and concrete consequences (AF:imminence; MF:impact likelihood) that accrued during regular exposure on ward rounds (AF:pattern of scheduling) than by more distant academic consequences e.g., impact on marks or progression, or ultimate ability to deliver good clinical care. This elicited more regular and evenly distributed "snack-learning" (LE:distribution of effort; LE:quantity of effort) by respondents than did the more periodic assessments on theoretical modules that induced periodic "bingelearning".

[Quote 2] "[a clinical rotation] is a bit different to [a theoretical module] because you basically have a round every day or an academic round with questions. So then you are tested every day, so you will learn a bit more, more regularly" (Resp13)

\section{Personal consequences}

Appraisal of impact magnitude (MF) also influenced respondents' learning, given that not being able to provide satisfactory inputs when asked on ward rounds could result in profoundly negative personal consequences (see also Quote 7).

[Quote 3] the students talk about how you "bleed" on a ward round if you get to a place where your knowledge runs out and you just get chewed out for that (Resp7)

Appraisal of response efficacy (MF) in the clinical context often related more to addressing self goals e.g., preserving esteem, through avoidance of negative intrapersonal consequences (i.e., avoidance goals) than to addressing assessmentrelated performance goals (i.e., approach goals). It was more a case of "If I do this, will it keep me 'safe' on the ward round tomorrow" than of "If I do this, will it help me pass (well)". The stakes are personal rather than assessment related, but nonetheless high.

[Quote 4] some consultants are more - how can I say, more pushy than others. ... you tend to prepare and prepare and prepare because you are preparing more out of fear of being humiliated there than out of the understanding as such. (Resp12) 
The prominence of personal consequences was not due to the lack of other sources of influence. Students had to achieve satisfactory marks for continuous and for exit assessment to pass the module and the year.

\section{Emotional valence}

The emotional valence of the learning environment was closely linked to, but distinct from, personal consequences and was generated by preceptors. Two extremes were discernible from characterizations by respondents of preceptors, called here "tyrants" and "teddy bears".

[Quote 5] You just get your two extremes, the one that will make you break out in fear and trembling, so you will... you will just learn because, yes, you don't want to continue to live in fear. And then you get those that... that are very nice and that explain everything nicely to you ... that doctor, you don't want to disappoint either. ... for that doctor, I will almost go even further... go out to learn, to bring back information and so on, to participate. (Resp14)

In the quote below, the respondent describes positive (bold) and negative (italics) learning environments created by different preceptors and her respective learning responses (underlined):

[Quote 6] [names consultant from one discipline] is a sweetie pie. ... you have to know your work ... you have to go and read up, but you can do it more calmly. You know, if you don't know something, you can tell him you don't know. You can remember it, but you can check in your notes and you can say "oh, this, you know, this is this". It's a much more relaxed atmosphere that you're going to read the stuff in. ... [names consultant from another discipline]... then you go and sit and you swot until you can remember that stuff. And every last thing ... you can't leave anything out. ... he asks the most impossible, weirdest stuff... so you try to read up everything that you can. [You do it] because he is very scary. He rebukes you such that you feel smaller than a snail. ... So you try as far as possible not to place yourself in that situation. ... [But] it's a crammed situation... one's anxiety levels are so high, you literally sit and force that stuff, that you can almost remember a page just so. But as soon as that presentation is finished, everything flies out of your mind, but if I've read for [names 1st consultant again], the stuff stays with me and l'll go and read about the stuff again in the evening, but with [names 2 nd consultant again] I'll never... I'll just make sure I know the next day's work. I won't still be interested in doing other stuff. (Resp6)

For preceptors characterized as tyrants, learning was a self-defence mechanism, driven by a performance avoid goal orientation. Appraisal of impact likelihood (MF) and impact magnitude (MF) resulted in effort being allocated (LE: allocation of effort) with a view to avoiding censure on ward rounds (see also Quote 4). Appraisal of response efficacy (MF) led respondents to conclude that they had to come to a ward round knowing "everything" (i.e., everything necessary to "stay safe" on that 
ward round), so they allocated extra effort (LE: quantity of effort) to learning. They selected content to learn (LE: choice of content) based on what the student grapevine (AF) indicated was what the preceptor wanted to hear. Avoiding the wrath of the consultant (MF: impact magnitude) gave short-term utility (MF: response value) to learning even material that was perceived as irrelevant to respondents' longerterm goals of becoming good generalist clinicians. Material was committed to shortterm memory, rather than being incorporated into mental models (LE: nature of cognitive processing activities), and then forgotten with alacrity once the ward round was over. Furthermore, once the ward round was over, the motivation to learn dissipated, and no further reinforcement (LE:distribution of effort; monitoring \& adjustment) took place. Respondents would not ask questions for fear of being ridiculed or attacked (MF:impact magnitude) for not knowing something they should already know.

[Quote 7] I feel more at liberty to ask [registrars], to ask easy questions, than I would asking a consultant. ... Because [consultants] maybe expect that I should know it. ... [I don't ask consultants] because I am scared they scold or get abusive ... and yes, I try and avoid that. While ... a [registrar] will explain to you quite nicely. [The consultant] will say to you "That class, did you not... do you not remember that class I gave, so and so much time ago", while the [registrars] will explain again nicely. (Resp13)

For preceptors characterized as teddy bears, appraisal of response value (MF) featured more prominently. Effort was allocated (LE) so as to be seen to be "doing your bit". Respondents were more likely to learn material of general relevance and of interest to themselves (LE:choice of content).

[Quote 8] then you get other... like I think of [names consultant]. I was with him for one week in third year, but I enjoyed that so much, because he... he made us think and he explains stuff and he just made us so interested. But you weren't... it wasn't like you really were reading up stuff out of fear, because you... if you didn't know something it wasn't like you were any less of a person. And that's much more pleasant. ... if you're relaxed, you feel free to ask questions and you actually enjoy the module then you... you know, you find the stuff interesting. (Resp4)

Learning was driven by a mastery approach goal orientation, with self-regulated reinforcement of learning taking place after the ward round (LE:distribution of effort; monitoring \& adjustment). Furthermore, respondents perceived teddy bears to be resources. They felt that if they did not know something, they could ask teddy bears on ward rounds (LE:choice of resources) and learn from them. This is not to say that teddy bears did not have high expectations. They did (see Quote 6). The learning environment they created was very different, however. 


\section{Discussion}

The purpose of this study was to explore whether the model describing the preassessment learning effects of assessment had explanatory potential in a clinical setting . In this study, the model could be utilized to analyse and explain observations generally in an assessment context different to that in which it was originally derived, albeit for the same group of respondents as were involved in the development of the model initially. One subcomponent of task demands, past papers, logically played no role in this context and one new context-specific subcomponent, interaction with preceptors, was identified. The model proved useful to explain the operation of this new subcomponent. To the best of our knowledge, no other model of the learning effects of assessment has been validated to any extent. Thus, while this study has various limitations (addressed below), we nonetheless believe it is an important - if modest - first step in what is typically a substantial and on-going process (Prochaska, Wright, \& Velicer, 2008) of model validation. We also believe that these results have ecological validity (Sadler, 1998), being derived from the lived experiences of respondents with no experimental manipulation.

Our results further demonstrate that the model is operational outside of a strictly summative assessment context. Summative assessment is not the key construct driving learning here, yet the model offers an explanation of what is happening. Conditions here were clearly "consequential" (Sundre \& Kitsantas, 2004) even though consequences for performance on assessment were not the primary consideration. This model is thus perhaps better conceptualized as one of the preassessment learning effects of consequential assessment.

The role of preceptors was an unexpected finding. Sadly, our respondents' characterization of "tyrant" preceptors supports other similar findings. Adverse interactions with preceptors have variously been characterized as an issue of style (Chitsabesan, Corbett, Walker, Spencer, \& Barton, 2006) or educator professionalism (Glicken \& Merenstein, 2007) and as involving disrespectful interactions, belittlement, humiliation, bullying, harassment and abuse (Coverdale, Balon, \& Roberts, 2009; Dyrbye, Thomas, \& Shanafelt, 2005; Elnicki, Ogden, \& Wu, 2007; Frank, Carrera, Stratton, Bickel, \& Nora, 2006; Lempp \& Seale, 2004; Wilkinson, Gill, Fitzjohn, Palmer, \& Mulder, 2006). Our findings add to a fairly limited literature describing the consequences of such adverse interactions (Dyrbye et al., 2005; Frank et al., 2006; Haglund et al., 2009; Wilkinson et al., 2006) and, further, provide an explanation of why students responded in the way that they did in our setting.

Our results yield some guidance for practitioners about the design of "assessment for learning". A supportive, low-risk learning environment characterized by high expectations and limited personal consequences resulted in deeper cognitive processing activities. In contrast, a negative, high-risk environment characterized by high expectations and negative personal consequences resulted in surface cognitive processing strategies and low engagement e.g., no question asking. To influence 
learning, assessment should be consequential and yield consequences that are concrete and substantial rather than abstract and trivial. Making assessment summative is one way of making assessment consequential. However, influencing personal stakes e.g., for esteem or agency and influencing emotion can also elicit (positive and negative) learning responses. Imminence of consequences is also important, with immediate consequences having a stronger influence than more deferred consequences.

One question this work raises is how to induce even distribution of learning effort with assessment without burning students out with unrelenting demands. Considered together with how respondents reacted to assessment in theoretical modules (Cilliers et al., 2012), it seems evident that regular accountability in clinical practice modules played a central role in determining students' overall learning pattern and had a negative knock-on effect on learning in subsequent theoretical modules. In theoretical modules, respondents described taking time off at the start of a module to "catch up" with the rest of their lives. In clinical practice modules, there was no indication that learning could be side-lined like that. Although not vocalized in interviews, it is tempting to speculate that the demands of the clinical setting were so pervasive and continuous that respondents had little opportunity to take time off to spend on non-academic aspects of their lives; that they were exhausted when they started the next theoretical module, and, being able to do so, took time off from their studies. The costs of doing so were less immediate in theoretical than in clinical practice modules, as was the likelihood of impact. Respondents did realize, though, that there was a deferred impact in the form of a higher workload in the run-up to assessment in theoretical modules. This "deferred" cost was deemed worthwhile, however, for the opportunity to devote time and attention to other aspects of their lives.

A potential limitation to this work is that it was undertaken with one group of undergraduate medical students in South Africa. Indeed, the data upon which this analysis is based were collected from the same group of respondents at the same time as was the data from which the model was derived originally. This analysis was conducted utilising a subset of data from that extensive dataset, though, data that had not previously been analysed. Ultimately, this is not considered a drawback as the purpose of the study was not to yield generalizable results but to explore the explanatory potential of the model. It could be argued that using a qualitative approach as a first step in the validation of the model is also a limitation. Again, given that explanation rather than prediction (Glanz \& Bishop, 2010; Prochaska et al., 2008) was a goal, this is not considered a drawback. In fact, this approach revealed a new construct at play i.e., interaction with preceptors, something that would not have been evident had a variance theory approach been adopted at this early stage of the validation of the model.

Future research should establish whether the model meets other criteria for validity such as have been proposed in the literature (Prochaska et al., 2008). Stronger evidence to support or falsify propositions needs be sought using quantitative meth- 
ods; so too stronger evidence for explanatory power. Future exploration of generalizability should include the determination of whether the model is operational in other settings e.g., other universities and other disciplines. It would also be interesting to explore whether this model is operational in low-stakes assessment settings and in postgraduate settings.

\section{Conclusion}

The model could have utility as a planning tool, to help prospectively plan an assessment system, or as a diagnostic tool, to help evaluate and enhance the learning effects of assessment in existing systems. However, it will be necessary to develop simplified instruments to utilize for this purpose. 


\section{References}

Becker, H. S., Geer, B., \& Hughes, E. C. (1968). Making the grade: The academic side of college life. New York: John Wiley \& Sons, Inc.

Broekkamp, H., \& van Hout-Wolters, B. H. A. M. (2007). Students' adaptation of study strategies when preparing for classroom tests. Educational Psychology Review, 19(4), 401-428.

Chitsabesan, P., Corbett, S., Walker, L., Spencer, J., \& Barton, J. R. (2006). Describing clinical teachers' characteristics and behaviours using critical incidents and repertory grids. Medical Education, 40(7), 645-653.

Cilliers, F. J., Schuwirth, L. W. T., Adendorff, H. J., Herman, N., \& van der Vleuten, C. P. M. (2010). The mechanism of impact of summative assessment on medical students' learning. Advances in Health Sciences Education, 15(5), 695-715.

Cilliers, F. J., Schuwirth, L. W. T., Herman, N., Adendorff, H., \& van der Vleuten, C. P. M. (2012). A model of the pre-assessment learning effects of summative assessment in medical education. Advances in Health Sciences Education, 17(1), 39-53.

Coverdale, J. H., Balon, R., \& Roberts, L. W. (2009). Mistreatment of trainees: Verbal abuse and other bullying behaviors. Academic Psychiatry, 33(4), 269-273.

Dochy, F., Segers, M., Gijbels, D., \& Struyven, K. (2007). Assessment engineering: Breaking down barriers between teaching and learning, and assessment. In D. Boud \& N. Falchikov (Eds.), Rethinking assessment in higher education: Learning for the longer term (pp. 87-100). Oxford: Routledge.

Dyrbye, L. N., Thomas, M. R., \& Shanafelt, T. D. (2005). Medical student distress: Causes, consequences, and proposed solutions. Mayo Clinic Proceedings, 80(12), 1613-1622.

Elnicki, D. M., Ogden, P., \& Wu, E., for the Pams Group. (2007). Medical student abuse from multiple perspectives. The Clinical Teacher, 4(3), 153-158.

Frank, E., Carrera, J. S., Stratton, T., Bickel, J., \& Nora, L. M. (2006). Experiences of belittlement and harassment and their correlates among medical students in the united states: Longitudinal survey. BMJ, 333(7570), 682.

Frederiksen, N. (1984). The real test bias: Influences of testing on teaching and learning. American Psychologist, 39(3), 193-202.

Gibbs, T., Durning, S., \& van der Vleuten, C. P. M. (2011). Theories in medical education: Towards creating a union between educational practice and research traditions. Medical Teacher, 33(3), 183-187.

Glanz, K., \& Bishop, D. B. (2010). The role of behavioral science theory in development and implementation of public health interventions. Annual Review of Public Health, 31(1), 399-418.

Glicken, A. D., \& Merenstein, G. B. (2007). Addressing the hidden curriculum: Understanding educator professionalism. Medical Teacher, 29(1), 54-57.

Haglund, M. E. M., aan het Rot, M., Cooper, N. S., Nestadt, P. S., Muller, D., Southwick, S. M., \& Charney, D. S. (2009). Resilience in the third year of medical school: A prospective study of the associations between stressful events occurring during clinical rotations and student well-being. Academic Medicine, 84(2), 258-268.

Heijne-Penninga, M., Kuks, J. B. M., Hofman, W. H. A., \& Cohen-Schotanus, J. (2008). Influence of openand closed-book tests on medical students' learning approaches. Medical Education, 42(10), $967-$ 974.

Lempp, H., \& Seale, C. (2004). The hidden curriculum in undergraduate medical education: Qualitative study of medical students' perceptions of teaching. BMJ, 329(7469), 770-773.

Maxwell, J. A. (2004a). Causal explanation, qualitative research, and scientific inquiry in education. Educational Researcher, 33(2), 3-11.

Maxwell, J. A. (2004b). Using qualitative methods for causal explanation. Field Methods, 16(3), 243-264.

Newble, D. I., \& Jaeger, K. (1983). The effect of assessment and examinations on the learning of medical students. Medical Education, 17(3), 165-171.

Prochaska, J. O., Wright, J. A., \& Velicer, W. F. (2008). Evaluating theories of health behavior change: A hierarchy of criteria applied to the transtheoretical model. Applied Psychology, 57(4), 561-588. 
Ross, M. E., Green, S., Salisbury-Glennon, J. D., \& Tollefson, N. (2006). College students' study strategies as a function of testing: An investigation into metacognitive self-regulation. Innovative Higher Education, 30(5), 361-375.

Ross, M. E., Salisbury-Glennon, J. D., Guarino, A., Reed, C. J., \& Marshall, M. (2003). Situated selfregulation: Modeling the interrelationships among instruction, assessment, learning strategies and academic performance. Educational Research and Evaluation, 9(2), 189-209.

Sadler, D. R. (1998). Formative assessment: Revisiting the territory. Assessment in Education: Principles, Policy \& Practice, 5(1), 77-85.

Schuwirth, L., Colliver, J., Gruppen, L., Kreiter, C., Mennin, S., Onishi, H., . . Wagner-Menghin, M. (2011). Research in assessment: Consensus statement and recommendations from the ottawa 2010 conference. Medical Teacher, 33(3), 224-233.

Stillman, P. L., Haley, H.-L., Regan, M. B., \& Philbin, M. M. (1991). Positive effects of a clinical performance assessment programme. Academic Medicine, 66(8), 481-483.

Sundre, D. L., \& Kitsantas, A. (2004). An exploration of the psychology of the examinee: Can examinee self-regulation and test-taking motivation predict consequential and non-consequential test performance? Contemporary Educational Psychology, 29(1), 6-26.

van Etten, S., Freebern, G., \& Pressley, M. (1997). College students' beliefs about exam preparation. Contemporary Educational Psychology, 22(2), 192-212.

Wilkinson, T. J., Gill, D. J., Fitzjohn, J., Palmer, C. L., \& Mulder, R. T. (2006). The impact on students of adverse experiences during medical school. Medical Teacher, 28(2), 129-135. 



\section{Appendix}

Additional Illustrative Quotes 
Published as:

An additional file available online at:

http://www.biomedcentral.com/imedia/7258051026868646/supp1.pdf

in support of

Cilliers, F. J., Schuwirth, L. W. T., \& van der Vleuten, C. P. M. (2012). A model of the pre-assessment learning effects of assessment is operational in an undergraduate clinical context. BMC Medical Education, 12: 9. 


\title{
Some Quotes to Illustrate a Model of the Pre-assessment Learning Effects of Consequential Assessment
}

\author{
SOURCES OF IMPACT \\ 1: Task demands \\ a: Task type \\ b: Assessment criteria \\ c: Nature of assessable material \\ d: Past papers \\ e: Cues from lecturers \\ $f$ : Cues from student grapevine \\ g: Lack of cues \\ 2: System design \\ a: Pattern of scheduling \& imminence* \\ $b$ : Prevailing workload

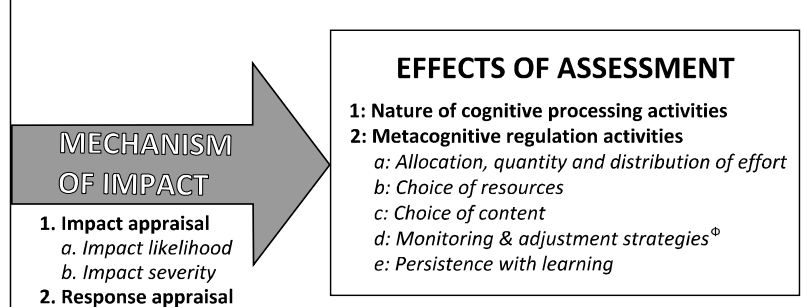 \\ 2. Response appraisal \\ a. Response efficacy \\ b. Response costs \\ c. Response value \\ 3. Perceived agency \\ 4. Interpersonal factors \\ a. Normative beliefs \\ b. Motivation to comply \\ \# student grapevine $=$ the informal communication networks between students \\ * imminence of assessment $=$ temporal proximity to assessment \\ ${ }^{\Phi}$ monitoring \& adjustment strategies = checking that learning is proceeding according to plan; adjusting learning based on that
}

The derivation of this model has been described elsewhere (Cilliers, Schuwirth, Adendorff, Herman, \& van der Vleuten, 2010; Cilliers, Schuwirth, Herman, Adendorff, \& van der Vleuten, 2012). This document is intended to equip a reader encountering the model for the first time with sufficient background to understand the model's constructs and their interrelationships. The model comprises three major components i.e., assessment factors, mechanism factors and learning effects.

The interplay between these can be visualized as a three-dimensional matrix. In different scenarios, different assessment factors and mechanism factors combine in varying intensities to yield different sets of learning effects. Not all factors are active in all students at any given time or, indeed, the same student at different times. Furthermore, different sets of interactions could be at play for different students in the same assessment context and for the same student in different assessment contexts.

The relationship between assessment factors and learning effects was mutually multiplex i.e., any given assessment factor influenced various learning effects and any given learning effect was influenced by various assessment factors. The following quote illustrates the interplay of factors.

[Resp1] ... in the earlier years... say first, second and third year you were thinking more along the lines of... I must pass... I must get through this exam. ... But now, when I started hitting last year and this year you start thinking. I'm actually going to be a doctor. It's no good to me using a way to memorize these facts when I'm not going to be able to use it practically in my job one day. ... I've started trying to change the way I study...... the way I approach a module is trying to maybe within the first two or three weeks of a four week block, to understand... to understand 
the concepts more and to sit with the concepts and try to work the concepts out rather than just memorizing. And then it's unavoidable when it comes to the last week, last week and a half of a block ... You just try and cram - try and get as many of those facts into your head just that you can pass the exam and it involves... sadly it involves very little understanding because when they come to the test, when they come to the exam, they're not testing your understanding of the concept. They're testing "can you recall ten facts in this way?" ... And yes you know that I'm gonna be asked to recall five facts. So then you just learn five facts rather than trying to understand the core concepts.

As assessment becomes more imminent ("when it comes to the last week, last week and a half of a block"), impact likelihood ("it's unavoidable") and impact magnitude ("just that you can pass the exam") are considered, along with response value (success in assessment increasing, patient care decreasing in value as assessment looms). These factors, together with task type ("they're not testing your understanding of the concept. They're testing 'can you recall ten facts in this way?'”) and response efficacy ("You just try and cram - try and get as many of those facts into your head just that you can pass the exam") considerations, generate an impact on the nature of cognitive processing activities (CPA) ("So then you just learn five facts rather than trying to understand the core concepts").

Adapted from (Cilliers et al., 2012)

What follows is a description of each construct and a quote or two, some of which have been used in previous descriptions of the model. These quotes are not meant to be exhaustive but rather illustrative. Please refer to the papers originally describing the model (Cilliers et al., 2010; Cilliers et al., 2012) for more complete descriptions. Any given quote may illustrate more than one construct and may thus be repeated. As you read these quotes, bear in mind who the respondents are that said these things, especially noting their average score over six years of medical school:

\begin{tabular}{|c|c|c|c|c|}
\hline \multirow[b]{2}{*}{$\begin{array}{l}\text { YEAR OF } \\
\text { STUDY }\end{array}$} & \multirow[b]{2}{*}{ GENDER } & \multicolumn{3}{|c|}{$\begin{array}{l}\text { AVERAGE SCORE OVER SIX YEARS } \\
\text { OF MEDICAL SCHOOL }\end{array}$} \\
\hline & & $<70 \%$ & $70-79 \%$ & $\geq 80 \%$ \\
\hline \multirow{3}{*}{4} & $\mathrm{~F}$ & Resp13 & & \\
\hline & M & \multicolumn{3}{|c|}{ Resp7 } \\
\hline & \multirow{4}{*}{$\mathrm{F}$} & Resp6 & $\begin{array}{c}\text { Resp16 } \\
\text { Resp2 }\end{array}$ & Resp4 \\
\hline \multirow{5}{*}{5} & & Resp12* & Resp11* & Resp8 \\
\hline & & Resp15* & & Resp9 \\
\hline & & Resp17 & & Resp18 \\
\hline & \multirow{2}{*}{$M$} & Resp3 & Resp5 & Resp1 \\
\hline & & & Resp14 & Resp10 \\
\hline
\end{tabular}

*: Respondent failed one/more modules during their studies 


\section{A. Assessment factors}

\section{A1 TASK DEMANDS}

A1a. Task type:

Students infer task demands directly from the type of assessment task to be used during an assessment event or indirectly based on their perceptions of the complexity of the cognitive challenge posed

(Resp4) If I go back to to second year [names module]. There was those true false questions ... You didn't study like in facts in the way that you would if you had to give a paragraph. You'd study it to understand it, because that's basically the true false questions were testing your understanding. ... if it's going to be multiple choice questions ... this and this is a complication of that, you only need to recognize it. You don't have to think it out yourself. ... if you've seen it before and you understand how it makes sense as a complication, you're not going to study it

(Resp6) at the end of the day, you leave pretty important stuff [referring to pathophysiology] out for now to learn ridiculous lists of thingeys. ... You know you must get these little lists in your head, but at the end of the day, your insight in... in the whole story is... left out. Now if you know the pathophysiology, you can figure out almost anything. So, you leave out pretty important things because you don't have time to swot them. ... [I learn lists] because that's what they ask. It's pretty much what they ask. You know then they will say, name five causes of this for me. Or list 10 differential diagnoses of this. You have to give lists.

\section{A1b. Assessment criteria:}

The criteria students perceive to be used to grade assessment products and how they perceive those criteria to be applied e.g. strictly or loosely

(Resp1) in the theory modules, you know that they are marking according to a memo ... very often even if you are correct, because it's not on the memo, they do not mark it correct. I've had that experience a number of times. So if I now write in my test paper ... you're very worried that you're going to be marked incorrectly for [the] thinking that you are thinking. You'd rather... give it to them in the exact form that they gave it to you. ... if you had to be examined by, say for example, [names professor from another module to that referred to above], he is very for lateral thinking and open minds, so you wouldn't study in the sense of trying to just recall those ten facts. You would more have an opinion on certain topics.

\section{A1c. Nature of assessable material:}

How easily material being studied for assessment can be grasped

(Resp10) ... [names subject] is not very logical. You cannot reason it out for yourself ... unless you go and look in super-depth ... at almost ... micro pathological level and 
... I have neither the time nor the interest to go and do that. ... I guess it's to a large extent about motivation to really understand that work ... [names subject again] is pretty much for me, you know, I must pass it. That's all I felt about it. It's not something I particularly wanted to do well or wanted to understand.

(Resp11) it also depends a lot on... on the type of work you are swotting*; because one thing is such that you can sort of explain it to yourself and another thing is, like, a little list. So then you must rather think of a way to remember that little list most easily.

* swot: study, especially intensively in preparation for an examination

\section{A1d. Past papers:}

\section{Cues inferred from previous assessment tasks}

(Resp7) what I will do is I will see a question paper, I browse through the whole paper, the whole paper is just five to ten point "listing" questions. They're not paragraph or insight or case-studies... Or the case studies are actually just again just to get the little lists out of you in another way... And so I will concentrate on that. If I page through that work and here is some or other description of a thing, l'll maybe skip over it, but you'll stop at a five or ten point list. Yes, then one just swots like that, you know, that is what will get you through.

(Resp12) ... closer to the time I would sort of have glimpse of a question paper if there's any. Yes, I think I usually use a question paper more than the actual outcomes. ... sometimes the outcomes are a pain to try and understand what exactly they are. And then so I use the question paper exactly as I should have been using the outcome, to try and understand what is more important.

\section{A1e. Cues from lecturers:}

\section{Cues inferred directly or indirectly from lecturers}

(Resp10) the lecturers do rather tend to give spots and then I always feel, okay, now I know that question will be asked. I think that it is a stupid question to ask, but I reckon it will be asked. Then I just go and swot that list ... sometimes they are very direct, the spots. You know, what lecturers say to you this is a type of thing that he will ask in the exam and so on. Other times, you know, it sort of comes via the grapevine, you just hear that this is important. ... It's also not necessarily always spots. They will say, I almost want to say negative spots too. This is not important for the test, but it is for the exam. ... obviously you have the past papers, but I mean we also have... I mean, the way that classes are presented. ... if the lecture goes on with a guy that puts up PowerPoint's that click, click, click, click, click and here comes a bunch of information, the next slide. You know, he's not really going to test your insights, because he didn't try and explain the concepts to you at all. He just simply gave you facts. So you can just expect that the paper will be factual. 


\section{A1f. Cues from student grapevine:}

Cues obtained from the informal communication networks between students

(Resp6) you talk to your friends a lot. You know, you listen and you talk in a group and you say 'what are you going to swot, what are you going to leave?'. Then someone says to you 'but they heard don't swot that'.

(Resp7) As far as assessment goes, I'll easily go and look at an old question paper or two or so, tips that other students say, and based on that, l'll go... go learn, focus on certain things

A1g. Lack of cues:

Where students could not discern cues about what to expect in assessment

(Resp3) in [names a module] ... they asked almost no GP stuff. They asked us very rare stuff. What I mean, it's superspecialist stuff that I don't think is relevant to the general GP. ... it almost forces you to learn everything and then one cannot say there's a safety... thingey... and say "That is a spot". Then one just tries to focus on everything. ... Then one already knows psychologically, before a module starts: but now I must pay more attention in class... make more good notes and work harder.

\section{A2. SYSTEM DESIGN}

\section{A2a. Pattern of scheduling and imminence}

\section{A2a(i). Pattern of scheduling:}

How assessment tasks are distributed in time

(Resp2) I think that because we write tests periodically, I swot periodically. ... I think [the block method] has definitely caused me to change from a person who worked continuously to a person who does the minimum for the first three weeks of every month and the maximum in the last week.

(Resp9) sometime you misjudge yourself with the amount of work ... Then as you get closer to the end, then you see 'oo, crumbs, I'm not going to get finished'. Then either you work harder, which you just do, or you decide ... this pack and this pack I'm going to leave out. ... then I know for the exam, okay, I didn't learn that pack ... and that pack and that pack very well and then I will plan my exam in such a way that there is still enough time for me to go through my old work and... to summarise the work I didn't learn well for the test well and go through it well 
A2a(ii). Imminence:

The temporal proximity of assessment at any given moment in time

(Resp1) depending where you are in the module depends on how many sorts of extra mural activities you get yourself involved with. ... at the moment I'm like "you know, I really don't feel like studying". So you find all these excuses in the book. Like "it's soccer tonight. I'll just watch the soccer game". Then after the soccer "I'm tired, I'm gonna go to bed". In bed by half past ten, eleven. But then when the test approaches, it's like you go into a different mode completely. You just almost become a different person. You know exactly what's expected of you. You know that you have to put in these hours otherwise you are going to come short and you just adapt yourself... you modify yourself.

(Resp13) [When I sit with a pack of notes] I at least have the textbook next to me too, so if I, say now with one or other disease... I'll just scan quickly, quickly, quickly in the book if there is something more than is in the notes. ... the PowerPoint is often just the points, the book is at least a little more a story to really gain some insight as to what it all is... so I will quickly read through that before I read just the PowerPoint just like that. But that is at the beginning then there is still lots of time, and if there is less time, then I just go through the PowerPoint. ... Yes, here around the second week... about four days before the test, I won't do that any more.

\section{A2b. Prevailing workload:}

The workload at any given moment in time

(Resp6) four weeks for such a bunch of work is very little. Is too little. You don't do it in a long term... it doesn't go in your long term memory. ... if you have more work, you are going to have to swot more superficially and swot more selectively too

(Resp10) If there is really a bad lectures or study material that one had, before I [will use journals, the internet or PubMed] ... it would have been very nice, but I mean there is plain and simply not enough time. I know [names module] last year... I mean our notes were unbelievably poor and out textbook was even worse. And I was forced... I looked at what they put up as other resources and then at the end of it all, I pulled a couple of [continuing medical education] articles. And it was very nice. ... but it was the only time that I ever used the internet or such places in my course, yes... ... You just don't have time. It would have been very nice, but I just don't get the time to do it. 


\section{B. Mechanism factors}

\section{B1. IMPACT APPRAISAL}

B1a. Impact likelihood:

How likely consequences are to accrue

(Resp6) ... [names module], it's a massive chunk of work ... you must swot so selectively about what you are going to leave out and it's not as though you leave out less important things. You leave things out that you think they will not ask. So it's maybe big things or maybe important things that could save a patient's life one day, but you don't swot it because you have to pass the test now and that's a problem for me.

\section{B1b. Impact magnitude:}

What the magnitude of consequences (negative or positive) is likely to be

(Resp2) ... initially, I studied more, as sick as it may sound, it was really actually nice to learn new things. Now, it's more so that I know when I go and write exams, it's just for my own peace of mind too. One learns so that you know you are not going to fail. That's a big motivation.

(Resp7) ... as far as assessment goes, I will easily go and look at an old question paper or two or so, tips that other students give and based on that, I will go... go learn, focus on certain things. And, to my own detriment for the day that clinical comes, skip some things, so then I didn't emphasise those, but when you're in a corner... when you are calmly underway, then you feel "I must just swot, uhm... I want to swot to be a good doctor", but when you are in a corner, then you swot to make one exam, because you know uhm... Yes, the pressure is pretty high some days, because then you know that your whole year can hinge ... on this one exam. In theory, you can plug your year... so then some days all the good intentions go out the window.

(Resp8) ...we are also assessed along the way with little assignments that we usually have to hand in. And sometimes there will be more than one small test during the module, that also contributes a bit. But my big problem with that is that it usually counts so little... that they give you an assignment that's maybe going to keep you busy for three days and you are going to have to devote all your attention to that if you really want to make a decent effort. And then it takes up so much of your time and then it counts $10 \%$. And now you've missed three days learning that you could actually have done for the exam that counts $90 \%$.... I don't think I learn anything, because I am busy just rushing it off most of the time, if I see that it is not going to count very much. ... in the beginning, you are a bit more committed, but once you start realising that the work that is covered in the assignments won't necessarily be 
asked again in a test or... then, I must say, I don't put as much effort as I can into it. I prefer to rather learn for the test at the end. That's more important to me.

\section{B2. RESPONSE APPRAISAL}

\section{B2a. Response efficacy:}

The efficacy of any given learning response in achieving a particular outcome

(Resp10) I can swot lists for tests, but I forget those again. And it... it frustrates me unbelievably much if I don't have insight. ... [I swot lists] because that is the only way I... well, I must get the marks. You know you must pass your course to become a doctor. Whether you agree with what they asked or not.

(Resp4) I think you tend to stress more earlier on the course ... You know you can get away with more later on, so you maybe start studying a little later. If you have experienced before that, okay, I can actually start at this stage and still be fine, then you... then you tend do it the next time in the same way.

(Resp1) if the person has a reputation of setting incredibly tough papers or papers which do not correlate very well with papers which have been set in the past... so if you know that this guy is going to set you a paper with questions which he has never set before and you will not find in previous test papers and which are going to be very difficult questions, your approach will be a lot more thorough and you won't just skip out in things, saying "He'll never ask that, he'll never ask that"

\section{B2b. Response costs:}

The costs of any given learning response; costs can be incurred by responding, and not, to the demands of assessment and may be internal or external to the student

(Resp6) ... the whole approach of four weeks for one large subject like [names module], it's a massive chunk of work and then you must swot so selectively about what you are going to leave out and it's not as though you leave out less important things. You leave things out that you think they will not ask. So it's maybe big things or maybe important things that could save a patient's life one day, but you don't swot it because you have to pass the test now and that's a problem for me.

(Resp9) ... some nights, I learned until 23:30 and got up 06:00 the next morning. But then... then you're in, like, super-stress mode. Then you do it of course because you think you are not going to pass. ... I think if there is no assessment, you won't learn, because that is basically what it's about in medicine. You have a four week module, for example, and you know the first week that you must get an overview of the work and then you know when your stress mechanism starts to kick in, you must now start learning and then you start learning. [I stress when] I feel if I didn't go through all the work properly... I won't pass the test. 
(Resp8) ...we are also assessed along the way with little assignments that we usually have to hand in. And sometimes there will be more than one small test during the module, that also contributes a bit. But my big problem with that is that it usually counts so little... that they give you an assignment that's maybe going to keep you busy for three days and you are going to have to devote all your attention to that if you really want to make a decent effort. And then it takes up so much of your time and then it counts $10 \%$. And now you've missed three days learning that you could actually have done for the exam that counts $90 \%$.

(Resp4) sometimes the modules do that. So it's a four weeks module and you have [a test] two weeks into the modules and then a test at the end. Some of them do that. ... I don't like it. Because, obviously you get to the stage of like, when you feel you've worked hard on your last clinical block and you feel like relaxing, socialising, then you see you've got a test. The first week of the module: not a good way to start. But I mean it definitely makes you start earlier.

\section{B2c. Response value:}

The value of any given learning response as measured against the student's personal goals and their conceptions of success and wellness

(Resp8) ... in our third year, we could progress [to the next year], so if you got 65, then you didn't need to go and write exams. Now, I cum'd all my theory modules at the end of the day... and so I didn't go and write the exams. And the one... there I go and get 65 on the nose. Then my parents said "are you going to do the exam". Then I said to them "no, I've got 65 . I'm going to progress". I'm not prepared to just, so that it will stand on paper that I cum'd that thing too, now put myself through all that stress of going to learn again and write an exam again. ... to go through the work again another time is, I suppose, always advantageous, but at that time, the pros and cons were just for me... it was just not that important to me. So, my knowledge would definitely have been better if I went and learned all that work again, but I don't think my mark would necessarily have improved.

\section{B3. PERCEIVED AGENCY}

The perception of being able to exert some control over a situation, even in the face of adversity

(Resp8) You know how long it takes you to learn something, when you must start waking up and you know when you are behind. And you know what your abilities are and how much you must do to... to be able to get to the test.

(Resp4) you feel less secure if you know you're going to get asked an interpretive question. Whereas you know it's going to be just sort of... like parrot fashion type questions, then you can pretty much study and know you're going to do well. But if it's going to be interpretive questions, you never quite sure exactly what they want. 


\section{B4. INTERPERSONAL FACTORS}

\section{B4a. Normative beliefs:}

The beliefs of referents, people (like lecturers and fellow students) whose opinion a student values

B4a(i). Normative beliefs - lecturers:

These were typically inferred as opposed to necessarily espoused or enacted beliefs

(Resp2) one gets a reasonable idea in later years what the lecturers think is important. So, if I can, I will swot everything that there is to swot, but if the time gets a bit too little, then I take... not chances, but then I concentrate more on the things that to me are clearly more important.

(Resp7) My theory is that a lecturer will not ask me something in an exam that he did not go to the trouble of mentioning in class.

(Resp12) I use the question papers to see what is more important and to, to test whether I can answer it. ... I believe that, that is my belief, that everything that is important is summarised in these question papers.

\section{B4a(ii). Normative beliefs - students}

(Resp7) I'll talk to guys that are a year or two ahead of me. ... l'll talk to them about how they experienced it, and they will... I'll talk to a couple of people, more or less in every block I start, and then you'll hear, then they say "... wow, they asked this big question in the test, but they said they'll never do that again" or "no, it was easy; look at the papers, they repeated the papers' questions a lot" or they will say "listen here, start really early"

B4b. Motivation to comply:

Students' motivation to comply with normative beliefs

(Resp7) ... as far as assessment goes, I will easily go and look at an old question paper or two or so, tips that other students give and based on that, I will go... go learn, focus on certain things. And, to my own detriment for the day that clinical comes, skip some things, so then I didn't emphasise those, but when you're in a corner... when you are calmly underway, then you feel "I must just swot, uhm... I want to swot to be a good doctor", but when you are in a corner, then you swot to make one exam, because you know uhm... Yes, the pressure is pretty high some days, because then you know that your whole year can hinge ... on this one exam. In theory, you can plug your year... uhm... so [laughs] then some days all the good intentions go out the window 


\title{
C. Learning effects of assessment
}

\section{C1. QUALITY OF LEARNING}

The cognitive processing activities students opt to use

\begin{abstract}
(Resp10) memorizing stuff ... it misses the point, because if you are going to swot like that just to pass a test, what will that help? ... But I mean, sometimes your time is just too little and you must just go and swot the stuff parrot-fashion, but I don't like doing it like that at all.

(Resp4) If I go back to to second year [names module]. There was those true false questions ... You didn't study like in facts in the way that you would if you had to give a paragraph. You'd study it to understand it, because that's basically the true false questions were testing your understanding. ... if it's going to be multiple choice questions ... this and this is a complication of that, you only need to recognize it. You don't have to think it out yourself. ... if you've seen it before and you understand how it makes sense as a complication, you're not going to study it
\end{abstract}

\section{C2. REGULATION OF LEARNING}

\section{C2a. Allocation, quantity and distribution of effort}

\section{C2a(i). Allocation of effort:}

Whether students choose to allocate effort to studies rather than to other aspects of their lives

(Resp8) the positive effect of [assessment] for me is that it forces me to learn and sometimes when one's self-discipline is just not that good, you are still going to have to learn and you know the assessment is coming and it is... it is... in that respect, it is an incentive to learn.

(Resp10) I don't really see tests as a way to get points, really, I just see the tests... in general, I just see motivation to go and learn the work. I don't know, I can't know if I could honestly say that I would have gone and swotted the work if there now wasn't a test that was going to assess it, but, you know, I like to think that I would, but I don't know.

(Resp13) I learn rather well under stress ... I swot in a more disciplined way ... I will say no to [other] stuff and so more, well, easily then... if I know I am under pressure, and I have little time 


\section{C2a(ii). Quantity of effort:}

\section{The amount and intensity of effort allocated to studies}

(Resp13) it depends how close we are to tests, if it is very... if it is, half, two weeks, I will start swotting immediately [I get home], an hour or so, until say six o'clock, and then relax until about whatever... eight o'clock and then study further. Otherwise I won't if it is, say, three thirty, I won't just study for an hour in the afternoon, then I will first wait for the evening.

(Resp16) I start learning the Sunday, yes, fine, and my focus is on the learning, and that's what my day is about and I don't do anything else, I don't actually go out or anything, but I do much less. It is like an eventual curve, half, of how much you do per unit of time, like, in the beginning it's still just like half like this and then it rises until... before your test you can learn three, four lectures in half an hour before the test, where you can still actually answer questions out of it, while five days ago you would have taken a whole evening to learn it.

\section{C2a(iii). Distribution of effort:}

How effort is allocated to studies over time

(Resp2) I think that because we write tests periodically, I swot periodically. ... I think [the block method] has definitely caused me to change from a person who worked continuously to a person who does the minimum for the first three weeks of every month and the maximum in the last week.

(Resp9) the workload of a module is going to determine when your stress level is going to kick in, of when you are going to start learning. So if it is a module with a high workload, then I will start earlier in the second week. Say Monday. If I know, 'Aah, there is still lots of time, I don't actually have to do that much yet' then I might only start learning the Thursday or the Friday.

\section{C2b. Choice of resources:}

The resources students opt to utilize when studying

(Resp1) ... with [names module] that we did last year. They kind of said to us we don't want you to study from the lecture notes we want you to study from [the] prescribed textbook. ... but if we had studied from [names textbook], we wouldn't have passed the test. So, you know, they've got their questions in their notes and that's basically what you have to study to get through.

(Resp10) If there is really a bad lectures or study material that one had, before I [will use journals, the internet or PubMed]. ... it would have been very nice, but I mean there is plain and simply not enough time. I know [names module] last year... I mean our notes were unbelievably poor and out textbook was even worse. And I was forced... I looked at what they put up as other resources and then at the end of it all, I pulled a couple of [continuing medical education] articles. And it was very 
nice. ... but it was the only time that I ever used the internet or such places in my course, yes... ... You just don't have time. It would have been very nice, but I just don't get the time to do it.

(Resp13) [When I sit with a pack of notes] I at least have the textbook next to me too, so if I, say now with one or other disease... I'll just scan quickly, quickly, quickly in the book if there is something more than is in the notes. ... the PowerPoint is often just the points, the book is at least a little more a story to really gain some insight as to what it all is... so I will quickly read through that before I read just the PowerPoint just like that. But that is at the beginning then there is still lots of time, and if there is less time, then I just go through the PowerPoint. ... Yes, here around the second week... about four days before the test, I won't do that any more.

\section{C2c. Choice of content:}

Having selected what resources to utilize, students make a second set of decisions about what content to study from those resources

(Resp7) what I will do is I will see a question paper, I browse through the whole paper, the whole paper is just five to ten point "listing" questions. They're not paragraph or insight or case-studies... Or the case studies are actually just again just to get the little lists out of you in another way... And so I will concentrate on that. If I page through that work and here is some or other description of a thing, l'll maybe skip over it, but you'll stop at a five or ten point list. Yes, then one just swots like that, you know, that is what will get you through.

\section{C2d. Monitoring \& adjustment strategies:}

Passive or active (e.g., self-testing) checking that learning is proceeding according to plan; and adjusting learning (e.g., activities; contents; or goals) based on monitoring

(Resp9) assessment also has an impact on yourself because it can also allow you ... it also lets you see how you are progressing, whether you are progressing well or whether you are progressing with the class or whether you are behind, whether you must put in more to keep up with the class or whether you are above the class or whether you can relax a bit

(Resp12) closer to the time I would sort of have glimpse of a question paper if there's any. Yes, I think I usually use a question paper more than the actual outcomes. ... sometimes the outcomes are a pain to try and understand what exactly they are. And then so I use the question paper exactly as I should have been using the outcome, to try and understand what is more important. ... What I usually do, I, I, I usually look at three question papers from different years. And I just look at it, just look at the questions, and then I just try to answer them, after having read a certain section. I just try and answer the question paper. And if I am not able to answer on my own, I go back to the section and I, I help myself from the notes to answer the question. ... I use the question paper to test, to test what, what, what, what I have already learned, and also to see what's more important. 
C2e. Persistence with learning:

Whether students persist in allocating time and effort to learning in the face of distractions or fatigue

(Resp4) sometimes the modules do that. So it's a four weeks module and you have [a test] two weeks into the modules and then a test at the end. Some of them do that. ... I don't like it. Because, obviously you get to the stage of like, when you feel you've worked hard on your last clinical block and you feel like relaxing, socialising, then you see you've got a test. The first week of the module: not a good way to start. But I mean it definitely makes you start earlier.

\section{References}

Cilliers, F. J., Schuwirth, L. W. T., Adendorff, H. J., Herman, N., \& van der Vleuten, C. P. M. (2010). The mechanism of impact of summative assessment on medical students' learning. Advances in Health Sciences Education, 15(5), 695-715.

Cilliers, F. J., Schuwirth, L. W. T., Herman, N., Adendorff, H., \& van der Vleuten, C. P. M. (2012). A model of the pre-assessment learning effects of summative assessment in medical education. Advances in Health Sciences Education, 17(1), 39-53. 


\section{CHAPTER 5}

Modelling the Pre-assessment Learning Effects of Assessment: Evidence in the Validity Chain 


\begin{abstract}
Objectives. We previously developed a model of the pre-assessment learning effects of consequential assessment and started validating it. The model comprises assessment factors, mechanism factors and learning effects. The purpose of this study was to continue the validation process. For stringency, we focussed on a subset of assessment factor-learning effect associations that featured least commonly in a baseline qualitative study. Our aims were to determine whether these uncommon associations were operational in a broader but similar population to that in which the model was initially derived.
\end{abstract}

Methods. A cross-sectional survey of 361 senior medical students was undertaken using a purpose-made questionnaire based on a grounded theory and comprising pairs of written situational tests. In each pair, the manifestation of an assessment factor was varied. The frequency with which learning effects were selected was compared for each pair of items. An adjusted alpha was used to assign significance. The frequency of involvement of mechanism factors was calculated.

Results. There were significant differences in the learning effect selected for 13 of this subset of 21 uncommon associations being investigated, even taking $p<0.00625$ as significant. Three mechanism factors were operational in most scenarios i.e., agency, response efficacy and response value. A role for all eight learning effects, all ten mechanism factors and six out of eight assessment factors investigated was substantiated.

Conclusions. For a subset of uncommon associations in the model, the role of most associations and the components involved were supported in a broader but similar population to that from which the model was derived. Although model validation is an on-going process, these results move the model one step closer to the stage of usefully informing interventions. Results illustrate how factors not typically included in studies of the learning effects of assessment can confound the results of interventions aimed at using assessment to influence learning.

Published as:

Cilliers, F. J., Schuwirth, L. W. T., \& van der Vleuten, C. P. M. (In press). Modelling the pre-assessment learning effects of assessment: Evidence in the validity chain. Medical Education. doi: 10.1111/j.1365-2923.2012.04334.x 


\section{Introduction}

Calls have been made for a greater role for theory in medical education research (Albert \& Reeves, 2010; Bordage, 2009; Cook, Bordage, \& Schmidt, 2008; Gibbs, Durning, \& van der Vleuten, 2011; Prideaux \& Bligh, 2002). A theory can be used to generate and frame research questions, which in turn should help to interrogate and further refine the theory. Theory can inform the interpretation of observations. Using theory also allows the findings of research to be linked to the work of others at a conceptual level. A variety of small advances can be consolidated with existing work, even from other fields, when theoretically grounded, whereas work not grounded in theory "runs the risk of being superficial and non-cumulative" (Bordage, 2009, p. 317). Theory also allows the informed development and investigation of solutions to problems.

Cautionary notes have been sounded about the uncritical use of theory, however (Bordage, 2009; Colliver, 2002; Norman, 2004). Colliver (2002, p. 1217) cautions against using theory that is "little more than metaphor, not rigorous, tested, confirmed scientific theory". Bordage (2009) admonishes that prior to adopting a conceptual framework, the evidence supporting that framework should be carefully examined. This raises questions about how to evaluate a theory before utilising it.

Prochaska, Wright \& Velicer (2008) reviewed the writings of philosophers of science to compile a hierarchical set of twelve criteria by which to evaluate theory, models and frameworks. A criterion higher in the hierarchy poses greater demands in terms of the type of evidence required to satisfy it than a criterion lower down. These criteria not only delineate an approach to evaluating theory, however: they also suggest an agenda for validating new theory. The hierarchical nature of the criteria supports the notion that validation is a process, not an event, and validity a journey, not a destination.

This paper is about one leg of a validity journey. Using grounded theory, we have proposed a model of the pre-assessment learning effects of consequential assessment (figure 1) (Cilliers, Schuwirth, Herman, Adendorff, \& van der Vleuten, 2012). Before addressing the central issue of model validity, some clarification of terminology is required.

'Learning effects of assessment': These effects have only recently been classified (Dochy, Segers, Gijbels, \& Struyven, 2007). Pre-assessment learning effects typically accrue to learning behaviours and occur before an assessment event (e.g., wellconstructed MCQ's driving learning for understanding before a test). Postassessment learning effects occur after an assessment event and accrue to learning behaviours or subsequent achievement (e.g., feedback influencing learning after a test or in-course assignments influencing examination performance). Pure learning effects occur during an assessment event (e.g., learning being influenced by the testing effect (Larsen, Butler, \& Roediger, 2008) or by constructing a portfolio). 
'Consequential assessment': Under consequential test conditions, stakes are typically high and assessment results in direct consequences for students, whereas under non-consequential test conditions, stakes are low and few or no consequences accrue (Sundre \& Kitsantas, 2004). While this may sound like summative and formative assessment, we have found that the stakes that influence learning in assessment situations encompass not only judgement-related academic consequences (typical of summative assessment) but also non-academic consequences e.g., accruing to self-esteem or a sense of agency (Cilliers, Schuwirth, \& van der Vleuten, 2012). This has led us to consider consequential assessment a better descriptor for the model than summative assessment.

Returning now to 'validity': Before any model can meaningfully inform practice and research, its validity needs to be established, the expectation being that interventions informed by substantiated theory will be more successful than would otherwise be the case (Lippke \& Ziegelmann, 2008; Prochaska et al., 2008). There is currently no validated model explaining the pre-assessment learning effects of assessment. There is much literature describing what the pre-assessment learning effects of assessment are. However, a dominant theme in this literature has been whether a particular assessment task or programme induces a surface or deep approach to learning (e.g., Heijne-Penninga, Kuks, Hofman, \& Cohen-Schotanus, 2008). Much less literature addresses the mechanism of this impact; most of this is fragmented (see Cilliers, Schuwirth, Adendorff, Herman, \& van der Vleuten, 2010 for a review). There have been few attempts to propose theoretical models to explain how preassessment learning effects come about (Becker, Geer, \& Hughes, 1968; Broekkamp \& van Hout-Wolters, 2007; Ross, Green, Salisbury-Glennon, \& Tollefson, 2006; Ross, Salisbury-Glennon, Guarino, Reed, \& Marshall, 2003; Sundre \& Kitsantas, 2004; van Etten, Freebern, \& Pressley, 1997). As noted, none of these models has been validated. Furthermore, none has gained traction to inform the practice of, or research about, assessment to induce sought-after pre-assessment learning effects, judging by citation patterns. This intriguing gap in the literature prompted us to develop and start validating our model (Figure 1).

As a first step in validating the model, we established that we could analyse and explain observations about the learning effects of assessment in a context different to that in which the model was derived (Cilliers, Schuwirth, \& van der Vleuten, 2012). This was done qualitatively and with the same group of respondents as was involved in the derivation of the model. The question now was how best to continue the model validation journey.

Given that the model had been derived qualitatively working with a small group of fourth and fifth year medical students at Stellenbosch University, we considered it a priority to explore whether the components and associations in the model were in play in a broader population of students. To establish the next link in the chain of validity evidence, we therefore elected to explore whether the model was operational more broadly among fourth and fifth year medical students at Stellenbosch University. 
A challenge in this endeavour was the large number of associations that could be explored (Figure 1). The baseline qualitative work yielded 40 assessment factorlearning effect associations (Cilliers, Schuwirth, Herman, et al., 2012). The factors in each association are linked by up to 10 mechanism factors. This yields a total of 400 possible associations. However we chose to investigate these associations, it was not feasible to investigate all simultaneously. Doing so would have required impracticably long testing times of respondents.

The selection of a subset of associations to study was informed by literature on theory-building citing Popper's maxim that theory must be falsifiable (Norman, 2004; Prochaska et al., 2008). Of the assessment factor-learning effect associations identified in the baseline work, 23 were classified as uncommon i.e., there were $<5$ references to each in the entire dataset. These associations were considered least likely to be in play in a broader population. However, the corollary of this belief was that if these associations were in play in a broader population, this would provide stronger (if as yet partial) evidence in support of the model than demonstrating that the 17 commoner associations were in play. Therefore, as the most stringent test of the model, we opted to first focus on this subset of uncommon associations and essentially try to refute their role in a broader population of students.

A subsequent challenge was designing a data collection instrument. This process was informed by the fact that the associations between factors are contextual. For any given student in any given assessment situation, learning effects result from the interplay between one/more assessment factors and one/more mechanism factors (Figure 1). For that student, the factors in play - and thus the learning effect(s) that result - can vary from one assessment scenario to the next. This depends on which factors in their mosaic of academic and personal motivation enjoy prominence at any given time. Moreover, for any given assessment scenario, different factors can be in play for different students, yielding different learning effects. Our research question was therefore: In how many cases does varying the manifestation of an assessment factor result in a change in the ensuing learning effect and the main mechanism factor involved, for a subset of uncommon associations between assessment factors and learning effects? To investigate this, we undertook a crosssectional survey using a purpose-made instrument in a population broader than but similar to that from which the model was derived. 


\section{ASSESSMENT FACTORS}

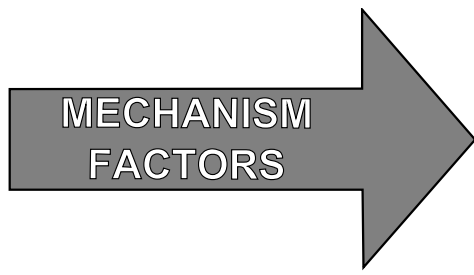

LEARNING EFFECTS



MECHANISM FACTORS

IMPACT APPRAISAL

(1) impact likelihood:

how likely consequences are to accrue

(2) - impact magnitude:

what the magnitude of consequences (negative or positive) is likely to be

(3) - response efficacy:

RESPONSE APPRAISAL

the perceived efficacy of any given learning response in achieving a particular outcome

(4) response costs:

the costs of any given learning response; costs can be incurred by responding, or not, to assessment, and can be internal or external to the student

(5) response value:

the value of any given learning response as measured against the student's personal goals and their conceptions of success and wellness

\section{PERCEIVED AGENCY}

6) - the perception of being able to exert some control over a situation, even in the face of adversity

\section{INTERPERSONAL FACTORS}

- normative beliefs

the beliefs of referents (people whose opinion a student values) against which a student can calibrate her/his behaviour

(7) (i) of lecturers

(8) (ii) of other students

- motivation to comply:

students' motivation to comply with normative beliefs

(9) (i) of lecturers

(10) (ii) of other students 


\section{Methods}

\section{Instrument}

Developing a data-collection instrument suitable for use with large numbers of respondents posed several challenges. We were working with an elaborate model developed from extensive descriptions of respondents' lived experiences. We wanted to determine what respondents' learning response was in any given assessment scenario and what mechanism factor best explained that learning response in that scenario. We also wanted to determine whether the learning response and the mechanism factor changed if the manifestation of the assessment factor was varied. This required an instrument that could both approximate assessment scenarios that respondents might find themselves in and test respondents' decision making at two levels, for 23 different scenarios.

To address these challenges, we opted for low-fidelity simulation using a selfreporting instrument. We developed items based on situational judgement tests (Lievens, Peeters, \& Schollaert, 2008) and incorporating the two-stage logic of the key features approach (Page, Bordage, \& Allen, 1995). We utilised data from the baseline qualitative study (Cilliers et al., 2010; Cilliers, Schuwirth, Herman, et al., 2012)to construct pairs of closed-ended items each comprising a vignette and two option sets (Exhibit 1).

Each vignette described an assessment scenario revolving around one assessment factor. The manifestation of the assessment factor was varied from one item to the next in each pair. Based on the baseline qualitative data, the two manifestations of each assessment factor were selected in such a way that they were expected to produce different learning effects for the two scenarios.

Figure 1: A model of the pre-assessment learning effects of consequential assessment for theory contexts.

Nine assessment factors and six learning effects are linked in 40 associations by a set of mechanism factors (Cilliers, Schuwirth, Herman, et al., 2012) i.e., not all assessment factors and learning effects have been shown to be involved in associations with each other. Each assessment factor-learning effect pair is potentially linked in up to 10 different ways, depending which mechanism factor(s) mediate any particular association. Which assessment factor(s) and mechanism factor(s) are in play-and therefore which learning effect(s) result - is influenced by personal and contextual factors. 
The first option set depicted possible learning effects in the context of the vignette, the second, possible reasons for the behaviour (i.e., mechanism factors) in that context. Respondents were required to select the one option they felt best applied to them in that scenario from each option set. This allowed us to explore whether the learning effect and mechanism factor selected by a respondent in sets of paired scenarios changed as the manifestation of an assessment factor varied.

Of the 23 assessment factor-learning effect associations classified as uncommon, one was not studied. The curriculum had since been altered; contemporary respondents would not be able to relate to the scenario. Another item was discarded when it proved impossible to construct a plausible alternate scenario.

\section{Exhibit 1. Example of item-pair.}

This item-pair addresses the influence of "cues from the student grapevine" (assessment factor) on "quantity of effort" (learning effect). Each vignette and the associated option sets were presented individually to respondents, not paired as illustrated here.

\begin{tabular}{|c|c|c|}
\hline $\begin{array}{l}\text { Vignette depicting } \\
\text { assessment factor }\end{array}$ & $\begin{array}{l}\text { Vignette } 1 \\
\text { It is the middle of the first semester. } \\
\text { You are at the start of a four-week } \\
\text { theory module. You have heard from } \\
\text { students who did the module last year } \\
\text { that the workload in the module is } \\
\text { very high and that if you do not start } \\
\text { studying early, you will never be ade- } \\
\text { quately prepared for the test. }\end{array}$ & $\begin{array}{l}\text { Vignette } 2 \\
\text { It is the middle of the first semester. } \\
\text { You are at the start of a four-week } \\
\text { theory module. You have heard from } \\
\text { students who did the module last year } \\
\text { that the workload in the module is } \\
\text { lower than is usually the case and that } \\
\text { you can safely spend time on things } \\
\text { other than your studies during the } \\
\text { module and still be adequately pre- } \\
\text { pared for the test. }\end{array}$ \\
\hline & \multicolumn{2}{|c|}{$\begin{array}{l}\text { When you decide how to spend your time this week, what are you most likely to } \\
\text { do? } \\
\text { Select the one choice that best applies } \\
\text { I will spend as much time as I usually do studying at this stage of a module } \\
\text { I will spend more time than I usually do studying at this stage of a module } \\
\text { I will spend less time than I usually do studying at this stage of a module }\end{array}$} \\
\hline & \multicolumn{2}{|c|}{$\begin{array}{l}\text { Which of the following best explains your decision making? } \\
\text { Although more than one option may be applicable, please select the one option } \\
\text { that best applies to you. } \\
\text { a. Nothing bad will happen to me academically if I do this } \\
\text { b. There is too much at stake to risk doing badly or failing } \\
\text { c. Doing this is necessary to get a result I'm comfortable with } \\
\text { d. It's not worthwhile letting my life get out of balance } \\
\text { e. It is important to me to do well: I don't want to do badly or fail } \\
\text { f. I believe that I'm capable of doing well enough under these circumstances if } \\
\text { I do this } \\
\text { g. I have heard from other students that if I do this, I will do well enough } \\
\text { h. Lecturers emphasise the importance of this } \\
\text { i. It is worth taking guidance from my fellow students } \\
\text { j. I value the opinion of lecturers who teach this module }\end{array}$} \\
\hline
\end{tabular}


In some cases, it was not possible to create an alternate scenario by varying the assessment factor of interest e.g., "lack of cues". Varying this would result in cues being given. It proved impossible to create a scenario where the mere presence, rather than the nature, of those cues would be the influencing factor. In these cases, another factor was added e.g., respondents had to contemplate a scenario of no cues distanced time wise from assessment and then with assessment imminent as the alternate scenario.

Twenty-one associations involving eight assessment factors and eight learning effects (Table 2) were thus investigated. The full item-set is available from author FJC. Essentially, each item-pair represented an individual study. These were only grouped together in a single questionnaire for convenience.

So as not to contaminate the respondent pool (see below) and given that third year students had insufficient experience of assessment methods for the purposes of the study, items were pilot-tested with six sixth-year medical students. The session lasted approximately two hours. While changes were suggested and made to item wording, students found all scenarios to be realistic and all the options offered to be plausible. Students were given a voucher worth \pm US\$20 but were not told ahead of time about this.

Based on how quickly students processed items in the pilot and to limit testing time to \pm 20 minutes, items were divided into two questionnaires of 10 and 11 pairs respectively. The reading load of each questionnaire was comparable. Learning effect option sets were scenario dependent. Items with similar learning effect options were placed consecutively in the questionnaire, to limit the cognitive burden on respondents. To the same end, respondents were alerted that mechanism factor option sets were identical for all scenarios.

Respondents self-reported what class they were in, average marks across the course up to that point, whether they had previously failed a module and gender.

\section{Population, data collection and ethical considerations}

The study population comprised all fourth $(\mathrm{N}=179)$ and fifth $(\mathrm{N}=182)$ year medical students at Stellenbosch University i.e., a population similar to but broader than that from which the model had been derived. Students followed a six-year curriculum. Most entered medical school directly from secondary school.

Students were randomly allocated to complete questionnaire one $(n=181)$ or questionnaire two $(n=180)$. Items were administered electronically and anonymously using an in-house survey tool based on Checkbox v4.6.4.7 (Checkbox Survey Solutions, Inc., 2009). All students in both classes were surveyed. The letter of invitation and the survey link were delivered using email address lists used by the faculty to communicate with students. 
We implemented various recommendations to optimise response rates (Dillman, Smyth, \& Christian, 2009; Göritz, 2006; Huang, Hubbard, \& Mulvey, 2003). This included offering students the incentive of being entered into a draw for one of 20 vouchers to a vendor of their choice valued at $\pm U S \$ 20$ each if they participated in the study. Contact information for the draw was collected in a separate survey to which respondents linked from the last page of the survey they completed.

\section{Data analysis}

Each item-pair was, in essence, a mini-study: any item-pair with responses to both scenarios could be included for analysis. There were more than two learning effect options for most items, so for analysis, the response considered to be most likely to vary in the context of the scenario was identified using the baseline qualitative data. Responses to other response options were grouped so as to generate a $2 \times 2$ table. The $\chi^{2}$ statistic was used to compare the frequency with which the learning effect considered most likely to vary was selected in the two variants of each scenario. $\mathrm{H}_{0}$ was that there would be no difference in the frequency with which the most likely learning effect was selected between the two scenarios.

Given the large number of associations being explored, we applied Holm's sequentially selective Bonferroni adjustment. The highest $p$-value considered significant was 0.00625 . We also performed a sign test to determine whether the number of associations in which a significant difference in learning effect between scenarios was noted, was greater than would be the case by chance alone.

We were also interested in the role of mechanism factors. The frequency with which any given mechanism factor was selected was tabulated. We also tabulated whether the mechanism factor selected changed from one scenario to the next for each item-pair.

To determine how representative responders were of the study population, the $\chi^{2}$ statistic was used to compare the two groups in terms of what class they were in, whether they had previously failed a module and their gender. For each characteristic compared, $\mathrm{H}_{0}$ was that there would be no difference between the two groups. $\mathrm{p}<0.05$ was considered significant.

Analyses were performed using Statistica data analysis software (StatSoft, Inc., Tulsa, USA, 2011, version 10).

\section{Results}

Questionnaires were completed by 152 respondents, yielding 80 complete responses to questionnaire 1,72 to questionnaire 2 . In addition, 15 respondents provided responses to $\geq 1$ item-pairs but did not complete a questionnaire. This resulted in 
varying numbers (between 74 and 84 ) of responses for each item-pair and a response rate of between 41.1 and $46.4 \%$.

\section{Representivity of respondents}

Compared to the study population, a greater proportion of fourth than fifth year respondents than would have been expected responded to both questionnaire 1 $\left(\chi^{2}=7.52 ; d f=1 ; p=0.006\right)$ and questionnaire $2\left(\chi^{2}=7.29 ; d f=1 ; p=0.006\right)$. There were no differences as regards respondents' gender or whether they had previously failed a module as compared to the study population. No comparisons were done for average scores, as respondents tended to report their average score in multiples of five. Scrutinising the data in table 1 suggests there is no difference.

Table 1: Demographic information for study population and non-responders. Average: Average score for programme as a whole

*: Calculated from faculty records

\#: Self-reported

\begin{tabular}{|c|c|c|c|c|c|c|}
\hline & \multirow[b]{3}{*}{ Program } & \multirow[b]{3}{*}{ Failed $\geq 1$ modules } & \multirow{2}{*}{\multicolumn{2}{|c|}{ Study population }} & & \\
\hline \multirow[b]{2}{*}{ Questionnaire } & & & & & \multicolumn{2}{|c|}{ Respondents } \\
\hline & & & Number & Average $^{*}(\mathrm{SD})$ & Number & $\begin{array}{l}\text { Average }^{\#} \\
\text { (SD) }\end{array}$ \\
\hline \multirow[t]{6}{*}{1} & \multirow[t]{3}{*}{ MBChB IV } & No & 68 & $69.3(6.3)$ & 42 & $69.5(6.1)$ \\
\hline & & Yes & 21 & $56.3(4.0)$ & 10 & $63.1(6.7)$ \\
\hline & & Subtotal & 89 & & 52 & \\
\hline & \multirow[t]{3}{*}{ MBChB V } & No & 63 & $68.0(5.3)$ & 23 & $66.4(4.7)$ \\
\hline & & Yes & 29 & $57.3(4.3)$ & 12 & $61.5(4.6)$ \\
\hline & & Subtotal & 92 & & 35 & \\
\hline 1 Total & & & 181 & & 87 & \\
\hline \multirow[t]{6}{*}{2} & \multirow[t]{3}{*}{ MBChB IV } & No & 72 & $68.4(6.8)$ & 34 & $69.4(7.7)$ \\
\hline & & Yes & 18 & $55.9(4.2)$ & 15 & $59.7(9.2)$ \\
\hline & & Subtotal & 90 & & 49 & \\
\hline & \multirow[t]{3}{*}{ MBChB V } & No & 59 & $69.6(6.2)$ & 20 & $68.9(4.7)$ \\
\hline & & Yes & 31 & $58.1(4.6)$ & 11 & $61.7(4.0)$ \\
\hline & & Subtotal & 90 & & 31 & \\
\hline 2 Total & & & 180 & & 80 & \\
\hline Grand Total & & & 361 & & 167 & \\
\hline
\end{tabular}

\section{Association between assessment factors and learning effects}

The results of what are essentially 21 separate studies are presented together for convenience. There were significant differences in the frequency with which the 

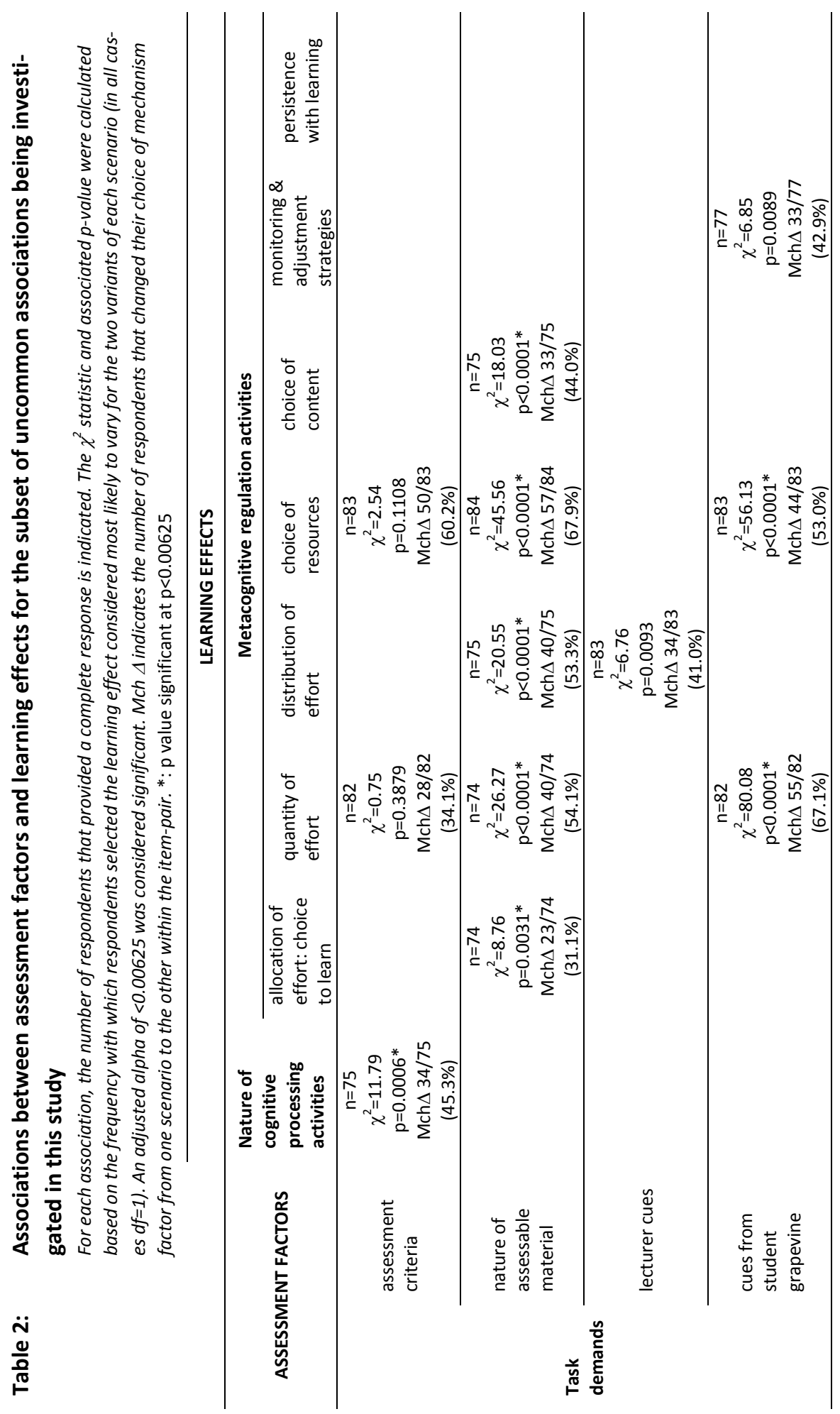


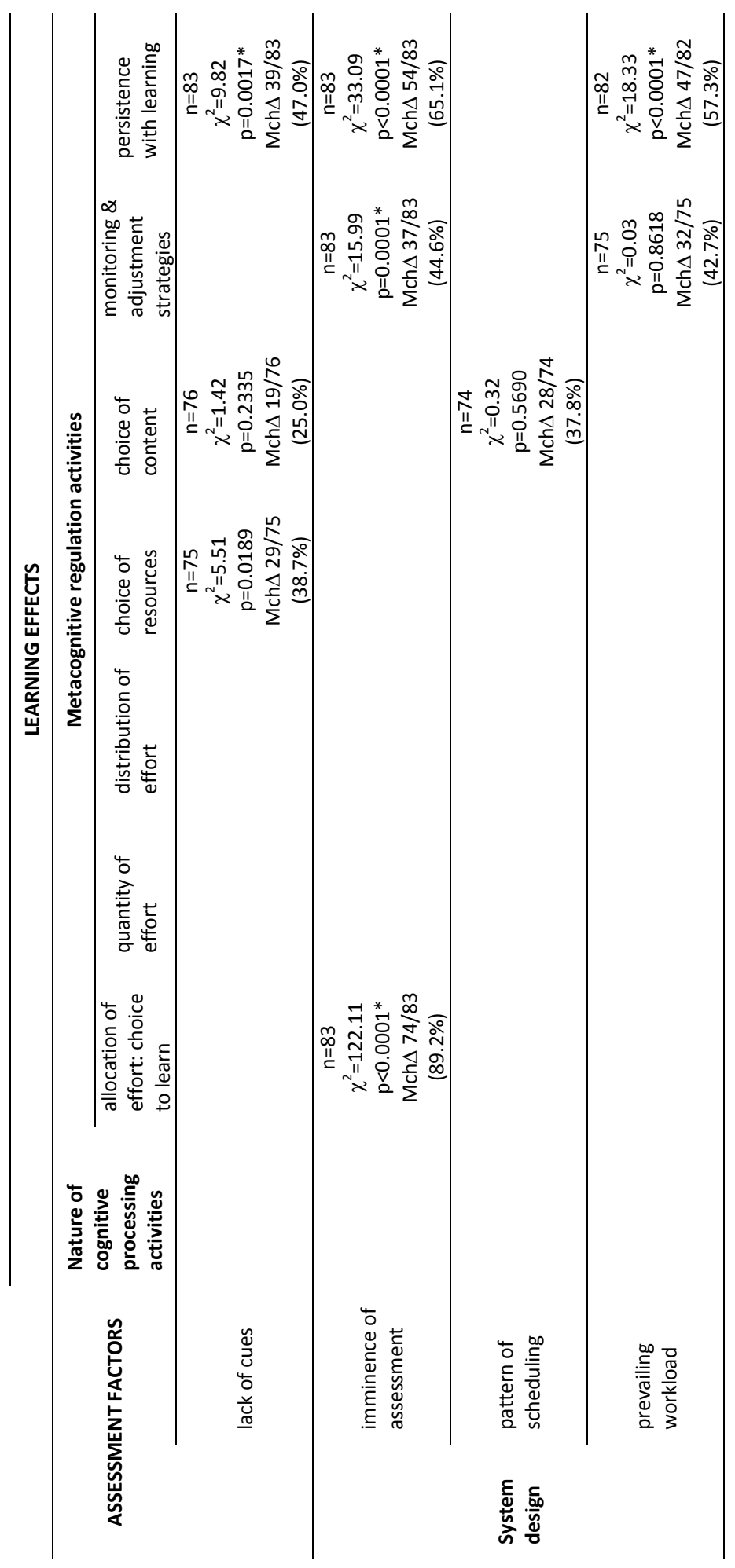


expected learning effect was selected between the two variants of a scenario for $13 / 21$ scenarios (Table 2 ). This is greater than would be expected by chance (sign test $Z=3.328201 ; p=0.000874)$. As judged by the baseline qualitative data, the nature of the associations and the changes observed were expected in all cases. The results therefore did not support the hypothesis that there would be no relationship between assessment factors and learning effects for most of this uncommon subset of associations between these factors.

\section{Role of mechanism factors}

All mechanism factors were selected more or less frequently (table 3 ). The proportion of respondents who changed the mechanism factor they selected varied from $25.0 \%$ to $89.2 \%$ across scenarios (Table 2). Across all item-pairs, three mechanism factors i.e., agency $(f)(n=815 ; 24.5 \%)$, response efficacy $(c)(n=792,23.8 \%)$ and response value (e) ( $n=508 ; 15.3 \%)$ accounted for $63.7 \%$ of responses. These results support the role of all subcomponents of the mechanism in the model.

Table 3: Frequency with which mechanism factors were selected overall

\begin{tabular}{|c|c|c|c|}
\hline Mechanism factor & Item wording & $\mathbf{n}$ & $\%$ \\
\hline a. Impact Appraisal & $\begin{array}{l}\text { Nothing bad will happen to me academically if I do } \\
\text { this }\end{array}$ & 281 & 8.5 \\
\hline b. Impact Severity & $\begin{array}{l}\text { There is too much at stake to risk doing badly or } \\
\text { failing }\end{array}$ & 337 & 10.1 \\
\hline c. Response Efficacy & $\begin{array}{l}\text { Doing this is necessary to get a result I'm comfort- } \\
\text { able with }\end{array}$ & 792 & 23.8 \\
\hline d. Response Costs & $\begin{array}{l}\text { It's not worthwhile letting my life get out of bal- } \\
\text { ance }\end{array}$ & 227 & 6.8 \\
\hline e. Response Value & $\begin{array}{l}\text { It is important to me to do well: I don't want to do } \\
\text { badly or fail }\end{array}$ & 508 & 15.3 \\
\hline f. Agency & $\begin{array}{l}\text { I believe that I'm capable of doing well enough } \\
\text { under these circumstances if I do this }\end{array}$ & 815 & 24.5 \\
\hline g. Normative beliefs: Peers & $\begin{array}{l}\text { I have heard from other students that if I do this, I } \\
\text { will do well enough }\end{array}$ & 131 & 3.9 \\
\hline h. Normative beliefs: Lecturers & Lecturers emphasise the importance of this & 68 & 2.0 \\
\hline $\begin{array}{l}\text { i. Motivation to comply with } \\
\text { normative beliefs: peers }\end{array}$ & $\begin{array}{l}\text { It is worth taking guidance from my fellow stu- } \\
\text { dents }\end{array}$ & 102 & 3.1 \\
\hline \multirow[t]{2}{*}{$\begin{array}{l}\text { j. Motivation to comply with } \\
\text { normative beliefs: lecturers }\end{array}$} & $\begin{array}{l}\text { I value the opinion of lecturers who teach this } \\
\text { module }\end{array}$ & 61 & 1.8 \\
\hline & Total: & 3322 & 100 \\
\hline
\end{tabular}

\section{Discussion}

The purpose of this study was to continue a process of validation of a model explaining the pre-assessment learning effects of consequential assessment. Tested in a broader but similar population to that from which the model was derived, we 
demonstrated predictable associations between assessment factors and learning effects for $13 / 21$ of the least common associations in the original study, even under the stringent conditions of assigning significance using an adjusted alpha. While these results could be the first step in falsifying the role of the eight associations for which we could not find support for model-based predictions, for now, we can conclude that 13 associations do, and eight do not, hold promise to further enhance our understanding of the pre-assessment learning effects of assessment.

We also demonstrated that even in this limited subset of uncommon associations, all of the mechanism factors played a role. Furthermore, different mechanism factors were in play for different versions of a scenario for many respondents. There were instances where even though the learning effect considered most likely was selected with similar frequency between the two variants of a scenario, a majority of respondents selected different mechanism factors in the two scenarios (e.g., the association between 'assessment criteria' and 'choice of resources'). This supports the model's prediction of contextual variability for the role of mechanism factors.

This study also supports the model by way of the process of developing the instruments used. Almost all components and associations in which we were interested proved testable given that we could devise relevant item-pairs that yielded useable data. We are confident of content validity - items were developed from extensive data generated using grounded theory - and have evidence supporting face validity - students pronounced items to be both recognizable and realistic during piloting.

Many of the subset of uncommon associations explored here are novel. Of these, two seemingly potent assessment factors we substantiate a role for are "nature of assessable material" and "imminence of assessment". Their associations with some, but not all, of the limited subset of learning effects studied here have been documented before, but in a limited fashion and typically in qualitative studies (Broekkamp \& van Hout-Wolters, 2007; Miller \& Parlett, 1974; Sambell, McDowell, \& Brown, 1997; Snyder, 1971; Thomson \& Falchikov, 1998; van Etten et al., 1997). This is perhaps not surprising given that most literature relating assessment and preassessment learning focuses on the influence of task type (which was not included in this study of uncommon associations as we previously found associations between task type and learning effects to be common). As regards mechanism factors, three were prominent in this setting. Interpreting the findings of other studies yields fragmentary support for the role of each of these i.e., appraisal of response efficacy (Becker et al., 1968; Becker, Geer, Hughes, \& Strauss, 1961; Frederiksen, 1984; Newble \& Jaeger, 1983; Ramsden, 1984; Sambell \& McDowell, 1998; Snyder, 1971; Thomson \& Falchikov, 1998; van Etten et al., 1997), appraisal of response value (Becker et al., 1968; Miller \& Parlett, 1974; Parlett, 1969; Sambell et al., 1997; Snyder, 1971; van Etten et al., 1997) and perceptions of agency (Becker et al., 1968; Snyder, 1971; van Etten et al., 1997). None of these components have been studied systematically, however. We would argue that our findings are opening potentially fruitful new avenues to explore. 
There are methodological issues to address, however. One association in the model could not be investigated using the approach adopted for this study. Although we have been able to show a role for all mechanism factors, this data was not amenable to statistical analysis. This potentially poses a problem in terms of the expectation that theories should be testable (Prochaska et al., 2008) and points to the need to explore other methods to investigate the role of some components and associations in the model.

The fact that the findings reported here represent self-reported behaviour rather than observed behaviour could have resulted in functional learning beliefs and behaviours being over-represented as compared to dysfunctional learning beliefs and behaviours (Callahan, Hojat, \& Gonnella, 2007). However, responses were anonymous and the researchers were unknown to the respondents.

A further limitation is that our results potentially oversimplify the reality they represent. Respondents were limited to selecting only the one most likely learning effect and mechanism factor in each scenario. While these results give an indication of the dominant factors in play in these scenarios for these respondents, judging from the results of the baseline studies (Cilliers et al., 2010; Cilliers, Schuwirth, Herman, et al., 2012), there are likely to be several factors in play in any real-life scenario. It would be interesting, if complicated, to explore what other factors are in play in any given scenarios and what factors explain whether any factor is in play or not in any given scenario.

A final limitation is that these findings are limited to one medical school in one country, the same medical school in which the model was originally developed. While we are happy that we can generalise our findings to the classes from which respondents were drawn, which was one aim of the study, these findings cannot yet be generalised to other groups.

Sambell \& McDowell (1998, p. 401) argued that if students each construct their own version of the hidden curriculum, 'this means that the outcomes of assessment as "lived" by students are never entirely predictable, and the quest for a "perfect" system of assessment is, in one sense, "doomed from the outset"'. We would rather share in Prochaska, Wright \& Velicer's (2008) optimism that being able to situate findings in a theoretical framework will ultimately lead to more effective interventions, in this case geared towards enhancing the pre-assessment learning effects of consequential assessment. Given the caveats imposed by the study's limitations, what guidance do our findings give for practice? The truth of the matter is that of the subset of factors studied here, few are either what one would want to target for interventions or, indeed, even amenable to interventions e.g., "cues from the student grapevine" or "imminence of assessment". The value of these results lies rather in furthering our understanding of those associations between assessment factors and learning effects that have proved significant and how, even if they are not the target of an intervention, they may act as (potentially powerful) confounders to influence the results of that intervention. One point these results underline is 
that the relationship between assessment and pre-assessment learning effects is not limited to students' perceptions of task demands as much literature would suggest. Instead, as Sambell \& McDowell (1998) have intimated, students do not respond homogenously to assessment, nor does assessment act as a homogenous trigger for action. Our model provides a framework to explore this heterogeneity.

Our findings set the stage for further steps in validating the model. This will need to include efforts to explore the generalizability to other populations e.g., medical students from other medical schools and countries, students studying other disciplines and postgraduate students. Future research should also explore the associations that were commonest in the initial study. Focusing on those factors that do lend themselves to interventions, experimental studies could be done to influence learning. Hopefully, as the validity evidence for the model is extended with further research, practitioners and researchers will have a stronger theoretical framework with which to work when designing interventions geared towards, and research about, the pre-assessment learning effects of consequential assessment. 


\section{References}

Albert, M., \& Reeves, S. (2010). Setting some new standards in medical education research. [Commentary]. Medical Education, 44(7), 638-639.

Becker, H. S., Geer, B., \& Hughes, E. C. (1968). Making the grade: The academic side of college life. New York: John Wiley \& Sons, Inc.

Becker, H. S., Geer, B., Hughes, E. C., \& Strauss, A. (1961). Boys in white. Student culture in medical school. Chicago: University of Chicago Press.

Bordage, G. (2009). Conceptual frameworks to illuminate and magnify. Medical Education, 43(4), 312319.

Broekkamp, H., \& van Hout-Wolters, B. H. A. M. (2007). Students' adaptation of study strategies when preparing for classroom tests. Educational Psychology Review, 19(4), 401-428.

Callahan, C. A., Hojat, M., \& Gonnella, J. S. (2007). Volunteer bias in medical education research: An empirical study of over three decades of longitudinal data. Medical Education, 41(8), 746-753.

Cilliers, F. J., Schuwirth, L. W. T., Adendorff, H. J., Herman, N., \& van der Vleuten, C. P. M. (2010). The mechanism of impact of summative assessment on medical students' learning. Advances in Health Sciences Education, 15(5), 695-715.

Cilliers, F. J., Schuwirth, L. W. T., Herman, N., Adendorff, H., \& van der Vleuten, C. P. M. (2012). A model of the pre-assessment learning effects of summative assessment in medical education. Advances in Health Sciences Education, 17(1), 39-53.

Cilliers, F. J., Schuwirth, L. W. T., \& van der Vleuten, C. P. M. (2012). A model of the pre-assessment learning effects of assessment is operational in an undergraduate clinical context. BMC Medical Education, 12.

Colliver, J. A. (2002). Educational theory and medical education practice: A cautionary note for medical school faculty. Academic Medicine, 77(12, Part 1), 1217-1220.

Cook, D. A., Bordage, G., \& Schmidt, H. G. (2008). Description, justification and clarification: A framework for classifying the purposes of research in medical education. Medical Education, 42(2), 128-133.

Dillman, D. A., Smyth, J. D., \& Christian, L. M. (2009). The tailored design method Internet, mail, and mixed-mode surveys: The tailored design method (3rd ed.). Hoboken, New Jersey: John Wiley \& Sons, Inc.

Dochy, F., Segers, M., Gijbels, D., \& Struyven, K. (2007). Assessment engineering: Breaking down barriers between teaching and learning, and assessment. In D. Boud \& N. Falchikov (Eds.), Rethinking assessment in higher education: Learning for the longer term (pp. 87-100). Oxford: Routledge.

Frederiksen, N. (1984). The real test bias: Influences of testing on teaching and learning. American Psychologist, 39(3), 193-202.

Gibbs, T., Durning, S., \& van der Vleuten, C. P. M. (2011). Theories in medical education: Towards creating a union between educational practice and research traditions. Medical Teacher, 33(3), 183-187.

Göritz, A. S. (2006). Incentives in web studies: Methodological issues and a review. International Journal of Internet Science, 1(1), 58-70.

Heijne-Penninga, M., Kuks, J. B. M., Hofman, W. H. A., \& Cohen-Schotanus, J. (2008). Influence of openand closed-book tests on medical students' learning approaches. Medical Education, 42(10), 967974.

Huang, J. Y., Hubbard, S. M., \& Mulvey, K. P. (2003). Obtaining valid response rates: Considerations beyond the tailored design method. Evaluation and Program Planning, 26(1), 91-97.

Larsen, D. P., Butler, A. C., \& Roediger, H. L., III. (2008). Test-enhanced learning in medical education. Medical Education, 42(10), 959-966.

Lievens, F., Peeters, H., \& Schollaert, E. (2008). Situational judgment tests: A review of recent research. Personnel Review, 37(4), 426-441.

Lippke, S., \& Ziegelmann, J. P. (2008). Theory-based health behavior change: Developing, testing, and applying theories for evidence-based interventions. Applied Psychology, 57(4), 698-716. 
Miller, C. M. L., \& Parlett, M. (1974). Up to the mark: A study of the examination game. London: Society for Research into Higher Education.

Newble, D. I., \& Jaeger, K. (1983). The effect of assessment and examinations on the learning of medical students. Medical Education, 17(3), 165-171.

Norman, G. (2004). Theory testing research versus theory-based research. [Editorial]. Advances in Health Sciences Education, 9(3), 175-178.

Page, G., Bordage, G., \& Allen, T. (1995). Developing key-feature problems and examinations to assess clinical decision-making skills. Academic Medicine, 70(3), 194-201.

Parlett, M. (1969). Undergraduate teaching observed. Nature, 223(5211), 1102-1104.

Prideaux, D., \& Bligh, J. (2002). Research in medical education: Asking the right questions. [Editorial]. Medical Education, 36(12), 1114-1115.

Prochaska, J. O., Wright, J. A., \& Velicer, W. F. (2008). Evaluating theories of health behavior change: A hierarchy of criteria applied to the transtheoretical model. Applied Psychology, 57(4), 561-588.

Ramsden, P. (1984). The context of learning. In F. Marton, D. Hounsell \& N. J. Entwistle (Eds.), The experience of learning (pp. 144-164). Edinburgh: Scottish Academic Press.

Ross, M. E., Green, S., Salisbury-Glennon, J. D., \& Tollefson, N. (2006). College students' study strategies as a function of testing: An investigation into metacognitive self-regulation. Innovative Higher Education, 30(5), 361-375.

Ross, M. E., Salisbury-Glennon, J. D., Guarino, A., Reed, C. J., \& Marshall, M. (2003). Situated selfregulation: Modeling the interrelationships among instruction, assessment, learning strategies and academic performance. Educational Research and Evaluation, 9(2), 189-209.

Sambell, K., \& McDowell, L. (1998). The construction of the hidden curriculum: Messages and meanings in the assessment of student learning. Assessment \& Evaluation in Higher Education, 23(4), 391-402.

Sambell, K., McDowell, L., \& Brown, S. (1997). 'But is it fair?': An exploratory study of student perceptions of the consequential validity of assessment. Studies in Educational Evaluation, 23(4), 349-371.

Snyder, B. R. (1971). The hidden curriculum. New York: Alfred A. Knopf.

Sundre, D. L., \& Kitsantas, A. (2004). An exploration of the psychology of the examinee: Can examinee self-regulation and test-taking motivation predict consequential and non-consequential test performance? Contemporary Educational Psychology, 29(1), 6-26.

Thomson, K., \& Falchikov, N. (1998). 'Full on until the sun comes out': The effects of assessment on student approaches to studying. Assessment \& Evaluation in Higher Education, 23(4), 379-390.

van Etten, S., Freebern, G., \& Pressley, M. (1997). College students' beliefs about exam preparation. Contemporary Educational Psychology, 22(2), 192-212. 



\section{CHAPTER 6}

Generalizability Findings for a Model of the Pre-assessment Learning Effects of Assessment in New Contexts 


\begin{abstract}
The belief that assessment drives learning yields the ambition to drive learning using assessment. Interventions based on a validated model should produce better outcomes than efforts based on weaker theory. Despite extensive literature on the topic, no validated model explaining the learning effects of assessment exists. Before using a recently developed model to inform interventions, it needs to be validated. The purpose of this study was to explore whether we could replicate tentative generalizability findings related to the model in novel assessment contexts. Cross-sectional surveys of 419 students at 2 universities were undertaken, using a purpose-made questionnaire comprising written situational tests. For stringency, the model's 21 weakest associations between assessment factors and learning effects were investigated. Thirteen of these associations were significant $(p<0.00625)$. The role of 7 of 8 assessment factors, 7 of 8 learning effects and all 10 mechanism factors investigated, were substantiated. Four mechanism factors (agency, response efficacy, response value and impact appraisal) together mediated most associations. The support for many of the model's weakest associations bodes well for future studies of the stronger associations. Although model validation is an on-going process, these results move the model one step closer to the stage of usefully informing interventions.
\end{abstract}

Under editorial review:

Cilliers, F. J., Schuwirth, L. W. T., Pickworth, G. E., Burch, V. C., \& van der Vleuten, C. P. M. Generalizability findings for a model of the pre-assessment learning effects of assessment in new contexts. 


\title{
Introduction
}

Using a theoretical model to inform the design of interventions should ideally result in more successful interventions than would otherwise be the case (Lippke \& Ziegelmann, 2008; Prochaska, Wright, \& Velicer, 2008). Lippke \& Ziegelmann (2008, p. 698, p. 698) put it thus:

\begin{abstract}
Theories need to specify a set of changeable predictors to describe, explain, and predict behaviour change, and they should enable us to design an effective intervention that produces exactly those changes in behaviour that are predicted by the relevant theory. To make this possible, theories need to be specified in such a way that they can be rigorously tested and falsified. Moreover, for the design of theorybased interventions it must be possible to derive change techniques from the theory and to use them to generate changes in behaviour.
\end{abstract}

A validated model allows for theoretically informed prediction during design of interventions and for meaningful explanation of observations during the study of interventions. Ultimately, a validated model should be shown to have utility, efficacy and impact (Prochaska et al., 2008).

The opinion that assessment drives learning is widely shared, as is the resultant desire to use assessment-based interventions to influence student learning behaviour. At first glance, such interventions would appear to have a rich literature to draw on - much effort over a long period of time has been devoted to exploring the learning effects of assessment (Abd El Fattah, 2011; Jones, 1923). Exploring this literature leads to a curious revelation, however, particularly if one's interest is in the so-called pre-assessment (Dochy, Segers, Gijbels, \& Struyven, 2007) learning effects of assessment.

Pre-assessment learning effects (e.g., effects on study behaviour) accrue prior to an assessment event. Post- and pure assessment learning effects, on the other hand, accrue after (e.g., in response to feedback) and during (e.g., the testing effect (Roediger \& Butler, 2011) or constructing a portfolio) assessment respectively. Notwithstanding the extent of the literature relating assessment and learning, few theoretical frameworks have been advanced to explain - rather than just describe the pre-assessment learning effects of assessment.

Self-regulation theory has enjoyed some attention (Ross, Green, Salisbury-Glennon, \& Tollefson, 2006; Ross, Salisbury-Glennon, Guarino, Reed, \& Marshall, 2003; Sundre \& Kitsantas, 2004; van Etten, Freebern, \& Pressley, 1997). Broekkamp \& van Hout-Wolters (2007) and van Etten et al. (1997) both proposed models relating assessment and learning. However, none of these frameworks or models has been validated, nor - judging by citation patterns - have any gained traction to successfully inform interventions to influence learning using assessment. 


\section{ASSESSMENT FACTORS}

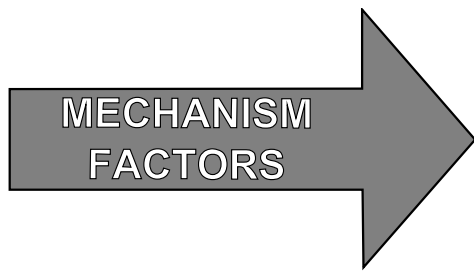

LEARNING EFFECTS

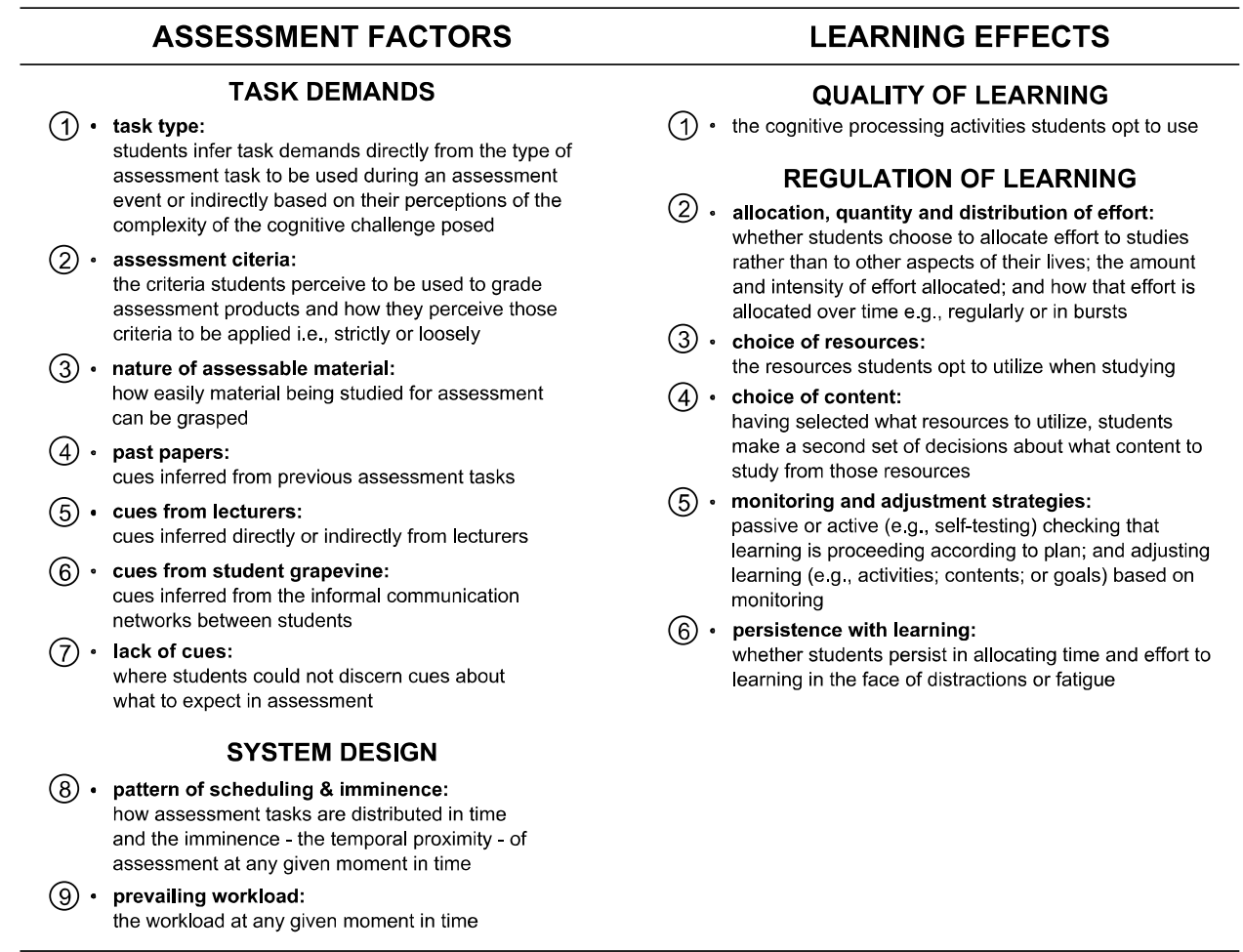

MECHANISM FACTORS

IMPACT APPRAISAL

(1) impact likelihood:

how likely consequences are to accrue

(2) - impact magnitude:

what the magnitude of consequences (negative or positive) is likely to be

(3) - response efficacy:

RESPONSE APPRAISAL

the perceived efficacy of any given learning response in achieving a particular outcome

(4) response costs:

the costs of any given learning response; costs can be incurred by responding, or not, to assessment, and can be internal or external to the student

(5) response value:

the value of any given learning response as measured against the student's personal goals and their conceptions of success and wellness

\section{PERCEIVED AGENCY}

6) - the perception of being able to exert some control over a situation, even in the face of adversity

\section{INTERPERSONAL FACTORS}

- normative beliefs

the beliefs of referents (people whose opinion a student values) against which a student can calibrate her/his behaviour

(7) (i) of lecturers

(8) (ii) of other students

- motivation to comply:

students' motivation to comply with normative beliefs

(9) (i) of lecturers

(10) (ii) of other students 
Intrigued by this state of affairs, we set out in a previous study to design a theoretical model to better understand the pre-assessment learning effects of assessment. Rather than attempting to apply or adapt one or other existing framework, we opted to start with a clean slate. We adopted a grounded theory approach and subsequently posited a novel mechanism linking assessment factors and learning effects (Cilliers, Schuwirth, Adendorff, Herman, \& van der Vleuten, 2010). We then described the development of a model of the pre-assessment learning effects of summative assessment (Figure 1) (Cilliers, Schuwirth, Herman, Adendorff, \& van der Vleuten, 2012).

Before trying to utilise this model to guide interventions, we initiated a process to first validate it. A subsequent paper (Cilliers, Schuwirth, \& van der Vleuten, 2012) replicated the findings of the first two within the same institutional culture but in a different part of the curriculum. We showed how, for the same group of respondents as were involved in the derivation of the model, the model was operational in a clinical assessment setting as distinct from the theory assessment setting in which the model was first described. In a later study (Cilliers, Schuwirth, \& van der Vleuten, in press), we explored the generalizability of the model. We showed that the weakest associations in the model still held in a population similar to but broader than that from which the model was derived.

The logical next step is now to explore whether the findings relating to the generalizability of the model can be replicated in other contexts. The purpose of this study was thus to explore whether we could replicate the initial generalizability findings in institutional assessment cultures other than that in which the model was derived. To do this, we undertook a cross-sectional survey using a purpose-made instrument comprising written situational tests. In these tests, the choices that respondents were required to make allowed us to explore how the components of the model are connected.

Figure 1: Model of the pre-assessment learning effects of consequential assessment for a theory context 


\section{Methods}

\section{Instruments}

Two purpose-made instruments designed for a previous study were used (available from author FJC). The instruments comprised pairs of written situational tests constructed using the logic of the key-features approach (Page, Bordage, \& Allen, 1995). Each item in a pair comprised three parts i.e., a vignette and two option sets. Each vignette depicted an assessment factor in a scenario derived from the baseline qualitative work (Cilliers et al., 2010; Cilliers, Schuwirth, Herman, et al., 2012). The way that this assessment factor was depicted was varied from one item to the next in each item-pair (see vignettes in Exhibit 1).

\section{Exhibit 1. Example of a pair of situational tests.}

This item-pair addresses the influence of "nature of assessable material" (assessment factor) on "distribution of effort" (learning effect). Each vignette and the associated option sets were presented individually to respondents, not paired as illustrated here.

\begin{tabular}{|c|c|c|}
\hline $\begin{array}{l}\text { Vignette depicting } \\
\text { assessment factor }\end{array}$ & $\begin{array}{l}\text { Vignette } 1 \\
\text { It is the middle of the first semester. } \\
\text { You are at the start of a four-week } \\
\text { theory module. The material being } \\
\text { covered in the module is not as dense } \\
\text { with facts as other modules you have } \\
\text { done and seems easy enough to un- } \\
\text { derstand. The hand-outs that the } \\
\text { lecturer has given you are mostly } \\
\text { copies of articles or book chapters. }\end{array}$ & $\begin{array}{l}\text { Vignette } 2 \\
\text { It is the middle of the first semester. } \\
\text { You are at the start of a four-week } \\
\text { theory module. The material being } \\
\text { covered in the module is quite dense } \\
\text { with facts. You are given hand-outs at } \\
\text { every lecture that are copies of Pow- } \\
\text { erPoint slides the lecturer uses in class. }\end{array}$ \\
\hline & \multicolumn{2}{|c|}{$\begin{array}{l}\text { When you decide how to spend your time studying for this module, what are you } \\
\text { most likely to do? } \\
\text { Select the one choice that best applies } \\
\text { a. I will start studying seriously for the test at the same time as I usually would } \\
\text { b. I will postpone starting to study seriously for the test longer than I usually } \\
\text { would } \\
\text { c. I will start studying seriously for the test earlier than I usually would }\end{array}$} \\
\hline & \multicolumn{2}{|c|}{$\begin{array}{l}\text { Which of the following best explains your decision making? } \\
\text { Although more than one option may be applicable, please select the one option } \\
\text { that best applies to you. } \\
\text { a. Nothing bad will happen to me academically if I do this } \\
\text { b. There is too much at stake to risk doing badly or failing } \\
\text { c. Doing this is necessary to get a result I'm comfortable with } \\
\text { d. It's not worthwhile letting my life get out of balance } \\
\text { e. It is important to me to do well: I don't want to do badly or fail } \\
\text { f. I believe that I'm capable of doing well enough under these circumstances if } \\
\text { I do this } \\
\text { g. I have heard from other students that if I do this, I will do well enough } \\
\text { h. Lecturers emphasise the importance of this } \\
\text { i. It is worth taking guidance from my fellow students } \\
\text { j. I value the opinion of lecturers who teach this module }\end{array}$} \\
\hline
\end{tabular}


The two option sets comprised learning effects and mechanism factors respectively. For each vignette, respondents were instructed to select the one learning effect that best applied to them for that scenario and the one mechanism factor that best explained why that learning effect was selected. We were thus able to investigate how variations in the manifestation of individual assessment factors influenced the learning effect and mechanism factor at play.

The instruments included one pair of items for each of the 21 associations under study. To limit testing time to \pm 20 minutes, items were divided into two instruments of 10 and 11 item-pairs respectively, each with a similar reading load. Given that incomplete responses could be utilised for analysis (see below), two versions of each instrument were prepared, with the order in which item-pairs were presented in the second reversed as compared to the first. This was done to ensure the maximum number of responses to each item-pair in the event that respondents started, but did not complete, an instrument.

Respondents self-reported their average marks in the course up to that point, whether they had previously failed a module and their gender, to allow a check of the representativeness of the sample.

\section{Population, data collection and ethical considerations}

All fourth-year medical students at the universities of Cape Town (UCT) ( $n=186)$ and Pretoria (UP) $(n=228)$ were surveyed. Fourth-year students were selected as they have typically experienced a wide range of assessment during the course of their studies up to that point. The assessment regimes at UCT and UP are quite distinct from that at Stellenbosch University (SU), where the model was derived and has been tested thus far.

At SU, students do alternating four-week modules in clinical theory and clinical practice. They must obtain a score of at least $40 \%$ at the end of each clinical theory module to gain admission to the year-end examination in that module and must pass examinations in all modules to progress to the fifth year of study. Students must pass all clinical practice modules to progress to the next year of study. There is no year-end assessment for clinical practice modules. At UCT, students' progression from year 4 to year 5 of the programme is determined by a year mark comprising three components. The first component is the average of students' scores in assessments (clinical and ECG/x-ray interpretation) at the end of a series of blocks during the year that integrate clinical theory and clinical practice. Students participate in year-end assessments irrespective of their score on individual blocks. The second component is a score derived from a year-end oral assessment based on a portfolio that students develop during the course of the year. The third component is a theory assessment also at year-end. At UP, students also do blocks that integrate clinical theory and clinical practice. They do separate theory and clinical assessments for each block, however. If their average score is $>60 \%$, they are not 
required to participate in year-end assessment for that block. If they score $<60 \%$, they participate in year-end assessment that comprises clinical theory and clinical assessment components.

Students were surveyed electronically using an in-house survey instrument based on Checkbox v4.6.4.7 (Checkbox Survey Solutions, Inc., 2009). Students were randomly allocated to complete a version of instrument 1 or instrument 2 . Surveys were delivered electronically to email addresses used by the respective institutions to communicate with students. Efforts were made to maximise response rates (Dillman, Smyth, \& Christian, 2009; Göritz, 2006; Huang, Hubbard, \& Mulvey, 2003), including offering students the opportunity of being included in a draw for 35 vouchers to the value of \pm US $\$ 20$ each. To preserve anonymity, respondents linked to a separate, unrelated survey from the last page of the data collection survey to provide contact details for the draw.

Ethical approval was obtained from each institution involved and informed consent from participants.

\section{Data analysis}

To determine whether there was a significant change in learning effect from one scenario to the next in each item-pair, the $\chi^{2}$ statistic was calculated. Based on the baseline qualitative data, the most likely effect in each scenario was identified; other responses were collapsed to generate a $2 \times 2$ table for analysis. Given the large number of associations being explored, an adjusted alpha was calculated using Holm's variant of the Bonferroni adjustment. $p<0.00625$ was considered significant. A sign test was also performed to determine whether the number of significant associations was greater than would be the case by chance alone.

Once significant associations had been identified, the individual assessment factors and learning effects that were and were not involved in significant associations were recorded.

Varying numbers of responses were obtained for individual item-pairs, given that some respondents started, but did not complete, an instrument. However, since each item-pair was essentially an individual study of the associations between an assessment factor, a learning effect and the set of mechanism factors, this did not pose a problem for analysis.

The frequency with which mechanism factors were selected was tabulated as was the frequency with which respondents changed their choice of mechanism factors from one scenario to the next in item-pairs.

The $\chi^{2}$ statistic was calculated to compare respondents in terms of institution, whether they had ever failed a module and their gender. $p<0.05$ was considered significant. 
Analyses were performed using Statistica data analysis software (StatSoft, Inc., Tulsa, USA, 2011, version 10).

\section{Results}

\section{Response rates and respondent profile}

Table 1: $\quad$ Response rates and gender of respondents.

\begin{tabular}{|c|c|c|c|c|c|c|}
\hline \multirow{2}{*}{ INSTRUMENT } & \multirow{2}{*}{ INSTITUTION } & \multirow{2}{*}{$\mathbf{N}$} & \multicolumn{3}{|c|}{ RESPONDENTS } & \multirow{2}{*}{ RESPONSE RATE } \\
\hline & & & Female & Male & Total & \\
\hline \multirow{3}{*}{1} & UCT & 92 & 25 & 15 & 40 & $43.5 \%$ \\
\hline & UP & 115 & 28 & 18 & 46 & $40.0 \%$ \\
\hline & Total & 207 & 53 & 33 & 86 & $41.5 \%$ \\
\hline \multirow{3}{*}{2} & UCT & 94 & 14 & 15 & 29 & $30.9 \%$ \\
\hline & UP & 113 & 39 & 17 & 56 & $50.0 \%$ \\
\hline & Total & 207 & 53 & 32 & 85 & $41.1 \%$ \\
\hline
\end{tabular}

Response rates are summarised in Table 1 . Eighty-six students responded to $\geq 1$ item-pairs for instrument 1, 85 for instrument 2. As not all students provided responses to all items, the number of responses per item varies (Table 3 ).

Distribution of respondents between the two institutions and between the two instruments was similar as regards gender (Table 1) and academic performance (Table 2) ( $p>0.05$ for $\chi^{2}$ ). Furthermore, there were only small differences in results between institutions, so for the sake of simplicity, data will be reported for both combined.

Table 2: $\quad$ Academic performance of respondents.

Average: Self-reported average score for programme as a whole

\begin{tabular}{|c|c|c|c|c|}
\hline \multirow[b]{2}{*}{ INSTRUMENT } & \multicolumn{4}{|c|}{ RESPONDENTS } \\
\hline & Institution & $\begin{array}{l}\text { Failed } \geq 1 \\
\text { modules }\end{array}$ & $\begin{array}{l}\text { Number } \\
\text { (\% of total) }\end{array}$ & Average (SD) \\
\hline \multirow{7}{*}{1} & \multirow{3}{*}{ UCT } & No & 21 & $69.4(4.5)$ \\
\hline & & Yes & 19 & $64.6(10.4)$ \\
\hline & & Subtotal & 40 (29.0\%) & $67.1(8.2)$ \\
\hline & \multirow{3}{*}{ UP } & No & 26 & $71.9(5.3)$ \\
\hline & & Yes & 20 & $65.6(11.6)$ \\
\hline & & Subtotal & $46(33.3 \%)$ & $69.1(9.1)$ \\
\hline & Total & & 86 & $68.2(8.7)$ \\
\hline \multirow{7}{*}{2} & \multirow{3}{*}{ UCT } & No & 14 & $71.7(5.8)$ \\
\hline & & Yes & 15 & $62.3(4.8)$ \\
\hline & & Subtotal & $29(21.6 \%)$ & $66.8(7.1)$ \\
\hline & \multirow{3}{*}{ UP } & No & 27 & $71.2(4.4)$ \\
\hline & & Yes & 29 & $67.1(5.1)$ \\
\hline & & Subtotal & $56(41.8 \%)$ & $69.1(5.2)$ \\
\hline & Total & & 85 & $68.3(5.9)$ \\
\hline
\end{tabular}



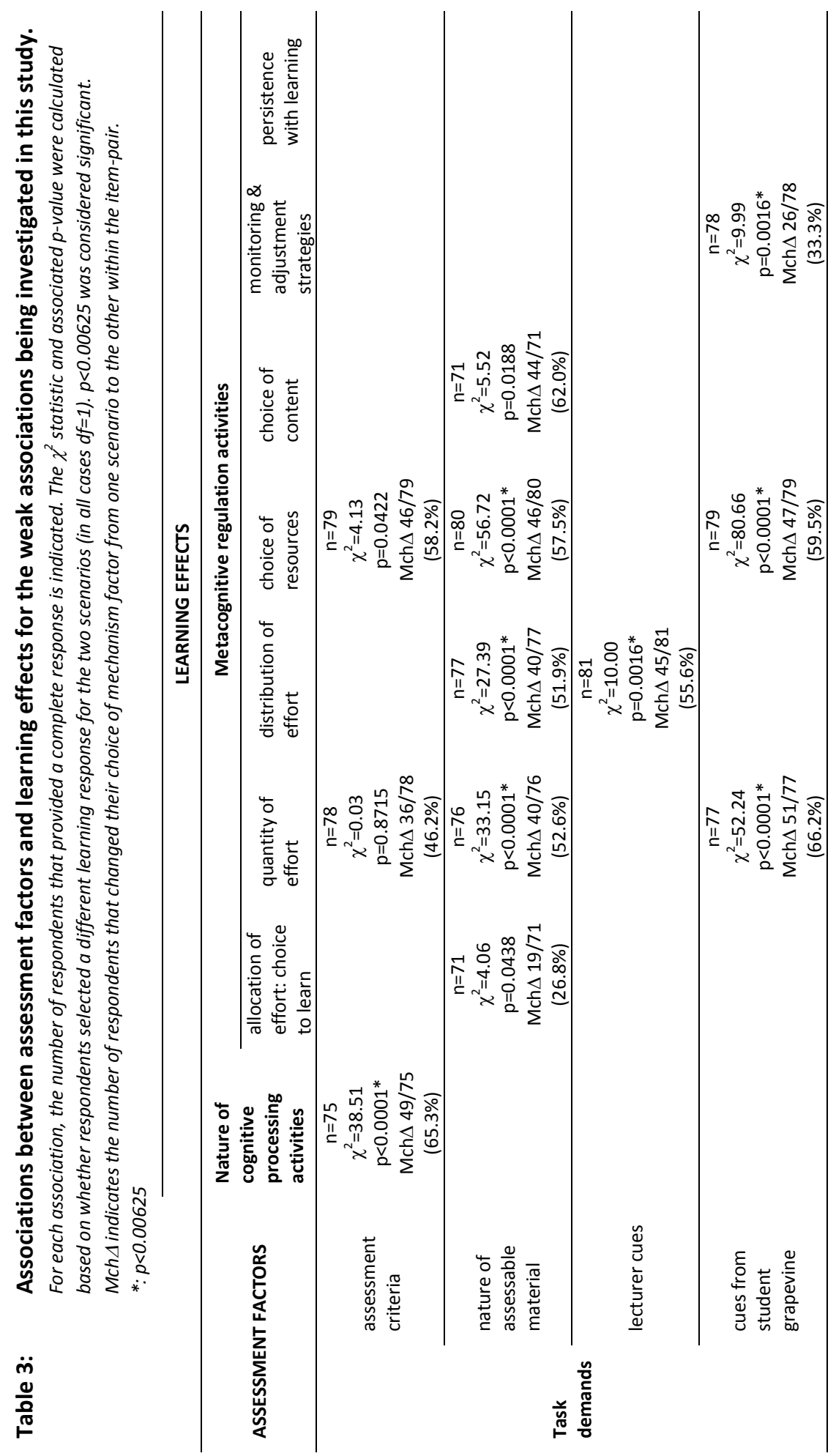


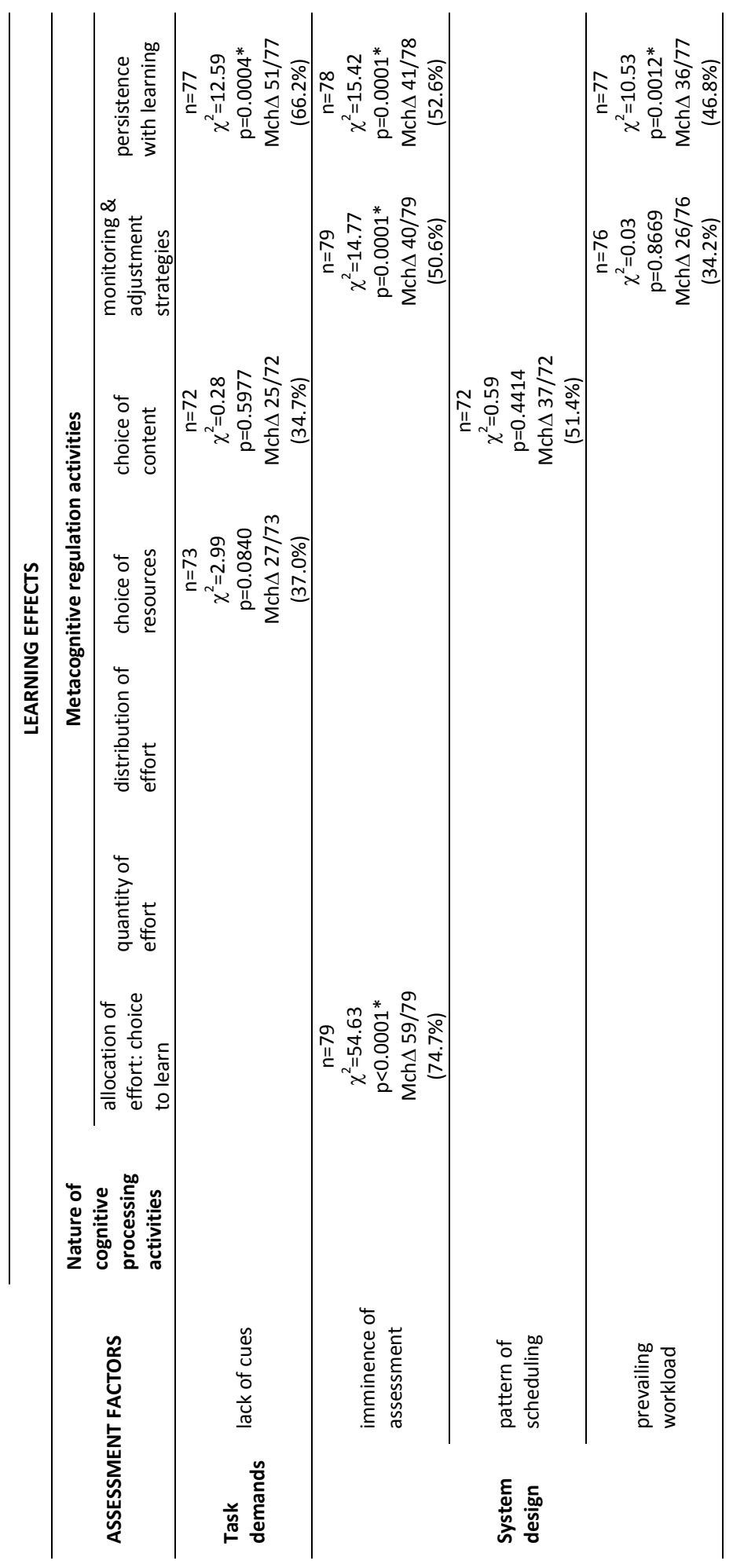




\section{Association between assessment factors and learning effects}

Of this weakest subset of associations, $13 / 21$ were significant $(p<0.00625)$ (Table 3$)$, a greater number than would be expected by chance (sign test $Z=3.33 ; p=0.0009$ ). This supports the role of most of this weakest subset of associations in these new contexts. Seven out of eight assessment factors - the exception was "pattern of scheduling" - and seven out of eight learning effects - the exception was "choice of content" - were involved in $\geq 1$ significant associations (Table 3 ). This supports the role of almost all assessment factors and learning effects in these new contexts.

\section{Role of mechanism factors}

Overall, agency (22.3\%), response efficacy (19.0\%), response value $(12.9 \%)$ and impact appraisal (11.7\%) accounted for two-thirds of mechanism options selected across all scenarios by respondents (Table 4).

Table 4: $\quad$ Frequency with which individual mechanism options were selected overall

\begin{tabular}{|c|c|c|c|}
\hline & & & \\
\hline & UCT & UP & Total \\
\hline $\begin{array}{l}\text { Mechanism factor } \\
\text { Item wording }\end{array}$ & n (\%) & n (\%) & n (\%) \\
\hline $\begin{array}{l}\text { a. Impact appraisal } \\
\text { Nothing bad will happen to me academically if I do this }\end{array}$ & 81 (10.1) & $121(13.1)$ & 202 (11.7) \\
\hline $\begin{array}{l}\text { b. Impact severity } \\
\text { There is too much at stake to risk doing badly or failing }\end{array}$ & $107(13.3)$ & $80(8.6)$ & $187(10.8)$ \\
\hline $\begin{array}{l}\text { c. Response efficacy } \\
\text { Doing this is necessary to get a result I'm comfortable with }\end{array}$ & $184(22.9)$ & $145(15.7)$ & $329(19.0)$ \\
\hline $\begin{array}{l}\text { d. Response costs } \\
\text { It's not worthwhile letting my life get out of balance }\end{array}$ & $59(7.4)$ & $87(9.4)$ & $146(8.4)$ \\
\hline $\begin{array}{l}\text { e. Response value } \\
\text { It is important to me to do well: I don't want to do badly or } \\
\text { fail }\end{array}$ & $107(13.3)$ & $116(12.5)$ & $223(12.9)$ \\
\hline $\begin{array}{l}\text { f. Agency } \\
\text { I believe that I'm capable of doing well enough under these } \\
\text { circumstances if I do this }\end{array}$ & $159(19.8)$ & $226(24.4)$ & $385(22.3)$ \\
\hline $\begin{array}{l}\text { g. Interpersonal factors: Normative beliefs: Peers } \\
\text { I have heard from other students that if I do this, I will do } \\
\text { well enough }\end{array}$ & $25(3.1)$ & $52(5.6)$ & $77(4.5)$ \\
\hline $\begin{array}{l}\text { h. Interpersonal factors: Normative beliefs: Lecturers } \\
\text { Lecturers emphasise the importance of this }\end{array}$ & $22(2.7)$ & $25(2.7)$ & $47(2.7)$ \\
\hline $\begin{array}{l}\text { i. Motivation to comply with normative beliefs: Peers } \\
\text { It is worth taking guidance from my fellow students }\end{array}$ & $46(5.7)$ & $42(4.5)$ & $88(5.1)$ \\
\hline $\begin{array}{l}\text { j. Motivation to comply with normative beliefs: Lecturers } \\
\text { I value the opinion of lecturers who teach this module }\end{array}$ & $12(1.5)$ & $32(3.5)$ & $44(2.5)$ \\
\hline Totals- $\mathbf{n}(\%)$ & $802(100)$ & $926(100)$ & $1728(100)$ \\
\hline
\end{tabular}




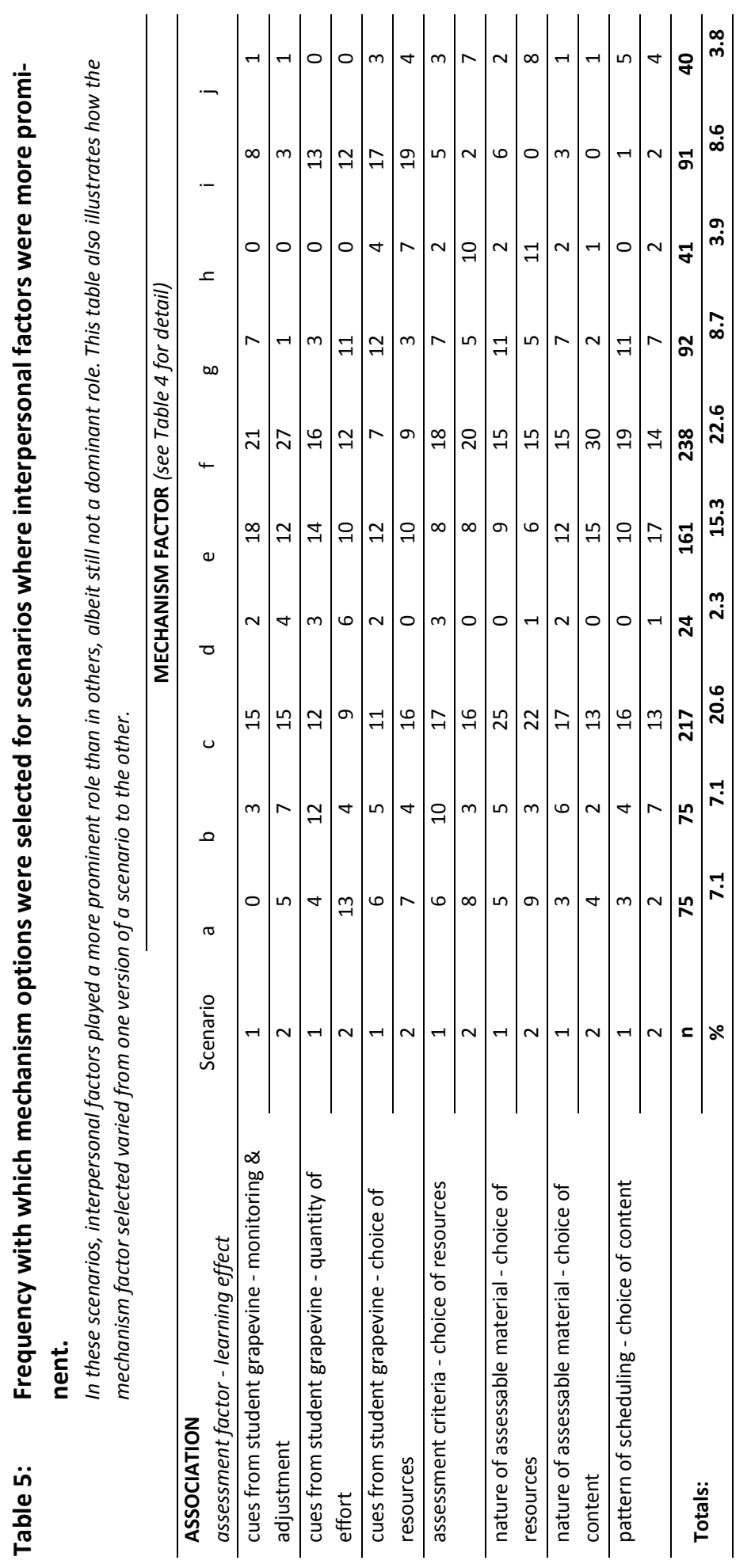


All other mechanism options played a role too, however. Overall, the four options relating to interpersonal factors i.e., perceptions of the beliefs of lecturers and of fellow students and motivation to comply with those respective beliefs, were selected least frequently. There were scenarios where these factors featured more prominently, though (Table 5). All three scenarios where cues from the student grapevine was the assessment factor were in this group. Three out of four scenarios where choice of resources was the learning effect and two out of three scenarios where choice of content was the learning effect were also in this group.

Further support for the role of the mechanism factors stems from evidence that different mechanism factors were at play for individual respondents as the manifestation of assessment factors changed. The mechanism factor selected by respondents changed from one scenario to the next in an item-pair in between $26.8 \%-74.7 \%$ of cases (Table 3). More detailed examples of these changes in individual scenarios are illustrated in Table 5.

Together, this data supports the role of all mechanism factors in these new contexts.

\section{Discussion}

The purpose of this study was to explore whether earlier generalizability findings could be replicated in institutional assessment cultures other than that in which the model was derived. The elements under investigation were the subset of weakest associations between assessment factors and learning effects in the model and the individual factors involved. We have been able to find support for most of the associations and factors involved in two institutions with different assessment programmes to that at which the model was derived.

For respondents from the two new institutions, 13/21 associations were significant. Of these, eleven associations were common to these results and the results of a previous study at Stellenbosch University (Cilliers et al., in press). This suggest that these eleven are the most robust of this subset of weakest associations. While the other four associations that were significant in the respective studies but not common across the studies clearly play a role in certain contexts, they are more variable in their manifestation. More information is needed about what contextual factors influence the manifestation of these associations. In the meantime, it would be unwise to ignore these associations as they could bedevil findings related to an intervention if that intervention is carried out in a context that happens to foreground these associations.

The substantial role documented previously (Cilliers et al., in press) for three of the mechanism factors in the model i.e., agency, response efficacy and response value is supported by this study. It will be interesting to see whether these 
three factors are also dominant when the stronger associations in the model are studied. Of these three factors, response efficacy is perhaps most amenable to interventions. Ensuring that the various elements related to an assessment task require good quality learning from students to perform well will hopefully help promote desirable learning behaviours.

Prochaska et al (2008) hold that a model should explain a phenomenon in "the least complex manner possible" (p565), the principle of parsimony. While the multifaceted nature of our model makes it somewhat complex, this complexity appears to be relevant. This is demonstrated in how the role of seemingly "minor" mechanism factors, specifically normative beliefs and motivation to comply with those, was verified in specific scenarios. Contemplating the overall slight contribution of these factors alone might lead one to conclude that they could safely be discarded, yet these results illustrate how that would detract from the value and versatility of the model.

While supporting many associations, this study now adds further evidence potentially falsifying the role of six non-significant associations to that documented previously (Cilliers et al., in press). Before concluding that these associations are not worth exploring further, however, more research into why these associations did not feature, specifically studies with greater sensitivity.

Data was generated for this study by way of self-reporting rather than observation of learning behaviours. Respondents might have yielded to the temptation of selecting options they believed to be more functional than their actual learning behaviours (Callahan, Hojat, \& Gonnella, 2007). The fact that the instruments were administered electronically and anonymously hopefully counteracted this tendency somewhat.

We have also previously expressed our concern that the instruments we have utilised (of necessity) cannot represent the complex interactions between multiple factors that were evident in the qualitative studies (Cilliers et al., 2010; Cilliers, Schuwirth, Herman, et al., 2012) that informed the development of these instruments. We do believe, however, that the paired-scenario approach we have developed allows us to explore the learning effects of assessment in a way that was not previously possible.

The findings of this study are limited to two medical schools in South Africa, each with distinct assessment regimes. The generalizability of these findings to medical schools with other assessment regimes, in South Africa and beyond, remains to be ascertained. Such studies are not considered a priority, however, as the role of this study was to garner validity evidence for certain elements in the model beyond the immediate context where it was developed. Having generated evidence supporting many of the weakest associations in the model, we believe there are now good grounds to infer that the model as a whole is likely to prove valid and hence is worth investigating further. The priority now is to undertake studies of the strongest asso- 
ciations. These studies should include students from medical schools using a variety of assessment regimes, expanding to include a range of countries, to explore the broader generalizability of the model. Data from those studies will also provide a better basis for experimental studies designed to positively influence preassessment learning with assessment.

For this subset of weakest associations, the findings reported here specifically support the role of the nature of assessable material - and the assessment-related inferences that students draw from that - that of imminence of assessment and that of cues from the student grapevine in influencing learning effects of assessment. Learning effects related to these factors need to be considered when designing assessment programmes in addition to those related to factors more typically considered like task type. None of these factors has been systematically studied before - their effects have only been documented piecemeal in mostly qualitative studies (Becker, Geer, \& Hughes, 1968; Broekkamp \& van Hout-Wolters, 2007; Miller \& Parlett, 1974; Sambell, McDowell, \& Brown, 1997; Snyder, 1971; Thomson \& Falchikov, 1998; van Etten et al., 1997). Experiments in controlled settings would typically not illuminate the role of either the student grapevine or that of imminence unless these factors were the specific issue being studied, perhaps explaining the dearth of literature on these two factors. The nature of assessable material has not been studied as an assessment factor in depth either, yet these results suggest that it has a substantial influence on students' assessment-related decisions.

Apart from planning the scheduling of assessment - and thus when it is imminent the factor of those studied that is most under the control of teachers is the nature of material that students use when preparing for assessment. Most teachers probably do not contemplate this when designing assessment, but rather when designing instruction. The results of this study suggest that this should change and that careful attention be paid the nature and amount of learning material to which students are exposed, not only in terms of relevance to the intended outcomes of instruction, but also in terms of the influence on students' pre-assessment learning.

The information network that is the student grapevine transmits a mixture of fact, fiction and mythology nourished by students' experiences and (mis)perceptions over time. This content may be transmitted by word of mouth or, probably increasingly, using online platforms. Its very nature likely puts it beyond the direct control of teachers, and studies aimed at understanding how it operates are probably requisite to attempts to influence it. Nonetheless, its influence cannot be ignored. In the interim, one approach could be to try and influence what is being fed into the student grapevine by educating students as to the purposes of the assessment programme and the way the assessment processes are aligned to attain this. This would require clarity of purpose among lecturers, careful explication of this purpose and careful planning and execution of an assessment programme.

The weakest associations in the model have now been investigated quantitatively at the institution where the model was developed (Cilliers et al., in press) and two 
other institutions (this study). The support for these associations and the components of the model involved that has been documented in these two studies bodes well for future studies of the stronger associations in the model. As the chain of validity evidence supporting the model slowly grows, researchers and practitioners are hopefully ever better positioned to design theory-driven studies and interventions. 


\section{References}

Abd El Fattah, S. M. (2011). The effect of test expectations on study strategies and test performance: A metacognitive perspective. Educational Psychology, 31(4), 497-511.

Becker, H. S., Geer, B., \& Hughes, E. C. (1968). Making the grade: The academic side of college life. New York: John Wiley \& Sons, Inc.

Broekkamp, H., \& van Hout-Wolters, B. H. A. M. (2007). Students' adaptation of study strategies when preparing for classroom tests. Educational Psychology Review, 19(4), 401-428.

Callahan, C. A., Hojat, M., \& Gonnella, J. S. (2007). Volunteer bias in medical education research: An empirical study of over three decades of longitudinal data. Medical Education, 41(8), 746-753.

Cilliers, F. J., Schuwirth, L. W. T., Adendorff, H. J., Herman, N., \& van der Vleuten, C. P. M. (2010). The mechanism of impact of summative assessment on medical students' learning. Advances in Health Sciences Education, 15(5), 695-715.

Cilliers, F. J., Schuwirth, L. W. T., Herman, N., Adendorff, H., \& van der Vleuten, C. P. M. (2012). A model of the pre-assessment learning effects of summative assessment in medical education. Advances in Health Sciences Education, 17(1), 39-53.

Cilliers, F. J., Schuwirth, L. W. T., \& van der Vleuten, C. P. M. (2012). A model of the pre-assessment learning effects of assessment is operational in an undergraduate clinical context. BMC Medical Education, 12.

Cilliers, F. J., Schuwirth, L. W. T., \& van der Vleuten, C. P. M. (in press). Modelling the pre-assessment learning effects of assessment: Evidence in the validity chain. Medical Education. doi: 10.1111/ j.1365-2923.2012.04334.x

Dillman, D. A., Smyth, J. D., \& Christian, L. M. (2009). The tailored design method Internet, mail, and mixed-mode surveys: The tailored design method (3rd ed.). Hoboken, New Jersey: John Wiley \& Sons, Inc.

Dochy, F., Segers, M., Gijbels, D., \& Struyven, K. (2007). Assessment engineering: Breaking down barriers between teaching and learning, and assessment. In D. Boud \& N. Falchikov (Eds.), Rethinking assessment in higher education: Learning for the longer term (pp. 87-100). Oxford: Routledge.

Göritz, A. S. (2006). Incentives in web studies: Methodological issues and a review. International Journal of Internet Science, 1(1), 58-70.

Huang, J. Y., Hubbard, S. M., \& Mulvey, K. P. (2003). Obtaining valid response rates: Considerations beyond the tailored design method. Evaluation and Program Planning, 26(1), 91-97.

Jones, H. E. (1923). Experimental studies of college teaching: The effect of examination on the permanence of learning. Archives of Psychology, 10, 1-70.

Lippke, S., \& Ziegelmann, J. P. (2008). Theory-based health behavior change: Developing, testing, and applying theories for evidence-based interventions. Applied Psychology, 57(4), 698-716.

Miller, C. M. L., \& Parlett, M. (1974). Up to the mark: A study of the examination game. London: Society for Research into Higher Education.

Page, G., Bordage, G., \& Allen, T. (1995). Developing key-feature problems and examinations to assess clinical decision-making skills. Academic Medicine, 70(3), 194-201.

Prochaska, J. O., Wright, J. A., \& Velicer, W. F. (2008). Evaluating theories of health behavior change: A hierarchy of criteria applied to the transtheoretical model. Applied Psychology, 57(4), 561-588.

Roediger, H. L., \& Butler, A. C. (2011). The critical role of retrieval practice in long-term retention. Trends in Cognitive Sciences, 15(1), 20-27.

Ross, M. E., Green, S., Salisbury-Glennon, J. D., \& Tollefson, N. (2006). College students' study strategies as a function of testing: An investigation into metacognitive self-regulation. Innovative Higher Education, 30(5), 361-375.

Ross, M. E., Salisbury-Glennon, J. D., Guarino, A., Reed, C. J., \& Marshall, M. (2003). Situated selfregulation: Modeling the interrelationships among instruction, assessment, learning strategies and academic performance. Educational Research and Evaluation, 9(2), 189-209. 
Sambell, K., McDowell, L., \& Brown, S. (1997). 'But is it fair?': An exploratory study of student perceptions of the consequential validity of assessment. Studies in Educational Evaluation, 23(4), 349-371.

Snyder, B. R. (1971). The hidden curriculum. New York: Alfred A. Knopf.

Sundre, D. L., \& Kitsantas, A. (2004). An exploration of the psychology of the examinee: Can examinee self-regulation and test-taking motivation predict consequential and non-consequential test performance? Contemporary Educational Psychology, 29(1), 6-26.

Thomson, K., \& Falchikov, N. (1998). 'Full on until the sun comes out': The effects of assessment on student approaches to studying. Assessment \& Evaluation in Higher Education, 23(4), 379-390.

van Etten, S., Freebern, G., \& Pressley, M. (1997). College students' beliefs about exam preparation. Contemporary Educational Psychology, 22(2), 192-212. 



\section{CHAPTER 7}

\section{General Discussion: \\ Updating the Players' Guide to the Examination Game}




\section{Introduction}

Miller and Parlett (1974) called it the Examination Game and a grand old game it is. One can only wonder how soon after the establishment of the first institutions of higher learning this game became established. Was it played over 2000 years ago at Takshashila, the Platonic Academy or the University of Nanjing? Did it originate at universities like Nalanda, Al Karaouine, Bologna, Paris or Oxford in the millennium that followed? Or is it only an artefact of more "modern" education systems such as those inhabited by Newman (1852), Osler (1913) and innumerable academics since?

Whatever its origins, it is clear from the voluminous literature exploring the relationship between assessment and learning, a literature that continues to proliferate on practical (Abd El Fattah, 2011) and theoretical (Schuwirth \& van der Vleuten, 2011) fronts, that the Examination Game is still widely played today. Yet how best to utilise what is a supposedly powerful influence on learning to positively influence student learning remains a vexed question (Joughin, 2010). In this dissertation, the argument is made that before we can more effectively and predictably utilise assessment to influence learning, we must first understand how assessment influences learning. This idea draws support from Prochaska, Wright \& Velicer (2008) who argue that "the best way to discover interventions is research based on a theory of behaviour or behaviour change" (p562). The goals of this work were therefore fourfold.

1. We were interested in discerning what components of assessment influenced what dimensions of learning in an authentic, complex system of summative assessment.

2. We also wanted to explore what mechanism was in play at the interface between assessment and learning in this assessment system.

3. Achieving these goals would allow the construction of a theoretically grounded model.

4. Finally, we wanted to take steps towards validating this model.

This series of papers first explored how assessment impacted on student learning in one higher education context, a medical school in South Africa. The professional programme that students follow has a very characteristic assessment regime. The programme is modular, with theory modules alternating with clinical modules from semester four to semester nine of the programme. Students are provided with study guides for each module that detail both intended learning outcomes and information about assessment. Summative assessment is used, repeatedly, to advance students through the programme. The initial phase of this work was qualitative and resulted in the proposal of a model linking assessment factors, mechanism 
factors and learning effects. Subsequent studies explored the validity of this model in a broader population in that same medical school, and then in two other medical schools in South Africa with assessment programmes distinct to that at the institution at which the model was derived.

In this chapter, four main findings from this work will first be discussed: 1) associations between assessment factors and learning effects are complex and contextual; 2) a novel mechanism is in play in theory and clinical assessment contexts 3) the model applies to consequential assessment rather than just summative assessment and 4) a model has been devised for which there is validity evidence. An agenda for future research will then be outlined. Finally, the limitations of this work will be discussed, before the implications of the research for practice are explored.

\section{Main findings and conclusions}

\section{Associations between assessment factors and learning effects are complex and contextual}

We identified 40 associations between assessment factors and learning effects. Some of these findings support results reported elsewhere (e.g., Broekkamp \& van Hout-Wolters, 2007; van Etten, Freebern, \& Pressley, 1997). However, having been generated by grounded theory, our findings offer a broader range of components for study than, for example, the associations between task type and learning styles that have enjoyed popularity - even dominated research - for some time (Joughin, 2010; Ross, Green, Salisbury-Glennon, \& Tollefson, 2006; Scouller, 1998; Segers, Nijhuis, \& Gijselaers, 2006; Tang, 1994).

We believe that our findings thus open potentially fruitful new avenues - new components, new associations - to explore with research. In fact, there are 400 associations that could be investigated - 40 associations between assessment factors and learning effects, each mediated by up to 10 mechanism factors. While all 400 could be systematically investigated, there are several associations amongst those we describe that appear more robust, some of which have not been well characterised in the literature previously. For example, of the weakest subset of associations studied in greater depth in Chapters Five and Six, those involving the "nature of assessable material" and "imminence of assessment" seem prominent yet have only been documented in a fragmentary fashion before (Broekkamp \& van Hout-Wolters, 2007; Miller \& Parlett, 1974; Sambell, McDowell, \& Brown, 1997; Snyder, 1971; Thomson \& Falchikov, 1998; van Etten et al., 1997). There are also a number of associations that were not significant (under the particularly stringent conditions we 
defined for significance) and that therefore appear to hold less promise to further our understanding of the pre-assessment learning effects of assessment.

Our findings emphasise just how dynamic the associations between components are, something alluded to before (Sambell \& McDowell, 1998; Sungur, 2007). Much other work exploring the influence of assessment on learning is cross-sectional, limited to a single point in time, often undertaken in controlled settings (d'Ydewalle, Swerts, \& De Corte, 1983; Feldt, 1990; Hakstian, 1971; Jersild, 1929; Ross et al., 2006; Sundre \& Kitsantas, 2004; Terry, 1933; Thiede, 1996; Vallance, 1947). Chapters Two, Three and Four explored the learning responses of students to assessment across the span of their university careers, not just at one point of intervention. Those learning responses were described in the authentic, messy, context of academic and non-academic factors in a "whole curriculum" setting; indeed, a "wholelife" setting. It was striking how, depending on the configuration of a student's motivational mosaic at any given time point, different components could be in play for a given student both at different stages of a particular assessment process and also in different assessment contexts. Different components could also be in play for different students in the same assessment context.

For example, whether assessment loomed imminent or was less prominent on the life-horizon of a student profoundly influenced her/his learning. With assessment distant, s/he was more likely to allocate effort to other aspects of her/his life and, when learning, to learn material $s /$ he was interested in or personally considered important. As assessment loomed, however, the student was more likely to seek out cues from various sources as to what was likely to feature in assessment. S/he was also more likely to abandon both learning what s/he personally considered important and learning in ways s/he considered would be of most benefit to her/his patients in the longer term in favour of learning more likely to be associated with success in assessment. These findings provide a nuanced, if partial, answer to Joughin's (2010) questions about contemporary students' cue-seeking behaviour. Our results show that assessment factors moderate both whether a student seeks cues or not and the intensity of that cue-seeking behaviour, even for students with a strong mastery goal orientation, as imminence becomes a factor and the realities of assessment loom.

\section{A novel mechanism is in play in theory and clinical assessment contexts}

In Chapter Two of the thesis, we describe a novel mechanism explaining the link between assessment factors and learning effects. This mechanism, derived using grounded theory, offers a new perspective to explaining the pre-assessment learning effects of summative assessment. Previous attempts to invoke theory have largely focussed on self-regulation theory or motivation theory (Ross et al., 2006; 
Ross, Salisbury-Glennon, Guarino, Reed, \& Marshall, 2003; Sundre \& Kitsantas, 2004; Sungur, 2007; van Etten et al., 1997) although there have been attempts to propose broader frameworks (Becker, Geer, \& Hughes, 1968; Broekkamp \& van Hout-Wolters, 2007; van Etten et al., 1997). The mechanism we propose encompasses some aspects of self-regulation theory and of motivation theory, but goes further. The constructs in the theory are not new, and trace their roots to action control theory and the many health behaviour theories (Bartholomew, Parcel, Kok, Gottlieb, \& Fernandez, 2011) that have developed from that. However, their applicability in the context of the learning effects of assessment is confirmed in the baseline work. Further support for the role of this mechanism is offered in Chapter Four, where the mechanism's operation in a clinical context is described. In Chapters Five and Six, the role of the mechanism factors is further supported by findings from a broader but similar population at the institution where the model was derived and at two other institutions in the same country with dissimilar assessment programmes.

There is only fragmentary support elsewhere in the literature for the three mechanism factors most prominent in Chapters Five and Six. Interpreting the findings of other studies yields some support for appraisal of response efficacy (Becker et al., 1968; Becker, Geer, Hughes, \& Strauss, 1961; Frederiksen, 1984; Newble \& Jaeger, 1983; Ramsden, 1984; Sambell \& McDowell, 1998; Snyder, 1971; Thomson \& Falchikov, 1998; van Etten et al., 1997), appraisal of response value (Becker et al., 1968; Miller \& Parlett, 1974; Parlett, 1969; Sambell et al., 1997; Snyder, 1971; van Etten et al., 1997) and perceptions of agency (Becker et al., 1968; Snyder, 1971; van Etten et al., 1997).

\section{The model applies to consequential assessment rather than just summative assessment}

While the model was initially conceived of as explaining the learning effects of summative assessment, as the research progressed, we came to consider the model as rather one of the learning effects of consequential assessment as we demonstrated that it is operational outside of a strictly summative assessment context (Cilliers, Schuwirth, \& van der Vleuten, 2012). Sundre \& Kitsantas $(2004$, p. 7) distinguish consequential test conditions, where assessment has "direct consequences for individuals completing them" and non-consequential test conditions, where results of assessment "have no bearing for individuals taking the test". We have illustrated how stakes in various domains including students' sense of agency, their self-esteem and emotions (Cilliers, Schuwirth, \& van der Vleuten, 2012) - and not just associated with assessment-related judgements - yielded assessment-related consequences. Conditions were clearly "consequential" even though consequences 
for performance on assessment were not the primary consideration. This transcends typical conceptions of summative assessment and associated judgementrelated consequences and makes consequential assessment a more appropriate descriptor.

\section{A model has been devised for which there is validity evidence}

In Chapter Three, a novel model was proposed linking assessment factors and learning effects in the context of consequential assessment in theoretical modules. Two things distinguish this model from other models and theoretical perspectives proposed in the past to link assessment and learning. The first is the distinctive mechanism (discussed above) that is proposed to link assessment factors and learning effects. The second is that steps have been taken to validate this model.

Of all of the theoretical perspectives advanced over the years to explain the relationship between assessment factors and learning effects (Alderson \& Wall, 1993; Becker et al., 1968; Broekkamp \& van Hout-Wolters, 2007; Ross et al., 2006; Ross et al., 2003; Sundre \& Kitsantas, 2004; van Etten et al., 1997), none has been further validated. This is problematic if the goal with describing a model is to generate a theoretical framework that can meaningfully inform practice and research. The process of validation of a theoretical model is complex and arduous. Prochaska, Wright and Velicer (2008) proposed a comprehensive hierarchy of criteria for the validation of theory, models and frameworks. It is beyond the scope of this thesis to attempt a validation that extensive. However, we have been able to generate some evidence supporting the validity of the model. An overview of what we know about the validity of the model as adjudged by these criteria will follow. However, in essence, what we set out to achieve in Chapters Four, Five and Six was to start the process of validation by seeking evidence that the model holds in new assessment contexts for the same respondents that were involved in the derivation of the model and others beyond that small group of respondents.

In Chapter Four, we showed that the model held for the same set of respondents as were involved in its derivation, but in a novel - clinical - context. Further validation posed methodological challenges, however. We wanted to show that the model was valid in a broader population to that from which it was derived but operating under the same assessment regime and in distinct assessment contexts beyond the institution in which the model was derived. Given the complexity of the model - both the high degree of interrelatedness of components and the dynamic and fluid nature of those associations - methods like factor analysis or structural equation modelling proved impracticable. We therefore had to devise a means of testing the associations and did so using situational tests with items based on the logic of the key-features approach (Bordage \& Page, 1987). 
While this solved one challenge, a further element to the complexity of the model was the high number of associations involved, potentially 400, as described above. It was not feasible to investigate all of these associations in one study. We therefore opted to study the weakest associations in the group. The reasoning behind this decision was that this stringent approach would yield the most useful information about the model. If we could show that the weakest associations in the model held in new contexts, this would be more useful than learning - as a first step - that the strongest associations in the model held. In essence, we were trying to falsify the model.

In Chapters Five and Six, then, we were able to demonstrate that the majority of the weakest associations in the model held for not only a similar but broader population subject to the same assessment regime as that under which the model was derived, but also a population of similar students from other institutions with dissimilar assessment regimes. Almost all assessment factors and learning effects were involved in these significant associations. Those that were not are involved in some of the stronger associations in the model and may yet be shown to play a significant role. We were also able to demonstrate a role for all of the mechanism factors posited in the model.

It serves to be emphasised that in assigning "significance", we opted to be particularly stringent. We used both a variant of the Bonferroni adjustment and a probabilistic (binomial) approach. Had we set significance to $p<0.05$, we would have been able to include even more associations as significant. Nonetheless, the 21 situational tests used can be considered locally independent. The model is contextual, rather than personal trait based, with the interaction between assessment factors, mechanism factors and learning effects being considered signal and not noise.

In contrast, then, to theoretical frameworks proposed in the past, we have accumulated some evidence of the validity of the model. This should help ensure that the role of the model in future assessment practice and research is clearer. If we now take an analysis of all of the data currently available about the model into consideration, what can we say about the validity of the model using Prochaska et al's (2008) twelve criteria?

\section{Clarity}

Prochaska et al (2008, p. 567) explain clarity as "that constructs are well defined and can be measured reliably and validly". In the baseline qualitative work, numerous discrete components and associations were identified (Cilliers, Schuwirth, Adendorff, Herman, \& van der Vleuten, 2010; Cilliers, Schuwirth, Herman, Adendorff, \& van der Vleuten, 2012). All components involved have been defined and summa- 
rised (Cilliers, Schuwirth, \& van der Vleuten, 2012). There is no redundancy between constructs in the model. We would argue that the model has content validity, having been derived from extensive, in-depth interviews with students. We would also argue for face validity. Students involved in pilot testing of items developed to explore the weakest associations between assessment factors and learning effects found the scenarios and option sets to be realistic (Cilliers, Schuwirth, \& van der Vleuten, under editorial review). Further evidence of face validity emanates from the responses of 50 academics from two institutions about the model in three workshops over a two year period. One institution, where teaching is typically lecture based, is in South Africa. The other institution, where problem based learning is the norm, is in the Netherlands. Academics from a range of disciplinary clusters at these universities indicated in a brief questionnaire that the model made sense, that it helped them to understand student responses to assessment and that it helped them to understand their own responses to assessment (data not shown). More informally, we have solicited responses to this data from conference audiences in the health sciences and in higher education in South African and international settings (e.g., Cilliers et al., 2008; Cilliers, Schuwirth, Adendorff, Herman, \& van der Vleuten, 2009). Participants there have invariably acknowledged the findings to represent a "recognisable reality", both from the perspective of their own experience as learners and that as lecturers.

\section{Consistency}

Consistency is defined as "that there be no internal contradictions between constructs that are otherwise clear" (Prochaska et al., 2008, p. 568). While there are no contradictions in the model thus far, there is evidence of variation in different contexts. Data reveals that one subcomponent of task demands, "past papers", plays no role in the clinical context (Cilliers, Schuwirth, \& van der Vleuten, 2012). This is logical, given that written assessment does not typically feature much as a component of clinical assessment. Equally, there was no evidence that the subcomponent "interaction with preceptors" played any role in the theory teaching context. It could be argued that there is overlap between the subcomponents "interaction with preceptors" and "cues from lecturers". Evidence thus far as to how these two constructs play out (Cilliers, Schuwirth, Herman, et al., 2012; Cilliers, Schuwirth, \& van der Vleuten, 2012) rather supports the contention that they are two distinct constructs, however.

Given the dynamic way in which the interactions between components play out in different assessment contexts and for any particular student in different contexts, we see no problem with the fact that a particular component does not feature in a given context. 
At this stage, having subjected a subset of the associations in the model to further testing, we have evidence that six of the 21 weakest associations between assessment factors and learning effects do not hold in either a broader but similar population at the institution at which the model was derived, or in similar populations at other institutions (Cilliers, Schuwirth, Pickworth, Burch, \& van der Vleuten, under editorial review; Cilliers, Schuwirth, \& van der Vleuten, under editorial review).

As far as mechanism factors go, three have been dominant in the two contexts studied (Cilliers, Schuwirth, Pickworth, et al., under editorial review; Cilliers, Schuwirth, $\&$ van der Vleuten, under editorial review). All other factors have been found to play a role, however. Some of the mechanism factors that are selected less frequently by students do manifest more prominently in certain scenarios (Cilliers, Schuwirth, Pickworth, et al., under editorial review), underlining their role in the model.

\section{Parsimony}

The principle of parsimony requires that a model "explains the phenomenon in the least complex manner possible" (Prochaska et al., 2008, p. 565). However, Prochaska et al $(2008$, p. 565) immediately add the caveat that "complexity may be desirable if a number of concepts and relationships are needed to explain and predict". There are certainly not few components and associations in this model. However, all derive from in-depth interviews with students describing their lived experience of assessment over a number of years. Research thus far has simplified the model somewhat. While the role of 11 associations between assessment factors and learning effects has been confirmed, that of six associations has been partly refuted and the role of a further four is equivocal. Even excluding these, there remain 190 threeway associations to investigate further - the 19 stronger associations between assessment factors and learning effects, each of which is in a potentially ten-way relationship with the other via the 10 components of the mechanism. Future research into these associations may decrease this number further. In addition, as noted above, these associations are dynamic, varying from one situation to another, adding further complexity. At this stage, however, it would appear that this is the most parsimonious model to describe the pre-assessment learning effects of consequential assessment.

\section{Testability - falsifiability}

Testability or falsifiability is defined as that "the propositions can be tested ... has the potential to be falsifiable or refuted" (Prochaska et al., 2008, p. 565). The components in the model and the associations between them have proved testable insofar as it was possible to generate items using the logic of the key-features approach to test the weakest associations in the model and the components involved 
(Cilliers, Schuwirth, \& van der Vleuten, under editorial review). It was also possible to generate useable data using these items, in different contexts (Cilliers, Schuwirth, Pickworth, et al., under editorial review; Cilliers, Schuwirth, \& van der Vleuten, under editorial review).

As discussed above, the role of 11 of the weakest associations in the model have been confirmed, that of six partly falsified, thus far, using this approach. None of the individual assessment factors or learning effects has yet had their role falsified. Although there was one association that could not be tested using this approach, we would argue this indicates the need to explore the development of other methods to test the association involved and, indeed, all associations, to increase the robustness of evidence generated.

\section{A. Empirical Adequacy: A) Predictive Power B) Explanatory Power}

Empirical adequacy has to do with whether a model's "theoretical claims are congruent with evidence, e.g. [retrospectively] explains why a behaviour change occurred and why it did not, and [prospectively] predicts when a behaviour change will and will not occur" (Prochaska et al., 2008, p. 565). As yet, no data has been generated relating to predictive power, which Prochaska et al characterise as the more powerful test of a model. We would posit that there is some evidence of explanatory power, however. There is fit between constructs and reality given that the propositions of the model were derived using grounded theory. The model was thus not generated through theorising but rather built based on data from respondents' lived assessment experiences in an authentic and complex setting, in the context of other academic and non-academic influences. This also gives the findings a high degree of ecological validity, something many other studies conducted in controlled settings cannot claim (Lundeberg \& Fox, 1991). The model could be used to explain the relationship between assessment and pre-assessment learning in both a theory teaching context (Cilliers et al., 2010; Cilliers, Schuwirth, Herman, et al., 2012) and a clinical teaching context (Cilliers, Schuwirth, \& van der Vleuten, 2012). In the latter context, the model could be used to explain the operation of the new subcomponent, "interaction with preceptors".

\section{Productivity}

Productivity or fertility "evaluates a theory in terms of the amount of knowledge and research that it produces" (Prochaska et al., 2008, p. 575). Generating the model has opened avenues of research about the model itself (Cilliers, Schuwirth, Pickworth, et al., under editorial review; Cilliers, Schuwirth, \& van der Vleuten, 2012, under editorial review) and various other avenues for research as highlighted in this chapter. There has as yet been little other uptake of the model in research papers 
(Boushell, Walter, \& Phillips, 2011), perhaps not surprising given that while it has been available online for some months, the paper describing the model (Cilliers, Schuwirth, Herman, et al., 2012) has only recently appeared in print. Apart from research exploring the mechanism, the model potentially opens new avenues of exploration about associations between assessment factors and learning effects that have enjoyed limited if any attention in the literature previously (Cilliers, Schuwirth, \& van der Vleuten, under editorial review). The model also offers an approach to explore the heterogeneity of responses of students to assessment that has been described in earlier chapters and elsewhere (Sambell \& McDowell, 1998; Sungur, 2007). Whether the model bears this fruit or not remains to be seen, however.

\section{Generalizability}

Generalizability has to do with whether the model "generalises to other situations, places, and times" (Prochaska et al., 2008, p. 565) and "the number of problems and populations to which a theory can be validly applied" (Prochaska et al., 2008, p. 575). There is evidence that for the same group of respondents as were involved in the derivation of the model, the model holds in a clinical teaching context in addition to the theory teaching context in which it was originally described (Cilliers, Schuwirth, \& van der Vleuten, 2012). There is also evidence that most of the weakest associations in the model - and the components involved - hold for a broader but similar population at the same institution as that at which the model was derived, as well as a similar population at two institutions in the same country that use dissimilar assessment regimes (Cilliers, Schuwirth, Pickworth, et al., under editorial review; Cilliers, Schuwirth, \& van der Vleuten, under editorial review).

Furthermore, teachers from a range of disciplines beyond medicine at the institution at which the model was derived and another with a different instructional approach have indicated that they find the model useful "to understand the ways that I have seen students respond to assessment" (data not shown). Lastly, the findings in Chapters Two and Three resonate strongly with findings reported elsewhere in the literature on the impact of assessment on student learning in a range of disciplines in various universities in other countries and in another era, largely with male students (Becker et al., 1968; Becker et al., 1961; Frederiksen, 1984; Miller \& Parlett, 1974; Snyder, 1971; van Etten et al., 1997).

\section{Integration}

Integration has to do with whether model components can be "combined in systematic and meaningful patterns, first conceptually, then empirically, and ideally mathematically" (Prochaska et al., 2008, p. 565). The model does provide conceptu- 
al integration (Cilliers et al., 2010; Cilliers, Schuwirth, Herman, et al., 2012), which is perhaps the stronger for being a grounded theory. Some of these patterns of integration have also now been confirmed empirically (Cilliers, Schuwirth, Pickworth, et al., under editorial review; Cilliers, Schuwirth, \& van der Vleuten, under editorial review).

\section{Utility, 11. Practicality and 12. Impact}

Utility has to do with whether the model "provides service and is useable" (Prochaska et al., 2008, p. 565). A model is considered to be practical when an intervention based on it "is demonstrated to have significant efficacy, producing greater behaviour change than a placebo or control" (Prochaska et al., 2008, p. 565) while impact is defined as "reach $\times$ efficacy $\times$ number of behaviours changed" . (Prochaska et al., 2008, p. 565). It remains to be seen what the utility of the model will be in the arenas of research and practice. There is also currently no evidence to support the validity of the model on the criteria of practicality or impact. This will be the ultimate test of the model in future research, however: whether it is possible to design interventions based on the model that result in a meaningful and desirable influence on student learning.

The criteria proposed by Prochaska et al are hierarchical, with criteria higher in the hierarchy being proposed to be both increasingly useful in practice but also increasingly difficult to meet. At present, there is clearly better evidence for the validity of the model at lower level criteria than at higher level criteria. However, this helps to specify a future research agenda regarding the model.

\section{An agenda for future research}

The highest priority for a future research agenda is to explore the stronger associations in the model. For maximum yield as far as adding to our store of knowledge about the validity of the model goes, this should preferably be done in as wide a range of different assessment regimes as is practical. Exploring the stronger associations in a range of disciplinary contexts would also help strengthen our understanding of the model prior to contemplating its use to inform intervention design.

This work could be extended to include explorations of whether the model is operational for postgraduate students in various disciplines and assessment contexts. Work could also be undertaken to investigate the operation of the model in various clinical assessment contexts. 
One specific issue that could not be addressed yet is whether there are associations between particular assessment factors and particular mechanism factors. Determining this requires a larger dataset than we currently have. Once more data has been accumulated, correspondence analysis could be used to explore these associations. This could play a key role in understanding what assessment factors should enjoy prominence in the design of an assessment programme.

Three mechanism factors were most prominent in Chapters Five and Six. Work investigating the stronger associations in the model will first need to ascertain whether these three mechanism factors also play a prominent role in those associations. However, in Chapter Six, the way that certain other of the mechanism factors were more prominent in a subset of scenarios was illustrated. At this juncture, it is not evident whether or why any of the components of the model manifest more stably under some circumstances than others. This highlights the need to elucidate factors that determine the mix of components and associations that will be active in any given assessment context i.e., what (mix of) personal, interpersonal and contextual factors foregrounds the influence of certain assessment and mechanism factors rather than others. This will be important to understand which associations are likely to yield the most robust results as the target of interventions in any given assessment context.

Once the stronger associations in the model have been investigated, it will be possible to proceed with the development of mathematical models providing information on the strength of links. Given the potential that each of the assessment factor - learning effect associations is locally independent, it may be prudent to start with the development of mathematical models for each association and the related mechanism factors, rather than for the model as a whole. As part of this research, a question to be answered is what the strength of the influence of task type is relative to other assessment factors in shaping learning effects. This will help inform the choice of factor to manipulate during interventions. This will also allow the large body of literature relating task type and learning effects to be understood in the context of the model.

A further priority will be to determine whether the model has predictive power in the context of interventions designed to alter pre-assessment learning using assessment and to ascertain what mix of factors to address in any given assessment context to yield sought after learning effects. Up to now, further tests of the model have been scenario-based. Developing an understanding of which components and associations in the model are best suited to inclusion in interventions must be a key outcome of any future research programme. It is likely that this process will need to focus on the design of assessment programmes (Schuwirth \& van der Vleuten, 2011; 
van der Vleuten et al., 2012) rather than of individual assessment tasks to be effective.

Besides these higher priority areas for research, there are various other potential avenues of research. The role of the six associations that were not significant (under the particularly stringent conditions we defined for significance) in any of the studies and the four associations were significant in one or other setting, but not both, could be explored further. The goal would be to either refute their role in the model or to better understand what factors influence the contextual variability of their manifestation. These factors appear to hold less promise to further our understanding of the pre-assessment learning effects of assessment, however.

The degree to which the distinction between summative assessment and consequential assessment is valid also offers interesting avenues for future research. If the distinction is valid, then one could expect to discern manifestations of the model in other assessment contexts such as those that do not utilise grades or ranking (Altahawi, Sisk, Poloskey, Hicks, \& Dannefer, 2012) or that make greater use of formative assessment and feedback or of peer assessment. Future research could explore whether the model is operational under these types of assessment regimes.

It would also be interesting to ascertain whether the subcomponent "interaction with preceptors" is in action in non-medical settings where, for example, students have more intense interactions with instructors e.g., in the setting of a series of practical's or perhaps even thesis-driven degrees and whether, if assessment in those settings is skills or competence based, past papers would also not feature.

It is also possible that where adequate data exist, interventions previously described in the literature - both successful and unsuccessful - could be evaluated using the model to explore both its explanatory power and to illuminate factors associated with the success or otherwise of interventions. One approach to identifying potential interventions may be to employ the model as a diagnostic tool in the evaluation of existing assessment programmes. In this regard, striving to refine the model to one that is as simple and useable as possible, yet which adequately captures the key features of what is a complex phenomenon, will be important.

Whatever future research is undertaken, Prochaska et al's (2008) criteria for evaluating models will serve as a useful compass to the overarching research programme to ensure that ever stronger evidence in support of the validity of the model is collected. 


\section{Limitations}

While the research thus far has garnered a reasonable body of evidence regarding the validity of the model, the fact remains that all this evidence emanates from senior undergraduate students in one discipline - medicine - in one country - South Africa. Given the uniqueness of South Africa's recent socio-political history, it is not inconceivable that medical students from this context could differ from their counterparts in other parts of the world. Generalisation to more junior students, to students in other disciplines and students from other countries is not presently justifiable.

The institutions from which respondents have been drawn practice dissimilar assessment regimes, although by no means a wide spectrum of assessment regimes. Some inferences can potentially be made as to the applicability of the model in institutions utilising similar assessment regimes. More data is needed, however, before inferences can be made about the applicability of the model in institutions operating under less traditional and punitive regimes.

The fact also remains that all data - qualitative and quantitative - have been drawn from volunteer respondents with the limitations attendant on that (Callahan, Hojat, \& Gonnella, 2007). Data from the quantitative studies are also self-reported, such that the over-representation of what were perceived to be desirable responses cannot be discounted.

Although derived directly from the qualitative data, the instruments used in the quantitative studies already represent a substantial simplification of the reality they purport to represent. The qualitative studies revealed how multiple components of the model could be in operation simultaneously. In a pragmatic decision aimed at limiting the cognitive burden on respondents, respondents were only asked to select the one learning effect and one mechanism factor most likely to be in play for any given assessment scenario. While making research feasible, this approach runs the risk of yielding impoverished results. It would be interesting, if challenging, to explore the relative contributions of different factors in individual assessment scenarios in future research.

It also serves to be emphasised that these studies have not explored the relative contribution of assessment and of other components of the learning environment to students learning. As various models of learning illustrate (Biggs, 1978 fig. 1 p. 267; Ramsden, 2003 fig. 5.1, p. 82) and as McLachlan (2006) pointed out, there are many other factors besides assessment driving student learning, some not even explicitly acknowledged by students themselves. Although we would agree with McLachlan that "assessment drives learning for assessment (rather than learning 
per se)", our results do suggest that a substantial portion of the total learning that students do - even those whose learning goals are mastery-oriented rather than performance-oriented - is influenced by assessment. Another area of future research will thus be to determine how strong a role assessment plays relative to other components of the learning environment in influencing learning.

\section{Implications for practice}

The ultimate goal that inspired this research was the hope that has since been expressed by Krupat and Dienstag (2009) thus: that we should be able to utilise "approaches and methods of assessment that fulfil their full potential to reinforce our educational goals" (p548). More specifically, if assessment does, indeed, have a powerful influence on student learning, then we should be able to use assessment to help create powerful learning environments (de Corte, Verschaffel, Entwistle, \& van Merriënboer, 2003), to create learning environments that foster what de Corte (2007) characterised as "productive learning". Even though we have some validity evidence for the model, it is still premature to extrapolate findings to the coalface of practice. Eleven associations between assessment factors and learning effects have been found to hold across different institutional contexts, nineteen remain to be confirmed (although, being the stronger associations between these factors, it is considered possible that most will be found to be significant). Nonetheless, there are certainly aspects of these findings that invite consideration as regards their implications for practice.

One thing that can be said with certainty even at this point is that there is unlikely to be a one-size-fits-all assessment intervention that yields a set of desirable learning effects. Instead, any intervention will have to focus on determining the optimal mix of assessment factors in any context that will have as positive as possible an effect on the learning of as many students as possible. It will probably be necessary to manipulate a set of assessment factors, rather than just tweak a single factor, to achieve meaningful results. As alluded to above, it may prove necessary to intervene at the level of assessment programmes rather than assessment tasks.

It is also the case that certain components of, and associations in, the model hold more promise as potential targets for intervention than others. Others are more likely to act as confounders in any intervention. Of the 11 associations between assessment factors and learning effects that have now been shown to be significant in various settings, there are three sets discernible i.e., where "nature of assessable material", "cues for the student grapevine" and "imminence of assessment" are the assessment factors involved. As we indicate in Chapter Five, although none are what 
would typically constitute targets for an intervention, in real life settings, they are all likely to have a substantial influence, such that they need to be factored in when designing interventions to influence learning using assessment. All of these could be meaningful confounders influencing the results of an intervention.

While it is tempting to speculate that simply increasing the amount of assessment can have salubrious effects on learning, ensuring as Gibbs (2004, p. 12) exhorts that "sufficient assessed tasks are provided for students to capture sufficient study time", the costs to students of engaging with a constant barrage of assessment needs to be considered. In Chapter Four, the negative impact of the interplay between assessment regimes in theory and clinical modules was discussed. While assessment may have beneficial effects on learning, an assessment programme should also not be so unrelenting that it contributes to burnout among students. This will only foreground "survival tactics" among students, geared to achieving an acceptable outcome in the Examination Game without what might be considered by students to be excessive effort.

The same result is likely if assessment tasks are too voluminous or too complex to be achieved in the time available. Time is a finite resource at students' disposal (Case \& Gunstone, 2003) and assessment influences how they choose to spend that time. That influence varies across time as workload and imminence of assessment vary. In fact, a wide range of metacognitive regulation activities can be influenced by attending to the prevailing workload and the imminence of assessment. An interesting prospect for future research will be to explore any overlaps between this model and game theory (Carmichael, 2005) and the extent to which insights from game theory could be used to strengthen this model and its application.

As for the other associations, of which many are as yet unverified, it appears that to influence the nature of cognitive processing activities students adopt, attention needs be paid to not only the assessment methods used, but also the level of cognitive challenge posed and, more specifically, students' perceptions of that level of challenge. In addition, the learning/assessment environment that is supportive and low-risk but characterised by high expectations and limited personal consequences is likely to lead to better quality learning than an environment that is negative, highrisk, with high expectations and negative personal consequences.

Various cues need to be managed and aligned if the content to which students attend is to be influenced. The nature and amount of material that students will be using to prepare for assessment should also enjoy careful attention as part of the design of the assessment programme, not just as part of the instructional design of a module. As is the case for the level of cognitive challenge of an assessment task, it is the inferences that students draw from the nature of the assessable material, 
rather than any "absolute" characteristic of that material, that influences learning responses.

Turning now to mechanism factors, understanding what the dominant mechanism factors are that are likely to be in play in the context of any intervention should also hopefully help inform the design of interventions. Again, there is currently just too little known about what mechanism factors are in play and what brings each or any given combination to the fore to meaningfully design interventions to hope to influence these with any confidence at present.

What does seem clear is that any intervention designed to influence student learning should have consequences, whether those consequences accrue to students' academic performance or whether they accrue to personal factors like students' sense of agency or self-esteem. The results in Chapter Four certainly suggest that bolstering rather than challenging these has the more desirable impact on learning. Consequences that are concrete, substantial and immediate are more likely to yield results than those that are abstract, trivial or deferred. The degree of impact that assessment has will likely be correlated with the magnitude of impact that it has at any one time or, perhaps, cumulatively - on these factors. This suggests that a project that counts for $5 \%$ of a year mark may have little impact on learning, unless, perhaps, the limited academic impact is bolstered by meaningful feedback that engenders a sense of agency or self-esteem in students.

Assessment tasks should be designed in such a way that when students make an appraisal of the most efficacious learning response, this appraisal leads them to choose to learn in a manner and to select content to learn that is fundamentally useful. While marking longer questions poses challenges to teachers in times of dwindling resources and increasing workloads (Tight, 2010), the impact this has on student decisions about what material to learn - and not - must be borne in mind.

Turning now to implications for educational development practice, a few attempts have been made thus far to share the findings of this research with university teachers. These efforts are made challenging by the complexity of the model. However, it appears that learning about the model not only raises the awareness of these teachers about the issues, but also gives them a framework within which to contemplate changing their practice, as these quotes from workshop feedback illustrate:

[The most useful aspect of this workshop?] The scientifically grounded findings about the impact of assessment are critically important for teachers. This is what we do day after day without realising that we have an enormous impact on student learning (Workshop participant 1, 2010) 
[What I will do differently is to] try and set more purposeful assessment because student perception is completely different to what I thought (my planning and classes differ from how they experience it) (Workshop participant 2, 2010)

It remains to be seen whether university teachers can be persuaded to actually change their assessment practice based on insights from this research. Further research will probably be needed geared towards understanding personal, interpersonal and contextual factors that influence university teachers' assessment practice.

This model predicts that there is not a linear or simple relationship between assessment and learning, as well-conceived yet largely unsuccessful attempts to influence learning using assessment would seem to illustrate (Gijbels, Segers, \& Struyf, 2008; Heijne-Penninga, Kuks, Hofman, \& Cohen-Schotanus, 2008; Segers et al., 2006). Simple interventions are thus unlikely to yield meaningful results, particularly in authentic as opposed to controlled, laboratory-like conditions. Joughin (2010, p. 342) recently went as far as to state that "the view that assessment, on its own, can be used to improve the quality of student learning is not supported by the evidence currently available". Perhaps the model will allow a different approach to the design of learning-oriented assessment interventions. We believe the model provides a theoretical framework within which to contemplate the heterogeneous effects of assessment on learning. We hope that future research will add to the basket of evidence about the model's validity and that it will provide researchers, evaluators and teachers with a stronger theoretical framework within which to work when designing research, evaluations and interventions related to the pre-assessment learning effects of consequential assessment. 


\section{References}

Abd El Fattah, S. M. (2011). The effect of test expectations on study strategies and test performance: A metacognitive perspective. Educational Psychology, 31(4), 497-511.

Alderson, J. C., \& Wall, D. (1993). Does washback exist? Applied Linguistics, 14(2), 115-129.

Altahawi, F., Sisk, B., Poloskey, S., Hicks, C., \& Dannefer, E. F. (2012). Student perspectives on assessment: Experience in a competency-based portfolio system. Medical Teacher, 34(3), 221-225.

Bartholomew, L. K., Parcel, G. S., Kok, G., Gottlieb, N. H., \& Fernandez, M. E. (2011). Planning health promotion programs: An intervention mapping approach. San Francisco: Jossey-Bass.

Becker, H. S., Geer, B., \& Hughes, E. C. (1968). Making the grade: The academic side of college life. New York: John Wiley \& Sons, Inc.

Becker, H. S., Geer, B., Hughes, E. C., \& Strauss, A. (1961). Boys in white. Student culture in medical school. Chicago: University of Chicago Press.

Biggs, J. B. (1978). Individual and group differences in study processes. British Journal of Educational Psychology, 48(3), 266-279.

Bordage, G., \& Page, G. (1987). An alternative approach to pmps: The 'key features' concept. In I. R. Hart \& R. M. Harden (Eds.), Further developments in assessing clinical competence (pp. 59-75). Montreal: Heal-Publications.

Boushell, L. W., Walter, R., \& Phillips, C. (2011). Learn-a-prep ii as a predictor of psychomotor performance in a restorative dentistry course. Journal of Dental Education, 75(10), 1362-1369.

Broekkamp, H., \& van Hout-Wolters, B. H. A. M. (2007). Students' adaptation of study strategies when preparing for classroom tests. Educational Psychology Review, 19(4), 401-428.

Callahan, C. A., Hojat, M., \& Gonnella, J. S. (2007). Volunteer bias in medical education research: An empirical study of over three decades of longitudinal data. Medical Education, 41(8), 746-753.

Carmichael, F. (2005). A guide to game theory. Harlow: Pearson Education Limited.

Case, J., \& Gunstone, R. (2003). Going deeper than deep and surface approaches: A study of students perceptions of time. Teaching in Higher Education, 8(1), 55-69.

Cilliers, F. J., Schuwirth, L. W. T., Adendorff, H. J., Bitzer, E. M., Herman, N., \& van der Vleuten, C. P. M. (2008). The impact of summative assessment of theory on how medical students learn. Paper presented at the AMEE Conference, Prague, Czech Republic.

Cilliers, F. J., Schuwirth, L. W. T., Adendorff, H. J., Herman, N., \& van der Vleuten, C. P. M. (2009). Assessment impacts on learning, you say? Please explain how. The impact of summative assessment of theory on how medical students learn. Paper presented at the Annual Conference of the Society for Research into Higher Education, Celtic Manor, Wales.

Cilliers, F. J., Schuwirth, L. W. T., Adendorff, H. J., Herman, N., \& van der Vleuten, C. P. M. (2010). The mechanism of impact of summative assessment on medical students' learning. Advances in Health Sciences Education, 15(5), 695-715.

Cilliers, F. J., Schuwirth, L. W. T., Herman, N., Adendorff, H., \& van der Vleuten, C. P. M. (2012). A model of the pre-assessment learning effects of summative assessment in medical education. Advances in Health Sciences Education, 17(1), 39-53.

Cilliers, F. J., Schuwirth, L. W. T., Pickworth, G. E., Burch, V. C., \& van der Vleuten, C. P. M. (under editorial review). Generalizability findings for a model of the pre-assessment learning effects of assessment in new contexts.

Cilliers, F. J., Schuwirth, L. W. T., \& van der Vleuten, C. P. M. (2012). A model of the pre-assessment learning effects of assessment is operational in an undergraduate clinical context. BMC Medical Education, 12.

Cilliers, F. J., Schuwirth, L. W. T., \& van der Vleuten, C. P. M. (under editorial review). Modelling the preassessment learning effects of assessment: Evidence in the validity chain.

d'Ydewalle, G., Swerts, A., \& De Corte, E. (1983). Study time and test performance as a function of test expectations. Contemporary Educational Psychology, 8(1), 55-67.

de Corte, E. (2007). Learning from instruction: The case of mathematics. Learning Inquiry, 1(1), 19-30. 
de Corte, E., Verschaffel, L., Entwistle, N. J., \& van Merriënboer, J. J. G. (2003). Powerful learning environments: Unravelling basic components and dimensions (1st ed.). Oxford: Pergamon.

Feldt, R. C. (1990). Test expectancy and performance on factual and higher-level questions. Contemporary Educational Psychology, 15(3), 212-223.

Frederiksen, N. (1984). The real test bias: Influences of testing on teaching and learning. American Psychologist, 39(3), 193-202.

Gibbs, G., \& Simpson, C. (2004). Conditions under which assessment supports students' learning. Learning and Teaching in Higher Education, 2004-05(1), 3-31.

Gijbels, D., Segers, M., \& Struyf, E. (2008). Constructivist learning environments and the (im)possibility to change students' perceptions of assessment demands and approaches to learning. Instructional Science, 36(5), 431-443.

Hakstian, A. R. (1971). The effects of type of examination anticipated on test preparation and performance. Journal of Educational Research, 64(7), 319-324.

Heijne-Penninga, M., Kuks, J. B. M., Hofman, W. H. A., \& Cohen-Schotanus, J. (2008). Influence of openand closed-book tests on medical students' learning approaches. Medical Education, 42(10), 967 974.

Jersild, A. T. (1929). Examinations as an aid to learning. Journal of Educational Psychology, 20(8), 602-609.

Joughin, G. (2010). The hidden curriculum revisited: A critical review of research into the influence of summative assessment on learning. Assessment \& Evaluation in Higher Education, 35(3), 335-345.

Krupat, E., \& Dienstag, J. L. (2009). Commentary: Assessment is an educational tool. Academic Medicine, 84(5), 548-550.

Lundeberg, M. A., \& Fox, P. W. (1991). Do laboratory findings on test expectancy generalize to classroom outcomes? Review of Educational Research, 61(1), 94-106.

McLachlan, J. C. (2006). The relationship between assessment and learning. [Editorial]. Medical Education, 40(8), 716-717.

Miller, C. M. L., \& Parlett, M. (1974). Up to the mark: A study of the examination game. London: Society for Research into Higher Education.

Newble, D. I., \& Jaeger, K. (1983). The effect of assessment and examinations on the learning of medical students. Medical Education, 17(3), 165-171.

Newman, J. H. (1852). Discourses on the scope and nature of university education, addressed to the catholics of dublin. Dublin: James Duffy.

Osler, W., Sir. (1913). Examinations, examiners and examinees. The Lancet, 1047-1059.

Parlett, M. (1969). Undergraduate teaching observed. Nature, 223(5211), 1102-1104.

Prochaska, J. O., Wright, J. A., \& Velicer, W. F. (2008). Evaluating theories of health behavior change: A hierarchy of criteria applied to the transtheoretical model. Applied Psychology, 57(4), 561-588.

Ramsden, P. (1984). The context of learning. In F. Marton, D. Hounsell \& N. J. Entwistle (Eds.), The experience of learning (pp. 144-164). Edinburgh: Scottish Academic Press.

Ramsden, P. (2003). Learning to teach in higher education (2 ed.). London: Routledge.

Ross, M. E., Green, S., Salisbury-Glennon, J. D., \& Tollefson, N. (2006). College students' study strategies as a function of testing: An investigation into metacognitive self-regulation. Innovative Higher Education, 30(5), 361-375.

Ross, M. E., Salisbury-Glennon, J. D., Guarino, A., Reed, C. J., \& Marshall, M. (2003). Situated selfregulation: Modeling the interrelationships among instruction, assessment, learning strategies and academic performance. Educational Research and Evaluation, 9(2), 189-209.

Sambell, K., \& McDowell, L. (1998). The construction of the hidden curriculum: Messages and meanings in the assessment of student learning. Assessment \& Evaluation in Higher Education, 23(4), 391-402.

Sambell, K., McDowell, L., \& Brown, S. (1997). 'But is it fair?': An exploratory study of student perceptions of the consequential validity of assessment. Studies in Educational Evaluation, 23(4), 349-371.

Schuwirth, L. W. T., \& van der Vleuten, C. P. M. (2011). Programmatic assessment: From assessment of learning to assessment for learning. Medical Teacher, 33(6), 478-485. 
Scouller, K. M. (1998). The influence of assessment method on students' learning approaches: Multiple choice examinations versus assignment essay. Higher Education, 35, 453-472.

Segers, M., Nijhuis, J., \& Gijselaers, W. (2006). Redesigning a learning and assessment environment: The influence on students' perceptions of assessment demands and their learning strategies. Studies In Educational Evaluation, 32(3), 223-242.

Snyder, B. R. (1971). The hidden curriculum. New York: Alfred A. Knopf.

Sundre, D. L., \& Kitsantas, A. (2004). An exploration of the psychology of the examinee: Can examinee self-regulation and test-taking motivation predict consequential and non-consequential test performance? Contemporary Educational Psychology, 29(1), 6-26.

Sungur, S. (2007). Contribution of motivational beliefs and metacognition to students' performance under consequential and nonconsequential test conditions. Educational Research \& Evaluation, 13(2), 127-142.

Tang, K. C. C. (1994). Effects of modes of assessment on students' preparation strategies. In G. Gibbs (Ed.), Improving student learning - theory and practice (pp. 151-170). Oxford: Oxford Centre for Staff Development, Oxford Brookes University.

Terry, P. W. (1933). How students review for objective and essay tests. The Elementary School Journal, 33, 592-603.

Thiede, K. W. (1996). The relative importance of anticipated test format and anticipated test difficulty on performance. Quarterly Journal of Experimental Psychology: Section A, 49(4), 901-918.

Thomson, K., \& Falchikov, N. (1998). 'Full on until the sun comes out': The effects of assessment on student approaches to studying. Assessment \& Evaluation in Higher Education, 23(4), 379-390.

Tight, M. (2010). Are academic workloads increasing? The post-war survey evidence in the uk. Higher Education Quarterly, 64(2), 200-215.

Vallance, T. R. (1947). A comparison of essay and objective examinations as learning experiences. Journal of Educational Research, 41(4), 279-288.

van der Vleuten, C. P. M., Schuwirth, L. W. T., Driessen, E. W., Dijkstra, J., Tigelaar, D., Baartman, L. K. J., \& van Tartwijk, J. (2012). A model for programmatic assessment fit for purpose. Medical Teacher, 34(3), 205-214.

van Etten, S., Freebern, G., \& Pressley, M. (1997). College students' beliefs about exam preparation. Contemporary Educational Psychology, 22(2), 192-212. 

Summary 
Googling the exact phrase "assessment drives learning" in early 2012 yields 8800 results, of which 610 are scholarly articles. This may be a rather unscientific way to start the summary of a dissertation, but it does give some indication of just how widely held this belief is. Yet although it is widely professed and a search of the literature on the topic reveals that there are vast numbers of research papers about various aspects of the topic, there is little uniformity about exactly what is meant by "assessment drives learning". There are also no validated models explaining the relationship between assessment and learning. It is therefore perhaps not surprising that there is a dearth of success stories in the literature about purposively using assessment to drive learning in desired ways. The ultimate goal that inspired this research, then, is the hope that has since been expressed by Krupat and Dienstag (2009) thus: that we should be able to utilise "approaches and methods of assessment that fulfil their full potential to reinforce our educational goals" ( $p 548)$. The specific issue that this dissertation is concerned with is deriving and starting to validate a model of the pre-assessment learning effects of summative assessment.

In Chapter One, the nature of the literature about the relationship between assessment and learning is reviewed and problematized. The lack of a mechanism and model explaining the relationship between assessment and pre-assessment learning effects is highlighted. The delimitation of the dissertation to the topic of the preassessment learning effects of assessment is explained and the fourfold goals of the dissertation spelled out i.e., 1) to discern what components of assessment influenced what dimensions of learning in an authentic, complex system of summative assessment; 2) to explore what mechanism was at play at the interface between assessment and learning in this assessment system; 3 ) to construct a theoretically grounded model and finally 4) to take steps towards validating this model.

Chapter Two makes the argument that it has become axiomatic that assessment impacts powerfully on student learning, but that there is a surprising dearth of research on how this happens. A study is described that explored the mechanism of impact of summative assessment on the process of learning of theory in higher education. Individual, in-depth interviews were conducted with medical students and analysed qualitatively. The impact of assessment on learning was found to be mediated through various determinants of action. Respondents' learning behaviour was influenced by: appraising the impact of assessment; appraising their learning response; their perceptions of agency; and interpersonal factors such as normative beliefs and motivation to comply with those beliefs. The results of the study add to scant extant evidence about the impact of assessment on learning and lead to the proposal of a mechanism to explain this impact.

Chapter Three highlights and reviews the surprisingly small amount of research that has been published emanating from authentic higher education and health sciences 
education settings about the nature and mechanism of the pre-assessment learning effects of summative assessment. This study explored the pre-assessment learning effects of summative assessment in theoretical modules by exploring the variables at play in a multifaceted assessment system and the relationships between them. Using a grounded theory strategy, in-depth interviews were conducted with individual medical students and analysed qualitatively. Respondents' learning was influenced by task demands and system design. Assessment impacted on respondents' cognitive processing activities and metacognitive regulation activities. Individually, our findings confirm findings from other studies in disparate non-medical settings and identify some new factors at play in this setting. Taken together, findings from this study provide, for the first time, some insight into how a whole assessment system influences student learning over time in a medical education setting. The findings from this authentic and complex setting paint a nuanced picture of how intricate and multifaceted interactions between various factors in an assessment system interact to influence student learning. A model linking the sources, mechanism and consequences of the pre-assessment learning effects of summative assessment is proposed that could help enhance the use of summative assessment as a tool to augment learning. The model is depicted on page 120 of this dissertation.

Chapter Four addresses the issue that no validated model exists to explain the learning effects of assessment and how this is a problem when designing and researching assessment for learning. The challenge addressed in this study is how to validate the model described in Chapter Three. The purpose of this study was to explore whether the model was operational in a clinical context as a first step in this process. Given the complexity of the model, a qualitative approach was adopted. Data from in-depth interviews with eighteen medical students were subject to content analysis. A code book developed previously using grounded theory was utilised. During analysis, we remained alert to data that might not conform to the coding framework and open to the possibility of deploying inductive coding. The three components of the model i.e., assessment factors, mechanism factors and learning effects were all evident in the clinical context. Associations between these components could all be explained by the model. "Interaction with preceptors" was identified as a new subcomponent of assessment factors. The model could explain the interrelationships of the three facets of this subcomponent i.e., regular accountability, personal consequences and emotional valence of the learning environment, with previously described components of the model. The model could thus be utilized to analyse and explain observations in an assessment context different to that from which it was derived. In the clinical setting, the (negative) influence of preceptors on student learning was particularly prominent. In this setting, learning effects resulted not only from the high-stakes nature of summative assessment but also from personal stakes, e.g. for esteem and agency. The results suggest that to influ- 
ence student learning, consequences should accrue from assessment that are immediate, concrete and substantial. The model could have utility as a planning or diagnostic tool in practice and research settings. The proposal that the model is one of consequential assessment rather than summative assessment is discussed.

In Chapter Five, we review how we previously developed and started validating a model of the pre-assessment learning effects of consequential assessment. The purpose of this study was to continue the process of validation. As the most stringent test of the model, the aims were to determine whether the least common associations between assessment factors and learning effects in the model and the components involved were testable and whether support could be found for the role of this subset of individual components and the associations between them in a broader but similar population to that in which the model was initially derived. Twenty-one different associations were investigated in a cross-sectional survey using a purpose-made questionnaire. Each association was tested using a pair of situational test items that were developed based on a grounded theory and structured using the logic of the key-features approach. For each association, the chisquare statistic was used to determine whether there were significant associations between assessment factors and learning effects. An adjusted alpha was used to assign significance. The frequency of involvement of mechanism factors was calculated. Almost all associations and components were testable. There were significant associations between assessment factors and learning effects for $13 / 21$ of this weakest set of associations being investigated, even taking $p<0.00625$ as significant. The role of all eight learning effects, all ten mechanism factors and six out of eight assessment factors investigated were substantiated. For the least common subset of associations in the model, the role of most components involved and the associations between them are therefore supported. This bodes well for future studies of the commonest associations in the model. The model also holds in a broader but similar population to that from which it was derived. Results illustrate how a range of factors can confound the results of interventions aimed at using assessment to influence learning.

Chapter Six revisits the rationale for model validation i.e., that interventions based on a validated model should produce better outcomes than efforts based on weaker theory. Despite extensive literature on the topic, no validated model explaining the learning effects of assessment exists. Before using a recently developed model to inform interventions, it needs to be validated. The purpose of this study was to explore whether tentative generalizability findings related to the model could be replicated in novel assessment contexts. Cross-sectional surveys of 419 students at two other universities were undertaken, using a purpose-made questionnaire comprising written situational tests. For stringency, the model's 21 least common asso- 
ciations between assessment factors and learning effects were investigated. Thirteen of these associations were significant $(p<0.00625)$. The role of seven of eight assessment factors, seven of eight learning effects and all ten mechanism factors investigated, were substantiated. Four mechanism factors (agency, response efficacy, response value and impact appraisal) together mediated most associations. This further support for many of the model's least common associations again bodes well for future studies of the commoner associations. Although model validation is an on-going process, these results move the model one step closer to the stage of usefully informing interventions.

Chapter Seven presents an overview of findings and conclusions from Chapters 2 6. Chapter 2 resulted in the proposal of a novel mechanism to explain why students respond to assessment in the ways that they do and not merely what their response is. Findings from Chapter 3 lead to the proposal of a model of the pre-assessment learning effects of summative assessment. Based on the findings reported in Chapters $4-6$, the conclusion is drawn that evidence collected thus far supports the validity of the model in various settings and that the model can be considered one of consequential assessment rather than of summative assessment.

Four main findings from this work are then discussed: 1) associations between assessment factors and learning effects are complex and contextual; 2) a novel mechanism is in play in theory and clinical assessment contexts; 3 ) the model applies to consequential assessment rather than just summative assessment and 4) a model has been devised for which there is validity evidence. After expanding on each of these four findings, existing evidence for the validity of the model is reviewed in light of a hierarchical set of criteria proposed by Prochaska, Wright \& Velicer (2008).

The limitations of this work are discussed. For the initial studies, these include limitations inherent in qualitative research. They also include the limitations inherent in utilising volunteers for both qualitative and quantitative research. For the quantitative work, the potential for generalizability of findings is as yet limited, given that only the least common associations in the model have been studied in a limited range of assessment contexts thus far.

The strengths of this dissertation are that the mechanism and model are derived from the lived experiences of students across the span of their degree studies, in a complex, authentic setting. The qualitative work also addressed many of the threats to causal inference identified by Maxwell (2004). Overall, the dissertation proposes a model explaining the pre-assessment learning effects of consequential assessment for which validation has been undertaken. This makes a contribution on two fronts. Firstly, the model offers a new perspective on how to relate assessment and preassessment learning by linking assessment factors and learning effects by way of a 
novel mechanism. Secondly, no other model proposed in the past has - as yet, anyway - been validated to any extent.

An agenda for future research is discussed before, finally, the implications of the research for teaching and educational development practice are explored.

\section{References}

Krupat, E., \& Dienstag, J. L. (2009). Commentary: Assessment Is an Educational Tool. Academic Medicine, $84(5), 548-550$.

Maxwell, J. A. (2004). Using Qualitative Methods for Causal Explanation. Field Methods, 16(3), 243-264.

Prochaska, J. O., Wright, J. A., \& Velicer, W. F. (2008). Evaluating Theories of Health Behavior Change: A Hierarchy of Criteria Applied to the Transtheoretical Model. Applied Psychology, 57(4), 561-588. 

Samenvatting

Summary in Dutch 
Zoeken op het internet naar de uitdrukking "toetsing stuurt leren" leverde, begin 2012, 8800 resultaten op, waaronder 610 wetenschappelijke artikelen. Al lijkt dit een onwetenschappelijke opening van de samenvatting van een proefschrift, het illustreert hoe breed de opvatting "toetsing stuurt leren" gedragen wordt. Des te opmerkelijker is het ontbreken - ondanks het indrukwekkende aantal wetenschappelijk publicaties dat diverse aspecten van dit idee belicht - van gevalideerde modellen die een verklaring bieden voor de veronderstelde relatie tussen toetsing en leren. Het wekt dan ook geen verwondering dat er in de literatuur weinig melding wordt gemaakt van succesvolle toepassingen van toetsing als methode om gewenste vormen van leren te stimuleren. Het onderzoek in dit proefschrift is ingegeven door de wens uitgesproken door Krupat en Dienstag (2009) dat 'toetsbenaderingen en -methoden de verwachting zullen waarmaken dat ze een bijdrage kunnen leveren aan de realisatie van onze onderwijsdoelen " (p. 548). Het onderzoek in dit proefschrift had tot doel een model te ontwikkelen van het effect van summatieve toetsing op het voorafgaande leren en daarnaast is een begin gemaakt met het valideren van dit model.

In Hoofdstuk 1 wordt een overzicht gegeven van de literatuur over de relatie tussen toetsing en leren en worden problemen van deze relatie belicht. Hierbij ligt de nadruk op het ontbreken van een verklarend mechanisme of model. Toegelicht wordt waarom het onderzoek in dit proefschrift uitsluitend gericht is op de invloed van toetsing op voorafgaande leereffecten en daarnaast worden de vier onderzoeksdoelen beschreven: 1) bepalen welke onderdelen van toetsing van invloed zijn op welke dimensies van het leren in een authentiek, complex systeem van summatieve toetsing; 2 ) onderzoeken welk mechanisme in dit toetssysteem een rol speelt op het raakvlak tussen toetsen en leren; 3) ontwikkelen van een theoretisch goed onderbouwd model en ten slotte 4) een eerste validering van het ontwikkelde model.

In Hoofdstuk 2 wordt beargumenteerd dat weliswaar algemeen als axioma wordt aanvaard dat toetsing het leren van studenten sterk beïnvloedt, maar dat er een opmerkelijk gebrek is aan onderzoek naar de wijze waarop dit effect tot stand komt. $\mathrm{Er}$ is gezocht naar een antwoord op de vraag welk mechanisme ten grondslag ligt aan het effect van summatieve toetsing op theoretisch leren in het hoger onderwijs. Hiertoe zijn diepgaande interviews met individuele geneeskundestudenten afgenomen en geanalyseerd. De resultaten lieten zien dat verschillende factoren het handelen van de deelnemers bepaalden en daarmee indirect een rol speelden bij de totstandkoming van het effect van toetsing op leren. Het leergedrag werd beïnvloed door: de inschatting van het belang van toetsing; de inschatting van de eigen leerrespons; het gepercipieerde vermogen tot zelfstandig handelen; en sociale factoren, zoals normatieve opvattingen en de motivatie om daarnaar te handelen. 
De resultaten van dit onderzoek vormen een aanvulling op het weinige bewijsmateriaal dat beschikbaar is ter ondersteuning van het effect van toetsing op leren. Daarnaast onderbouwen ze het mechanisme dat voorgesteld wordt als verklaring van dit effect.

Hoofdstuk 3 geeft een overzicht en benadrukt het geringe aantal publicaties waarin onderzoek gerapporteerd wordt dat is uitgevoerd in authentieke leeromgevingen in het hoger en gezondheidszorgonderwijs naar de manier waarop summatieve toetsing het voorafgaande leren bepaalt en het onderliggende mechanisme. In een exploratief onderzoek is onderzocht welke variabelen, met hun onderlinge relaties, in een toetssysteem met veel verschillende facetten een rol spelen bij de totstandkoming van effecten van summatieve toetsing van theoretische modules op het voorafgaande leren. Het onderzoek werd uitgevoerd volgens de 'grounded theory'-methode en bestond uit afname en kwalitatieve analyse van interviews met individuele geneeskundestudenten. Het leren van de deelnemers werd beïnvloed door taakgerelateerde eisen en de aard van het toetssysteem. Toetsing beïnvloedde de activiteiten van de deelnemers met betrekking tot cognitieve verwerking en metacognitieve regulering. De resultaten bevestigen bevindingen uit ander onderzoek in verschillende niet-medische omgevingen en brengen nieuwe factoren aan het licht die daar een rol spelen. Dit is het eerste onderzoek dat inzicht biedt in de wijze waarop het toetssysteem als geheel het leren van studenten gedurende het hele curriculum beïnvloedt. De resultaten van dit onderzoek in een authentieke en complexe leeromgeving schetsen een genuanceerd beeld van de manier waarop ingewikkelde en veelvormige interacties tussen verschillende factoren in het toetssysteem het leren van studenten beïnvloeden. Een model wordt voorgesteld waarin bronnen, mechanisme en gevolgen van het effect van summatieve toetsing op leren met elkaar in verband worden gebracht met als doel summatieve toetsing optimaal te kunnen toepassen als instrument om het leren te bevorderen. Het model is te vinden op bladzijde 120 van dit proefschrift.

Hoofdstuk vier gaat in op het ontbreken van een gevalideerd model dat de leereffecten van toetsing kan verklaren en hoe dit een belemmering vormt voor het ontwerpen en onderzoeken van toetsing als stimulans voor leren. Gezien de complexiteit van het model is een kwalitatieve onderzoeksmethode toegepast. Volgens de 'content analysis'-methode zijn diepgaande interviews met achttien geneeskundestudenten geanalyseerd waarbij gebruik is gemaakt van een bestaand codeboek dat voortkwam uit een analyse op basis van 'grounded theory'. Tijdens de analyse werd steeds rekening gehouden met de mogelijkheid dat sommige gegevens niet in overeenstemming konden zijn met het model en werd voor deze gegevens inductieve codering toegepast. Alle drie componenten van het model, namelijk toetsfactoren, mechanismefactoren en leereffecten, bleken aanwezig te 
zijn in de klinische context en alle gevonden relaties tussen deze componenten konden door het model verklaard worden. Daarnaast werd een nieuwe subcomponent aan de toetsfactoren toegevoegd, namelijk 'interactie met begeleiders'. Het model verklaarde de onderlinge relaties tussen de drie facetten van deze subcomponent (regelmatig verantwoording afleggen, consequenties op het persoonlijke vlak en de gevoelsmatige waardering voor de leeromgeving) en de eerder beschreven componenten van het model. Dit betekent dat het model geschikt is voor het analyseren en verklaren van bevindingen in andere toetssituaties dan die waarin het oorspronkelijk is ontwikkeld. De (negatieve) invloed van begeleiders op het leren van studenten kwam vooral sterk naar voren in de klinische context. Niet alle leereffecten in deze omgeving werden bepaald door ingrijpende consequenties van summatieve toetsing: persoonlijke belangen, zoals waardering en de ruimte voor zelfstandig handelen, speelden ook een rol. De resultaten geven aan dat toetsing het leren beïnvloedt als de consequenties ervan direct, concreet en aanzienlijk zijn. Het model kan gebruikt worden als instrument voor planning en diagnostiek in de onderwijspraktijk en in onderzoek van onderwijs. Er wordt ingegaan op de vraag of het model beter aansluit bij toetsing met ingrijpende consequenties dan bij summatieve toetsing.

Hoofdstuk vijf beschrijft de ontwikkeling en een eerste aanzet tot validering van een model dat kan verklaren hoe toetsing met ingrijpende consequenties het voorafgaande leren beïnvloedt. Het onderzoek is een voortzetting van het eerder gestarte valideringsproces. Om het model aan een zeer strenge test te onderwerpen werd onderzocht of de zwakste relaties tussen toetsfactoren en leereffecten in het model en de betrokken componenten getoetst konden worden en of de rol van deze subset van individuele componenten en hun onderlinge relaties bevestigd kon worden in een populatie die breder was dan, maar vergelijkbaar aan, de populatie waarvan het model oorspronkelijk was afgeleid. In een transversaal onderzoek met behulp van een speciaal daarvoor ontworpen vragenlijst zijn 21 verschillende relaties onderzocht. Elke relatie werd getoetst met behulp van situatiegebonden vragenparen ontwikkeld volgens de 'groundedtheory'-methode en gestructureerd volgens de 'key-features'- benadering. Door middel van chi-kwadraattoetsen werd per relatie bepaald of er sprake was van een significante relatie tussen toetsfactoren en leereffecten. Significantie werd bepaald met behulp van een aangepaste alfa. De frequentie van de betrokkenheid van mechanismefactoren werd berekend. Bijna alle relaties en componenten konden getoetst worden. Voor dertien van de 21 zwakste relaties werd een significante correlatie gevonden tussen toetsfactoren en leereffecten, zelfs op het significantieniveau $p<0.00625$. De resultaten bevestigen de rol van alle acht leereffecten, alle tien mechanismefactoren en zes van de acht toetsfactoren die onderzocht zijn. Voor de subset van de zwakste relaties in het model betekent dit 
een bevestiging van de rol van de meeste componenten en hun onderlinge relaties. Dit biedt gunstige vooruitzichten voor toekomstig onderzoek naar de sterkste relaties in het model. Het model blijkt dus ook van toepassing op een populatie die breder is dan, maar vergelijkbaar aan, de populatie waarop het oorspronkelijk is gebaseerd. De resultaten illustreren hoe verschillende factoren een verstorend effect kunnen hebben op interventies waarin toetsing wordt gebruikt als instrument om het leren te sturen.

Hoofdstuk zes grijpt terug op het principe van het valideren van modellen, namelijk dat interventies gebaseerd op een gevalideerd model betere resultaten moeten opleveren dan interventies gebaseerd op een zwakkere theorie. Ondanks de omvangrijke literatuur, bestaat er geen gevalideerd model van de leereffecten van toetsing en een nieuw model dient eerst gevalideerd worden voordat het als basis kan dienen voor interventies. Onderzocht is of bevindingen betreffende de generaliseerbaarheid van het model gerepliceerd konden worden in nieuwe toetssituaties. In transversaal onderzoek bij 419 studenten van twee andere universiteiten werd een speciaal voor het onderzoek ontwikkelde enquête afgenomen, bestaande uit schriftelijke situatiegebonden testen. Om het onderzoek zo stringent mogelijk te maken, werden de 21 zwakste verbanden tussen toetsfactoren en leereffecten onderzocht. Dertien hiervan bleken significant te zijn $(p<0.00625)$. De resultaten bevestigen de rol van zeven van de acht toetsfactoren, zeven van de acht leereffecten en alle tien mechanismefactoren. Een combinatie van vier mechanismefactoren (mogelijkheid tot zelfstandig handelen, doeltreffendheid van de respons, waarde van de respons en inschatting van het effect van toetsing) speelde een indirecte rol in de meeste relaties. Deze verdere bevestiging van een groot aantal van de zwakste relaties in het model biedt goede vooruitzichten voor toekomstig onderzoek naar de sterkere relaties. Hoewel de validering van het model nog niet is afgerond, komt het model door deze resultaten dichterbij het stadium waarin het een goed uitgangspunt kan zijn voor interventies.

Hoofdstuk zeven geeft een overzicht van de bevindingen en conclusies uit Hoofdstuk 2-6. Uit het onderzoek in Hoofdstuk 2 komt een volledig nieuw mechanisme naar voren dat niet alleen kan verklaren hoe studenten reageren op toetsing maar ook waarom zij zo reageren. Op basis van de bevindingen uit Hoofdstuk 3 wordt een model voorgesteld dat de leereffecten van summatieve toetsing op het voorafgaande leren kan verklaren. Op basis van de bevindingen in Hoofdstuk 4-6 wordt geconcludeerd dat het tot dusver gevonden bewijs de validiteit van het model in verschillende situaties bevestigt en dat het model beter aansluit bij toetsing met ingrijpende consequenties dan bij summatieve toetsing.

Hierna worden de vier belangrijkste onderzoeksbevindingen besproken: 1) relaties tussen toetsfactoren en leereffecten zijn complex en contextgebonden; 2) een 
geheel nieuw mechanisme is gevonden dat een rol speelt in toetsing van theorie en toetsing in klinische situaties; 3) het model sluit beter aan bij toetsing met ingrijpende consequenties dan bij summatieve toetsing. $\mathrm{Na}$ een uitvoerige bespreking van deze vier bevindingen wordt ingegaan op het bestaande bewijs voor de validiteit van het model bezien vanuit een hiërarchie van criteria voorgesteld door Prochaska, Wright \& Velicer (2008).

Vervolgens wordt ingegaan op de beperkingen van het onderzoek. De initiële onderzoeken zijn onderhevig aan de beperkingen die inherent zijn aan kwalitatief onderzoek en aan het gebruik van vrijwilligers in zowel kwalitatief als kwantitatief onderzoek. De resultaten van het kwantitatieve onderzoek zijn vooralsnog beperkt generaliseerbaar, omdat tot nu toe alleen de zwakste relaties in het model zijn onderzocht in een beperkt aantal toetssituaties.

De kracht van dit proefschrift ligt in het aangetoonde mechanisme en het ontwikkelde model, beide gebaseerd op authentieke ervaringen van studenten gedurende de volledige studieduur in een complexe, authentieke omgeving. In het kwalitatieve onderzoek is ook aandacht besteed aan de door Maxwell (2004) gesignaleerde bedreigingen van causale inferentie. Het proefschrift als geheel beschrijft niet alleen de ontwikkeling van een model ter verklaring van de leereffecten van toetsing met ingrijpende consequenties, maar tevens de eerste stappen in het valideringsproces van dit model. Hiermee levert het proefschrift een tweeledige bijdrage. In de eerste plaats biedt het model nieuwe inzichten in de relatie tussen toetsing en het voorafgaande leren door de introductie van een volledig nieuw mechanisme dat de relatie tussen toetsfactoren en leereffecten kan verklaren. In de tweede plaats, bestaat er, tenminste tot nu toe, geen ander in enige mate gevalideerd model dat de leereffecten van toetsing kan verklaren.

In de loop van dit hoofdstuk ontvouwt zich een agenda voor toekomstig onderzoek en ten slotte wordt aandacht besteed aan de implicaties van het onderzoek voor onderwijspraktijk en onderwijsontwikkeling.

\section{References}

Krupat, E., \& Dienstag, J. L. (2009). Commentary: Assessment Is an Educational Tool. Academic Medicine, $84(5), 548-550$.

Maxwell, J. A. (2004). Using Qualitative Methods for Causal Explanation. Field Methods, 16(3), 243-264.

Prochaska, J. O., Wright, J. A., \& Velicer, W. F. (2008). Evaluating Theories of Health Behavior Change: A Hierarchy of Criteria Applied to the Transtheoretical Model. Applied Psychology, 57(4), 561-588. 



\section{Opsomming \\ Summary in Afrikaans}


'n Google soektog aan die begin van 2012 met die woordgreep "assessment drives learning" het 8800 resultate opgelewer, waarvan 610 wetenskaplike artikels is. Dit is dalk ' $n$ ietwat onwetenskaplike manier om die opsomming van ' $n$ verhandeling te begin, maar gee tog ' $n$ aanduiding van hoe wydverspreid hierdie opvatting is. Alhoewel die stelling wyd verkondig word en talryke navorsingsartikels oor verskeie aspekte van die onderwerp deur ' $n$ literatuursoektog opgelewer word, is daar geen eenvormigheid oor wat presies deur "assessment drives learning" bedoel word nie. Daar is ook geen modelle waarvan die geldigheid bepaal is wat die verhouding tussen assessering en leer verklaar nie. Dit is derhalwe nie ' $n$ verrassing dat daar in die literatuur ' $n$ skaarste van suksesverhale is oor die doelgerigte aanwending van assessering om leer op gewenste maniere te dryf nie. Die uiteindelike doel wat hierdie navorsing geïnsipreer het is die hoop wat sedertdien deur Krupat en Dienstag (2009) verwoord is naamlik dat ons benaderings en metodes van assessering behoort te kan aanwend wat hul volle potensiaal sal gebruik ten einde ons opvoedkundige doelwitte te vervul (bl. 548). Die spesifieke kwessie waaroor hierdie verhandeling handel is die afleiding van ' $n$ model oor die voor-assesserings leereffekte van summatiewe assessering en om die geldigheid daarvan te begin bepaal.

In Hoofstuk Een, word die literatuur oor die verwantskap tussen assessering en leer beskou en probleme daarmee uitgelig. Die gebrek aan 'n meganisme en 'n model wat die verwantskap tussen assessering en leer verklaar, word beklemtoon. Die afbakening van die verhandeling tot die onderwerp van die voor-assesserings leereffekte van assessering word verduidelik en die viervoudige doelwitte van die verhandeling uitgespel naamlik 1) om te bepaal watter komponente van assessering watter dimensies van leer in 'n outentieke, komplekse sisteem van summatiewe assessering beïnvloed het; 2 ) om ondersoek in te stel na watter meganisme op die spel was by die raakvlak tussen assessering en leer in hierdie assesseringstelsel; 3) om 'n teoreties begronde model te bou en 4) om stappe te neem wat die bepaling van die geldigheid van die model vorentoe sou neem.

In Hoofstuk Twee, word die argument aangevoer dat dit aksiomaties geword het dat assessering 'n kragtige invloed op studenteleer uitoefen, maar dat daar 'n verrassende skaarste van navorsing is oor hoe dit gebeur. ' $n$ Studie word beskryf wat die meganisme van impak van summatiewe assessering op die proses van die leer van teorie in hoër onderwys ondersoek het. Individuele, diepgaande onderhoude is met mediese studente gevoer en kwalitatief ontleed. Daar is gevind dat die impak van assessering op leer bemiddel word deur verskeie bepalers van aksie. Respondente se leergedrag is deur die volgende beïnvloed: skatting van die impak van assessering; skatting van hul leerrespons; hul persepsies van agentskap ("agency") en interpersoonlike faktore soos normatiewe oortuigings en motivering 
om hieraan te voldoen. Die resultate van die studie dra by tot die karige bestaande bewyse oor die impak van assessering op leer en lei tot die voorstel van 'n meganisme om hierdie impak te verklaar.

Hoofstuk Drie beklemtoon en beskou die verbasend klein hoeveelheid navorsing wat gepubliseer is vanuit outentieke hoër onderwys- en gesondheidswetenskappeonderrigopsette oor die aard en meganisme van die voor-assesserings leereffekte van summatiewe assessering. Hierdie studie het ondersoek ingestel na die voorassesserings leereffekte van summatiewe assessering in teoretiese modules deur die veranderlikes op die spel in 'n veelsydige assesseringstelsel asook die vewantskappe tussen hulle na te vors. Diepgaande onderhoude is met individuele mediese studente gevoer en kwalitatief ontleed aan die hand van 'n gefundeerde teorie strategie. Respondente se leer is deur die eise van die taak en sisteemontwerp beïnvloed. Assessering het op respondente se kognitiewe prosesseringstrategieë en metakognitiewe reguleringsaktiwiteite ingespeel. Afsonderlik bevestig ons bevindings dié van ander studies in uiteenlopende nie-mediese opsette en identifiseer dit 'n paar nuwe faktore wat in hierdie opset op die spel is. Gesamentlik, werp die bevindings van hierdie studie 'n bietjie lig op hoe 'n assesseringstelsel as geheel studenteleer oor tyd heen in 'n mediese onderrig-opset beïnvloed, die eerste studie wat so makk. Die bevindings vanuit hierdie outentieke en komplekse opset skilder ' $n$ genuanseerde prent van hoe die interaksies tussen verskeie ingewikkelde en veelsydige faktore in 'n assesseringstelsel op mekaar inwerk om studenteleer te beïnvloed. 'n Model word voorgestel wat die bronne, meganisme en gevolge van die voor-assesserings leereffekte van summatiewe assessering koppel en wat die benutting van summatiewe assessering as 'n werktuig om leer te verhoog, sou kon versterk. Die model word op bladsy 120 van hierdie verhandeling uitgebeeld.

Hoofstuk Vier spreek die kwessie aan dat daar geen model bestaan om die leereffekte van assessering te verklaar waarvan die geldigheid bepaal is nie asook hoe hierdie leemte 'n probleem veroorsaak tydens die ontwerp van en navorsing oor assessering vir leer. Die uitdaging wat in hierdie studie aangepak word is hoe om die geldigheid te bepaal van die model wat in Hoofstuk Drie beskryf is. Die doel van die studie was dus om, as eerste stap, ondersoek in te stel of die model wel in 'n kliniese opset in werking was. Weens die kompleksiteit van die model, is ' $n$ kwalitatiewe benadering toegepas. Data van diepgaande onderhoude met agtien mediese studente is aan inhoudsanalise onderwerp. ' $n$ Kodeboek wat voorheen met behulp van gefundeerde teorie ontwikkel is, is gebruik. Tydens analise, is die opsie vir die moontlikheid van induktiewe kodering, as gevolg van data wat nie in die koderingsraamwerk ingepas het nie, die hele tyd voor oë gehou. Die drie komponente van die model naamlik assesseringsfaktore, meganisme faktore en 
leereffekte word almal in die kliniese konteks duidelik. Verwantskappe tussen hierdie komponente kon almal aan die hand van die model verklaar word. "Interaksie met kliniese toesighouers" is as 'n nuwe sub-komponent van assesseringsfaktore identifiseer. Verwantskappe tussen die drie fasette van hierdie sub-komponent naamlik gereelde toerekenbaarheid, persoonlike gevolge en emosionele valensie van die leeromgewing en komponente van die model wat reeds voorheen beskryf is, kon aan die hand van die model verklaar word. Die model kon dus aangewend word om waarnemings in 'n assesseringskonteks andersoortig as dié waarin die model afgelei is, te ontleed en verklaar. Die (negatiewe) invloed van kliniese toesighouers op studenteleer is besonder prominent in die kliniese opset. In hierdie opset, het leereffekte nie net gespruit uit die feit dat daar met summatiewe assessering baie op die spel ("high stakes") is nie, maar ook vanuit persoonlike gevolge bv., vir agting en agentskap ("agency"). Die resultate dui aan dat ten einde studenteleer te beïnvloed, gevolge vanuit assessering moet voortspruit wat onmiddellik, konkreet en beduidend is. Die model mag nut hê as 'n beplannings- of diagnostiese werktuig in praktyk- en navorsingsopsette. Die voorstel dat die model een van gevolgdraende assessering eerder as summatiewe assessering is, word bespreek.

In Hoofstuk Vyf, word die voorafgaande ontwikkeling asook poging tot die bepaling van geldigheid van die model van die voor-assesserings leereffekte van gevolgdraende assessering in oënskou geneem. Die doel van hierdie studie was om die proses van bepaling van geldigheid voor te sit en wel met 'n strawwe toets van die model. Die doelwitte was dus om te bepaal of die mins algemene verwantskappe wat bestaan tussen assesseringsfaktore en leereffekte in die model, en die komponente betrokke, toetsbaar is en of steun vir die rol van hierdie onderversameling van individuele komponente en die verwantskappe tussen hulle, gevind kon word in 'n breër maar soortgelyke populasie as dié waarin die model aanvanklik afgelei is. Een-en-twintig verskillende verwantskappe is in 'n dwarsdeursnitopname met ' $n$ doelgemaakte vraelys ondersoek. Elke verwantskap is getoets deur gebruik te maak van pare omstandigheidstoetsitems wat aan die hand van 'n gefundeerde teorie ontwikkel en volgens die logika van die kernkenmerkebenadering gestruktureer is. Vir elke verwantskap is die chi-kwadraat statistiek gebruik om te bepaal of daar betekenisvolle assosiasies tussen assesseringsfaktore en leereffekte was. 'n Aangepaste alfa is gebruik om betekenis toe te wys. Die frekwensie van betrokkenheid van meganismefaktore is bereken. Feitlik alle verwantskappe en komponente is toetsbaar. Daar was betekenisvolle verwantskappe tussen assesseringsfaktore en leereffekte vir 13/21 van hierdie onderversameling van mins algemene verwantskappe wat ondersoek is, al is $\mathrm{p}<0.00625$ as betekenisvol aanvaar. Die rol van al agt leereffekte, al tien meganismefaktore en ses uit agt assesseringsfaktore wat ondersoek is, is gestaaf. 
Dus, vir die onderversameling van mins algemene verwantskappe in die model, geniet die rol van meeste komponente betrokke asook die verwantskappe tussen hulle, steun. Dit hou belofte in vir toekomstige studies van die algemeenste verwantskappe in die model. Die model geld ook in 'n breër, dog soortgelyke populasie, as dít waaruit dit afgelei is. Resultate illustreer hoe 'n spektrum van faktore die resultate van intervensies wat ten doel het om assessering te gebruik om leer te beïnvloed, kan verwar.

Hoofstuk Ses herbesoek die rasionaal vir die bepaling van geldigheid van modelle naamlik dat intervensies wat gegrond is op 'n model waarvan die geldigheid bepaal is, beter uitkomste behoort op te lewer as pogings wat op swakker teorie gegrond is. Desnieteenstaande omvangryke literatuur oor die onderwerp, bestaan daar geen model, waarvan die geldigheid bepaal is, wat die leereffekte van assessering verduidelik nie. Voordat 'n model wat onlangs ontwikkel is gebruik word om intervensies toe te lig, moet die geldigheid daarvan eers bepaal word. Die doel van hierdie studie was om ondersoek daarna in te stel of voorlopige veralgemeenbaarheidsbevindings ten opsigte van die model, in nuwe assesseringskontekste herhaal kon word. Dwarsdeursnitopnames van 419 studente by twee ander universiteite is onderneem met behulp van ' $n$ doelgemaakte vraelys bestaande uit skriftelike omstandigheidstoetsitems. Ter wille van strengheid, is die model se 21 mins algemene verwantskappe tussen assesseringsfaktore en leereffekte ondersoek. Dertien hiervan is betekenisvol $(p<0.00625)$. Die rol van sewe uit agt assesseringsfaktore, sewe uit agt leereffekte en al tien meganismefaktore wat ondersoek is, is gestaaf. Vier meganismefaktore (agentskap ["agency"], respons doelmatigheid, responswaarde en impakskatting) het saam die meeste verwantskappe bemiddel. Hierdie verdere steun vir baie van die model se mins algemene verwantskappe hou weereens belofte in vir toekomstige studies van die algemeenste verwantskappe. Alhoewel die bepaling van die geldigheid van 'n model ' $n$ voortdurende proses is, bring hierdie resultate die model een tree nader aan ' $n$ punt waar dit intervensies sinvol kan toelig.

Hoofstuk Sewe bied 'n oorsig van bevindings en gevolgtrekkings van Hoofstukke 2 6 aan. Hoofstuk 2 het 'n voorstel ten opsigte van 'n nuwe meganisme wat verklaar hoekom studente op assessering reageer op die wyses wat hulle doen en nie bloot wat hulle respons is nie, tot gevolg gehad. Bevindings vanuit Hoofstuk 3 het tot die voorstel van ' $n$ model van die voor-assesserings leereffekte van summatiewe assessering gelei. Begrond op die bevindings wat in Hoofstukke $4-6$ gerapporteer word, word die gevolgtrekking gemaak dat bewyse wat tot dusver ingesamel is die geldigheid van die model in verskeie opsette ondersteun en dat die model beskou kan word as een van gevolgdraende assessering eerder as van summatiewe assessering. 
Vier hoof bevindings vanuit die werk word dan bespreek: 1) verwantskappe tussen assesseringsfaktore en leereffekte is kompleks en konteksgebonde; 2) 'n nuwe meganisme is op die spel in teorie- en kliniese assesseringskontekste; 3) die model geld vir gevolgdraende assessering eerder as bloot summatiewe assessering en 4) 'n model is afgelei waarvoor bewyse ten opsigte van geldigheid bestaan. Nadat daar op elk van die vier bevindings uitgebrei is, word bestaande bewyse ten opsigte van die geldigheid van die model beskou aan die hand van 'n hiërargiese stel kriteria wat deur Prochaska, Wright \& Velicer (2008) voorgestel is.

Die beperkings van hierdie werk word bespreek. Vir die aanvanklike studies, sluit dit beperkings inherent aan kwalitatiewe navorsing in. Dit sluit ook beperkings ten opsigte van die gebruik van vrywilligers vir beide kwalitatiewe asook kwantitatiewe navorsing in. Vir die kwantitatiewe werk, is die potensiaal vir veralgemeenbaarheid van bevindings nog beperk, gegewe dat slegs die mins algemene verwantskappe in die model in ' $n$ beperkte verskeidenheid assesseringskontekste tot dusver ondersoek is.

Die sterkpunte van hierdie verhandeling is dat die meganisme en die model vanaf die deurleefde ervarings van studente oor die duur van hul graadstudies heen, in 'n komplekse, outentieke opset afgelei is. Die kwalitatiewe werk het ook vele van die probleme met oorsaaklike afleidings wat deur Maxell (2004) identifiseer word, aangespreek. In die geheel gesien, stel die verhandeling 'n model voor wat die voorassesserings leereffekte van gevolgdraende assessering verklaar en waarvoor stappe ten opsigte van die bepaling van geldigheid geneem is. Hierdie maak op twee fronte ' $n$ bydrae. Eerstens, bied die model 'n nuwe perspektief oor hoe om assessering en voor-assesseringsleer met mekaar in verband te bring deur die koppeling van assesseringsfaktore en leereffekte met behulp van 'n nuwe meganisme. Tweedens, is die geldigheid van geen ander model wat in die verlede voorgestel is - tot op hede, in elk geval - tot enige mate bepaal nie.

'n Agenda vir toekomstige navorsing word bespreek, voordat die implikasies van die navorsing vir onderrig en onderrigontwikkeling op die einde verken word.

\section{Verwysings}

Krupat, E., \& Dienstag, J. L. (2009). Commentary: Assessment Is an Educational Tool. Academic Medicine, 84(5), 548-550.

Maxwell, J. A. (2004). Using Qualitative Methods for Causal Explanation. Field Methods, 16(3), 243-264.

Prochaska, J. O., Wright, J. A., \& Velicer, W. F. (2008). Evaluating Theories of Health Behavior Change: A Hierarchy of Criteria Applied to the Transtheoretical Model. Applied Psychology, 57(4), 561-588. 

Acknowledgements 
Looking back over everything that has brought me to this point, it is humbling to realise how many people have helped to make this quest possible. I know that in highlighting the role of some people here, I run the risk of not acknowledging the contribution of others, so: to all who have contributed to this enterprise in ways big and small, I say thank you. To colleagues, friends and family who over the years have whispered a word of encouragement, know that these were all heard and that they all made a difference.

I owe a debt of inspiration to Lambert Schuwirth and Cees van der Vleuten for igniting my fascination with the world of assessment with their presentations and writings. But, of course, that is the least of the debts that I owe Lambert and Cees. The way that you have so supportively yet profoundly shaped my thinking has been extraordinary. Despite the extensive questioning, prodding, feedback and coaching that characterised our interactions, you had a gift for engendering inspiration without ever being disheartening. This was never more the case than when, on more than one occasion, I thought that I had scaled an intellectual peak and you gently turned me around, showed me how I had merely reached the edge of a plateau and pointed to a new peak across the way waiting to be conquered. You have helped me to achieve things that I would never have believed possible. Those visits to Maastricht were, intellectually, like entering a wondrous new world of riches, riches that were generously shared. In addition, your never-ending enthusiasm and your excitement as the thesis took shape helped me to keep going. I always left Maastricht invigorated by our interactions. I am also most grateful to Lambert, Cees and their families for the warm hospitality they extended whenever I visited Maastricht.

While my thoughts are in Maastricht, I would like to thank Lilian Swaen for all she has done for me over the years. Mereke Gorsira, thank you for your help with translation. In Stellenbosch, Myrna van Zyl and later Farrel Kleinsmith have helped in varied ways to keep this project running.

Another debt of inspiration that I owe is to Erik de Corte en Filip Dochy, both of whom I had the privilege of hearing talk in Stellenbosch on separate occasions. Their talks helped crystallise an interest in the learning effects of assessment (not that they were called that then!) from the cloud of ideas that was swirling in my mind during the time that I was trying to fix on a topic for study.

Over time, numerous people have helped pave the way towards this amazing journey with their contributions to my intellectual development. Clearly many other teachers have made their mark, but there are two to whom I would like to pay a particular tribute. The first is Patience Mansfield from my high school years, who 
taught me how to think. The second is Johan Koeslag, who I worked under and who taught me both to be rigorous and to question dogma.

I also owe a debt of gratitude to Jan Lochner who all those years ago suggested, at an outpatient clinic we were doing together, that I consider applying for a post as a lecturer. That moment proved to be a turning point in my life.

For helping to fund some of my trips to Maastricht, my thanks are due to the Foundation for Advancement of International Medical Education and Research (FAIMER).

Then, I owe a debt of care and concern to a great many people who have held my hand, even carried me part way, on this phenomenal adventure. When I was just starting out with my PhD, a colleague, who was at that point finishing her PhD, forwarded me an email with as subject "Lord Of The Rings an allegory for a PhD?". In this piece, the protagonist "very quickly encounters the shadowy forces of fear and despair which will haunt the rest of his journey". At the time I thought this a bit melodramatic but now... Well, now, I understand. The point is this, though. While this experience seems common to the stories of all who have tackled doctoral studies, I have come to realise that doing a $\mathrm{PhD}$ is not the lonesome undertaking it often seems to be. Rather, it is a joint effort with the people around one that help carry one through these periods that ultimately make such an undertaking possible.

I am deeply grateful to my colleagues who, in various ways, have not only taken up so much slack to give me the space to live this dream but also buoyed me and helped me to persevere. Nicoline Herman and Hanelie Adendorff who were there all the way; Susan van Schalkwyk and Karin Cattell who became (witting or unwitting?!) companions on this journey along the way. It is a rare privilege to work with colleagues such as you.

Valerie Corfield, you are a foil to me in so many ways, particularly when I take life (and myself!) too seriously. Your encouragement has meant a great deal to me. I have learned so much from you over the years about things intellectual and about life and treasure your friendship.

Last but not least, Sean Dalgety, my companion on life's journey. You have patiently tolerated so much to allow me to pursue my obsession. I could never have done this without your loving support. Thank you for allowing me the space to take this on and for everything that you have done to help make it a success. You raise me up. 


\section{Curriculum vitae}


François Cilliers was born in Harare, Zimbabwe in 1966. Following his secondary schooling in Zimbabwe at Marondera High School, he obtained an MB,ChB at Stellenbosch University in South Africa in 1989. An ember of passion for teaching was ignited when he was asked to tutor struggling scholars from his high school in mathematics during university vacations. After a brief spell in full-time clinical medicine, that ember was fanned to a flame when he secured a post teaching Medical Physiology at Stellenbosch University in 1992. An Honours degree in Medical Biochemistry was followed by an MPhil(Higher Education) at Stellenbosch University, which François completed in 2004. That paved the way for his PhD studies at the University of Maastricht. Based on his growing passion for teaching, he was drawn into the implementation of a major revision of the $\mathrm{MB}, \mathrm{ChB}$ curriculum at Stellenbosch University around the turn of the century. This in turn led to an appointment as senior educational adviser in health sciences education in 2000. In 2006, François took up a post as deputy director with Stellenbosch University's Centre for Teaching and Learning. He initiated what have grown to become the annual national conferences of the South African Association for Health Educationalists (SAAHE) by hosting a regional conference on health sciences education for SAAHE in the Western Cape Province in 2004. He completed a fellowship with the Foundation for Advancement of International Medical Education and Research (FAIMER) in 2006. François still does part time clinical work. He also teaches on the MPhil(Health Sciences Education) and MMed(Family Medicine) (module on teaching and learning in general practice, which he also helped design) programmes at Stellenbosch University and the SA FAIMER Regional Institute (SAFRI). His research interests are the learning effects of assessment and the impact of educational development initiatives. He is married to Sean Dalgety. He enjoys jogging with their two dogs and tending his bonsai collection. 